\title{
Clinical Effects of Hydrogen Administration: From Animal and Human Diseases to Exercise Medicine
}

\author{
Garth L. Nicolson ${ }^{*}$, Gonzalo Ferreira de Mattos $^{2}$, Robert Settineri ${ }^{3}$, Carlos Costa ${ }^{2}$, \\ Rita Ellithorpe ${ }^{4}$, Steven Rosenblatt ${ }^{5}$, James La Valle ${ }^{6}$, Antonio Jimenez ${ }^{7}$, \\ Shigeo Ohta ${ }^{8}$ \\ ${ }^{1}$ Department of Molecular Pathology, The Institute for Molecular Medicine, Huntington Beach, USA \\ ${ }^{2}$ Laboratory of Ion Channels, School of Medicine, Universidad de la República, Montevideo, Uruguay \\ ${ }^{3}$ Sierra Research, Irvine, USA \\ ${ }^{4}$ Tustin Longevity Center, Tustin, USA \\ ${ }^{5}$ Saint John's Health Center, Santa Monica, USA \\ ${ }^{6}$ Progressive Medical Center, Orange, USA \\ ${ }^{7}$ Hope Cancer Institute, Playas de Tijuana, Mexico \\ ${ }^{8}$ Department of Biochemistry and Cell Biology, Graduate School of Medicine, Nippon Medical School, Kawasaki, \\ Japan \\ Email: "gnicolson@immed.org
}

Received 8 December 2015; accepted 19 January 2016; published 22 January 2016

Copyright (C) 2016 by authors and Scientific Research Publishing Inc.

This work is licensed under the Creative Commons Attribution International License (CC BY).

http://creativecommons.org/licenses/by/4.0/

(c) ()

\section{Abstract}

Here we review the literature on the effects of molecular hydrogen $\left(\mathrm{H}_{2}\right)$ on normal human subjects and patients with a variety of diagnoses, such as metabolic, rheumatic, cardiovascular and neurodegenerative and other diseases, infections and physical and radiation damage as well as effects on aging and exercise. Although the effects of $\mathrm{H}_{2}$ have been studied in multiple animal models of human disease, such studies will not be reviewed in depth here. $\mathrm{H}_{2}$ can be administered as a gas, in saline implants or infusions, as topical solutions or baths or by drinking $\mathrm{H}_{2}$-enriched water. This latter method is the easiest and least costly method of administration. There are no safety issues with hydrogen; it has been used for years in gas mixtures for deep diving and in numerous clinical trials without adverse events, and there are no warnings in the literature of its toxicity or longterm exposure effects. Molecular hydrogen has proven useful and convenient as a novel antioxidant and modifier of gene expression in many conditions where oxidative stress and changes in gene expression result in cellular damage.

"Corresponding author.

How to cite this paper: Nicolson, G.L., de Mattos, G.F., Settineri, R., Costa, C., Ellithorpe, R., Rosenblatt, S., La Valle, J., Jimenez, A. and Ohta, S. (2016) Clinical Effects of Hydrogen Administration: From Animal and Human Diseases to Exercise Medicine. International Journal of Clinical Medicine, 7, 32-76. http://dx.doi.org/10.4236/ijcm.2016.71005 


\title{
Keywords
}

\author{
Anti-Oxidant, Hydrogen Therapy, Gene Regulation, Gamates, Inflammatory Disease, \\ Neurodegenerative Disease, Rheumatic Disease, Infections, Aging, Exercise, Metabolic Disease, \\ Ischemia, Cardiovascular Disease, Neuromuscular Disease, Radiation, Skin, Sepsis
}

\section{Introduction}

Hydrogen $(\mathrm{H})$ is the lightest and most abundant element in the universe; in its molecular form $\mathrm{H}_{2}$ is a colorless, odorless, tasteless non-toxic nonmetallic gas [1]. Although hydrogen can burn at temperatures above $570^{\circ} \mathrm{C}$, at normal temperatures and partial pressures (at concentrations below 4\%), it is a harmless gas that can act as a cellular antioxidant [1]-[3]. Hydrogen was first used as a medical gas in 1888 by Pilcher [4]. It was infused as a gas into patients' rectums to identify colorectal perforations in order to avoid unnecessary surgery [4]. Until recently hydrogen was thought to be physiologically inert [2], but in 2007 it was reported that hydrogen could ameliorate cerebral ischemia reperfusion injury and selectively reduce strong cytotoxic oxygen radicals, including hydroxyl radical $(\bullet \mathrm{OH})$ and peroxynitrite $\left(\mathrm{ONOO}^{-}\right)$[2] [5]. This followed from experiments by Christensen and Sehested where molecular hydrogen was found to neutralize hydroxyl radicals in aqueous solutions at $20^{\circ} \mathrm{C}$ [6].

The formation of oxygen and nitrogen radicals, as seen under conditions of oxidative stress, is thought to be an important if not an essential element contributing to the formation of a number of diseases, such as cardiovascular, rheumatic, gastrointestinal, neurodegenerative, metabolic, neoplastic and other diseases [2] [5] [7][10]. It is also important in tissue injury and aging [1] [2] [5] [7]-[11]. In this process, free radicals, such as reactive oxygen species (ROS) and reactive nitrogen species (RNS), are generated as by-products of oxidative metabolism. When in excess over endogenous antioxidants, ROS/RNS can induce casual and cumulative oxidative damage to cellular macromolecules, eventually resulting in cellular dysfunction, cell death and in some cases, leading to the development of various diseases [12] [13].

Mitochondria appear to be closely involved in oxidative stress and the aging process [7] [12]-[14]. They are the main intracellular source of free radical superoxide anion, as well as the initial target of oxidative damage [11]-[14]. Under physiological conditions, low concentrations of ROS/RNS are generated indirectly by the electron transport chain in the inner mitochondrial membrane, and these ROS/RNS are normally neutralized by cellular antioxidants [5] [7] [14] [15]. However, excess ROS/RNS generated under pathological conditions cause progressive oxidative damage to mitochondrial membranes, proteins and mitochondrial DNA and eventually other cellular constituents [16]-[19].

Mitochondrial dysfunction caused by excess concentrations of ROS/RNS is found in essentially all chronic diseases [17] [20]-[22]. Cell death is an important consequence of mitochondrial dysfunction, and the demise of cells can occur via a number of pathways that are initiated in mitochondria and involve apoptosis, autophagy and necrosis [20] [23].

Under normal physiological conditions ROS/RNS exist at low cell concentrations that do not cause excessive cellular damage. The levels of these potentially dangerous free radicals are kept in check by endogenous antioxidant systems that include superoxide dismutase, catalase, glutathione peroxidase and various vitamins [15] [20]-[24]. However, when the concentrations of ROS/RNS exceed the endogenous capacity to neutralize them, oxidative stress and cellular damage can occur. Excess production of ROS/RNS can occur due to a variety of exposures, from irradiation to chemical exposure or by physical stress [25]-[27].

\section{Hydrogen Acts as a Cellular Antioxidant and Gene Regulator}

Although historically hydrogen $\left(\mathrm{H}_{2}\right)$ was considered inert and nonfunctional [28], Ohsawa et al. [5] found that $\mathrm{H}_{2}$ could act as a therapeutic antioxidant by selectively reducing cytotoxic ROS/RNS. We now know that $\mathrm{H}_{2}$ can act as a cytoprotective anti-oxidation agent in isolated cells in culture, as well as in animals and patients [1] [2] [4] [5] [29].

$\mathrm{H}_{2}$ acts by reducing the most reactive ROS and RNS oxidants, hydroxyl radical $(\bullet \mathrm{OH})$ and peroxynitrite $\left(\mathrm{ONOO}^{-}\right)$, but not the most plentiful ROS and RNS oxidants, hydrogen peroxide $\left(\mathrm{H}_{2} \mathrm{O}_{2}\right)$ and nitric oxide (NO), 
in cells and tissues [1] [2] [5] [29]. Thus $\mathrm{H}_{2}$ can reduce oxidative stress and readjust the redox status of cells [30]. As a result of its mild but efficient antioxidant properties, $\mathrm{H}_{2}$ can cause multiple effects in cells and tissues, including anti-apoptosis, anti-inflammation, anti-allergic and metabolic effects, in most cases by reducing oxidative stress and excess amounts of ROS/RNS [1] [2] [5] [29].

Hydrogen can also affect gene regulation that is modified or initiated by ROS/RNS, such as gene regulation by p53, AP-1 and NF- $\kappa$ B [30]-[36]. Hydrogen has the ability to modify signal transduction. Using a rat liver DNA microarray the effects of hydrogen were examined on general gene expression [35]. After drinking $\mathrm{H}_{2}-$ enriched water for 4 weeks, the DNA microarray was used to show that 548 genes were up-regulated and 695 genes were down-regulated in hepatic liver gene microarray. The genes encoding oxidoreduction proteins were enriched in the up-regulated genes. Thus hydrogen can have both specific and general effects on cells and tissues.

\section{Methods of Hydrogen Administration}

Hydrogen has some distinct advantages as an antioxidant. Since it is a gas, it can be given by a variety of methods, and as a gas or as hydrogen dissolved in fluids, $\mathrm{H}_{2}$ has extraordinary penetration and tissue distribution properties. Hydrogen as a gas dissolves in physiological fluids and distributes rapidly. It can easily penetrate cellular membranes and enter intracellular compartments [1] [2] [29]. Most antioxidant supplements are limited in their cellular distributions and are poorly taken up by organelles like mitochondria [37] [38], but hydrogen has the ability to effectively penetrate biomembranes and infiltrate into organelles, such as mitochondria and the nucleus. In contrast to many antioxidants, $\mathrm{H}_{2}$ also has the advantage of being able to penetrate the blood-brainbarrier [39].

Inhalation of $\mathrm{H}_{2}$ gas is the most straight-forward but not the most convenient method of medical hydrogen administration [1] [29]. At concentrations below $4 \% \mathrm{H}_{2}$ can be inhaled via mask, nasal cannula or ventilator. When inhaled at these concentrations, $\mathrm{H}_{2}$ does not affect blood pressure [2] [4], and $\mathrm{H}_{2}$ concentrations have been monitored in animal models by inserting hydrogen electrodes directly into tissues [40]. Inhalation of $\mathrm{H}_{2}$ has been used in organ transplantation to reduce intestinal and pulmonary transplant injury and prevent organ inflammation [41]. Exposure to $2 \% \mathrm{H}_{2}$ gas also significantly improved gastrointestinal transit, reduced lipid peroxidation and blocked production of several pro-inflammatory cytokines [41].

In a mouse sepsis model $\mathrm{H}_{2}$-treatment improved the survival rate and organ damage by reducing blood and tissue levels of early and late pro-inflammatory cytokines [42]. This same group investigated the effects of $\mathrm{H}_{2}$ on survival, tissue damage, and cytokine responses in a zymosan-induced multiple organ damage and inflammation model [43]. They found that $\mathrm{H}_{2}$ treatment reduced levels of oxidation damage, increased activities of antioxidant enzymes, and reduced the levels of pro-inflammatory cytokines in serum and tissues [43].

Hydrogen has also been administered as an injectable saline solution [44]. For example, Cai et al. [44] used $\mathrm{H}_{2}$ in saline injected intraparatoneally into neonatal rats as a model of hypoxia-ischemia to demonstrate the neuroprotective effects of hydrogen. Using an Alzheimer's disease model in rats $\mathrm{H}_{2}$-saline injections decreased oxidative stress and inflammation markers, and prevented memory and motor disturbances [45].

By far the easiest, most practical and effective method of $\mathrm{H}_{2}$ administration is oral ingestion of hydrogen water [29]. Hydrogen dissolved in water is a convenient and safe means of delivering $\mathrm{H}_{2}$ [46]. For example, $\mathrm{H}_{2}$ can be dissolved in water at up to $0.8 \mathrm{mM}$ at normal atmospheric pressure and room temperature, and it does not add taste, color or change in any way the characteristics of water. Once ingested, hydrogen-infused water passes quickly into the blood [47].

\section{Safety of Hydrogen}

Hydrogen has been used for years, without incident, in deep diving gas mixtures to prevent decompression sickness and arterial gas thrombi [48]. Even at relatively high concentrations, $\mathrm{H}_{2}$ has been reported to have no toxicity [48]-[50].

The safety of $\mathrm{H}_{2}$ in humans has been well documented in gas mixtures. For example, Hydreliox, a gas mixture used for deep diving, contains $49 \%$ hydrogen, $50 \%$ helium and $1 \%$ oxygen. Hydreliox was shown to be essential in preventing nitrogen narcosis and to prevent decompression sickness in working dives at great depths [48] [51]. In other deep diving studies $\mathrm{H}_{2}$ was used during compression at 20 ATM to reduce bradycardia and other nervous and psychosensorimotor symptoms (high pressure nervous syndrome) without any long-term safety issues 
[52]. Although a mild narcotic effect of hydrogen was detected from breathing hydrogen-helium-oxygen mixtures at high pressure, it was reversed upon return of the divers to ambient pressures [51].

Hydrogen in other forms, such as $\mathrm{H}_{2}$-water, has not demonstrated any toxic or safety issues [1] [2]. For example, rats were fed $\mathrm{H}_{2}$-water $(0.19 \mathrm{mM}$ hydrogen) or degassed water ad libitum for one year, and there were no reported changes in morbidity or mortality between the $\mathrm{H}_{2}$ and control group of animals. There was, however, reduced periodontal damage in the $\mathrm{H}_{2}$ group [53]. In clinical studies there were no reported toxic effects of ingesting $\mathrm{H}_{2}$ [54]. Thus hydrogen is a safe and non-toxic substance when used at relatively low concentrations under normal conditions of pressure and temperature.

\section{Hydrogen as a Therapeutic or Preventive Agent in Models for Human Diseases}

Animal models of human disease have been used to test the therapeutic effectiveness of $\mathrm{H}_{2}$ administration. This area has been amply covered in various reviews [1] [2] [29] [54]-[56]. For example, Ohno et al. [55] reviewed the effects of hydrogen in 63 animal models of human disease. They found multiple successful studies in animals where hydrogen had been administered as a gas (21 publications), by saline injection (27 publications) or as $\mathrm{H}_{2}$ water (23 publications) [55]. Other publications have used ocular solutions containing $\mathrm{H}_{2}$ [57], hydrogenrich water baths [46], or direct instillation of $\mathrm{H}_{2}$ solutions into the stomach or other organs [56]. Although most studies have used rodents as models, other animal models have also been used, such as rabbits or pigs [55] [56].

The first studies on the biology of hydrogen used hydrogen-producing algae and bacteria [59] [60]. Hydrogen has been found to promote growth of plants and regulate plant hormones and cytokines [61] [62]. Clinically, hydrogen has been used for a variety of conditions (Figure 1). Some of the most beneficial clinical uses of hydrogen will be discussed in this review.

\section{Hydrogen and Ischemia/Reperfusion Injury}

Many animal studies on the effects of hydrogen have used models for ischemia/reperfusion injury. Ischemia reperfusion injury is a phenomenon that is found clinically and can be attained experimentally. It is described as lack of oxygen supply to cells and tissues due to diminished perfusion, followed by local, and sometimes remote, inflammation due to acute reperfusion of the ischemic cells and tissues that may aggravate the original ischemic failure [2] [4] [29] [40] [41] [44] [62]. Several mechanisms have been proposed to explain ischemia/reperfusion, such as activation of redox signaling pathways, changes in mitochondrial permeability, autophagy, innate immunity, and other mechanisms [63]-[68]. Mitochondria appear to play an essential role in the process of ischemia/reperfusion [67]-[69].

Molecular hydrogen has been proposed as a possible protective molecule in ischemia/reperfusion [1] [2] [4] [29] [54]-[56]. In addition, recent evidence suggests that hydrogen might influence gene expression, possibly as a molecule that can counteract gene expression changes that occur during chronic adaptation responses to tissue damage [70].

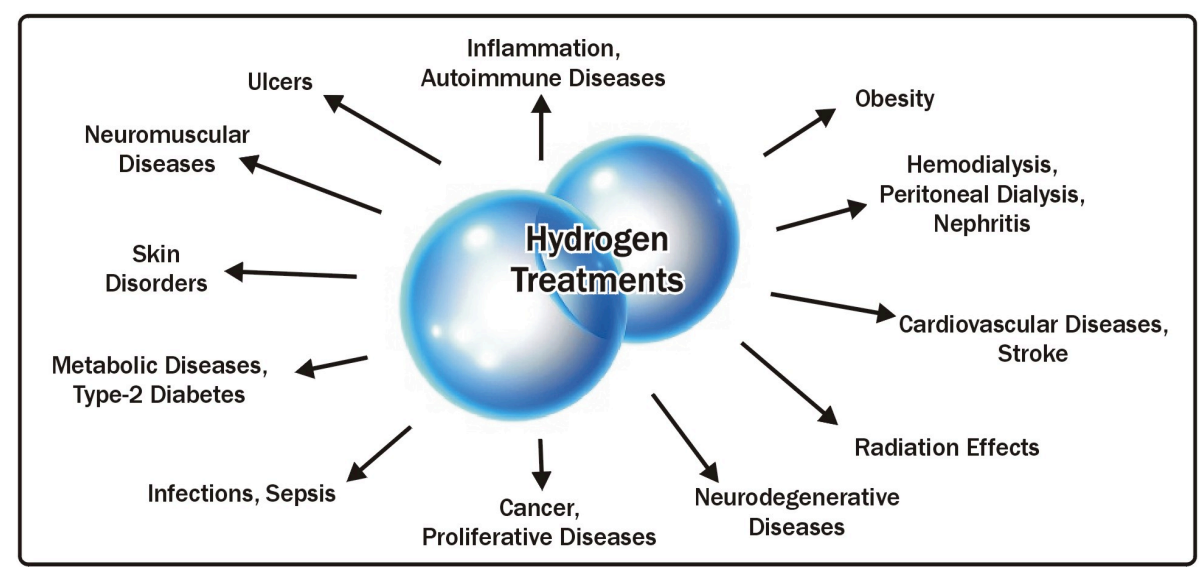

Figure 1. Hydrogen therapy and some of its uses in various acute and chronic clinical conditions. 
While ischemia/reperfusion can occur in several organs, it is frequently observed in heart, brain, kidney, liver, retina, lungs, and the gastrointestinal tract [71] [72]. Molecular hydrogen has been used as a prophylactic and therapeutic agent for acute or chronic ischemia/reperfusion in those organs [1] [2] [54] [73]. As ischemia-reperfusion injury might play a significant role in organ transplantation, the effects of molecular hydrogen could also be important in organ transplantation [73]-[76].

The beneficial effects of hydrogen in ischemia/reperfusion models in animals have been extensively reviewed [29] [55]-[77]. Several possible uses of $\mathrm{H}_{2}$ in humans has been mostly extrapolated or hypothesized from a relevant series of ischemia/reperfusion experiments performed in animals [1] [2] [29] [54]-[56] [73] [78].

Focusing on one organ, the heart, it has been shown that molecular hydrogen administered as a gas in rodents can improve the functional performance of the heart after cardiac arrest [39]. It does so with an efficacy comparable to hypothermia [39]. Hydrogen was proven to be better when $\mathrm{H}_{2}$ gas was inhaled at $2 \%$ concentration, synchronized with the beginning of cardio-pulmonary resuscitation and continued for a minimum of two hours, reducing the increment of damage caused by ROS/RNS free radical reactions related to cardiac arrest.

Molecular hydrogen treatment has been shown to dramatically reduce the size of heart infarcts in rat models of myocardial ischemia/reperfusion injury [40]. It has been hypothesized that this is related to the rapid diffusion of molecular hydrogen gas, which is even faster than that of the coronary reperfusion after an ischemic incident, and its ability to interact with cellular free radicals [5]. ROS/RNS species seem to play a central role in ischemia reperfusion injury mechanisms, and the rapid diffusion of molecular hydrogen and its ability to counteract ROS/RNS species, especially hydroxyl radicals $(\bullet \mathrm{OH})$ and peroxynitrites $\left(\mathrm{ONOO}^{-}\right)$[5], has been proposed to significantly reduce damage during ischemia/reperfusion injury. Thus, the experimental infarct size in rats can be significantly reduced with $\mathrm{H}_{2}$ gas treatment [40].

A similar effect was reported using hydrogen in a saline solution; hydrogen saline protected against the damage produced by free radicals released during ischemia /reperfusion injury [79]-[82]. Hydrogen-saline has been also reported to improve heart failure produced by doxorubicin treatment in rats [83]. Combining $\mathrm{H}_{2}$ with nitric oxide in a gas mixture also reduced free radicals, as well as protecting from heart damage and reducing infarct size in experiments done on murine hearts [84].

Cardioprotection by ischemic preconditioning or post-conditioning is an important approach to reducing ischemic/reperfusion cardiac injury [85]. Cardioprotection has been defined as "all mechanisms and means that contribute to the preservation of the heart by reducing or even preventing myocardial damage” [86]. Ischemic preconditioning is the protection conferred to ischemic myocardium by preceding brief periods of sublethal ischemia separated by periods of reperfusion [87]. Ischemic post-conditioning is the reduction of infarct size produced by several cycles of coronary occlusion/reperfusion after a sustained ischemia capable of producing an infarct [88]. In this process the opening of mitochondrial pores inhibited by ATP $\mathrm{K}^{+}$channels (mKATP) has been implicated in cardioprotecion, as their opening inhibits the permeability of the mitochondrial permeability pore (mPTP), a crucial event for ischemic reperfusion damage to take place [89] [90].

The administration of molecular hydrogen as a gas has been recently shown to activate mKATP, inhibiting mPTP, and thus acting as a cardioprotective agent in mice, rats and pigs [91]-[93]. More recent experiments performed in H9c2 cells in culture have shown that the induction of expression of antioxidant enzymes, such as heme oxygenase-1, by molecular hydrogen is another mechanism by which hydrogen prevents damage during ischemia/reperfusion injury [94].

In another variation of the use of hydrogen to reduce heart transplant damage, organ grafts for transplants were found to show enhanced preservation by submerging them in cold, $\mathrm{H}_{2}$-supplemented water [54] [91]. For example, in rat heart transplants the grafts were better preserved in cold, $\mathrm{H}_{2}$-supplemented water baths [91] [92]. Indicators of cardiac injury, such as the release of myocardial creatin phosphokinase and troponin I in serum, diminished significantly in grafts maintained in a cold, hydrogen bath [58] [95] [96]. Addition of hydrogen to HTK (histidine, tryptophan, ketoglutarate) solutions has also been reported to be a major improvement for preserving grafts during heart transplantation in rats [97]. The proposed mechanism is that molecular hydrogen prevents ROS and RNS production after excision of tissue and temporary ischemia and during grafting for transplantation.

Ischemic/reperfusion injury can also occur in gastrointestinal tissues where it can result in dysmotility, inflammation, and finally organ failure in grafts and transplants. Inhaled molecular hydrogen, or applied in $\mathrm{H}_{2^{-}}$ enriched saline solutions, has been tested as a protective agent for gastrointestinal tract transplants in animal models in order to reduce oxidative stress in the grafts [98]-[101]. A recent report using rats has shown that it 
has significant beneficial effects in small bowel transplants, when administered to the luminal side as an enriched hydrogen solution [102]. The antioxidant effects of molecular hydrogen, especially its attenuation of hydroxyl radicals, was proposed to play a significant role. Intestinal ischemia/reperfusion injury results in the release of a group of pro-inflammatory agents, such as tumor necrosis factor- $\alpha$ and interleukin- $1 \beta$, plus neutrophil infiltration and peroxidation of membrane lipids. This damage, potentiated by the production of ROS, can be diminished by hydrogen-rich saline solutions in rats [103].

The lungs can be involved in ischemia/reperfusion injury, especially during lung transplantation, or cardiac bypass, by mechanisms that are not fully understood [104]. Lung ischemia/reperfusion injury is characterized by diffuse alveolar damage within the first few hours after transplantation. It seems to be related to multiple mechanisms comprising production of ROS, but also alterations in intracellular calcium, the Na-K pump and the production of pro-inflammatory factors [105]. Hydrogen has been applied in rats either by inhalation or hydrogen-rich saline solutions to prevent damage in lung grafts [41] [106]-[110]. Although part of the explanation in the improvement of lung grafts with hydrogen application is likely due to its effects in preventing ROS damage [102] [111], there is evidence that it also ameliorates the damage produced by pro-inflammatory agents and protecting against lipopolysaccharide induction damage [112] [113]. It has been also reported that the administration of hydrogen can protect against damage through the expression of proteins related to the production of surfactants, ATP synthases and stress-response molecules [113]. Recent experiments show that the combination of the administration of hydrogen and nitric oxide seems to be even more beneficial than hydrogen alone [114]. It is interesting that in this case, the protective effects of hydrogen are not fully correlated with its protection against oxidative damage, suggesting that hydrogen can also reduce adverse effects by other mechanisms [1] [2].

Retinal ischemia/reperfusion injury is associated with several diseases such as glaucoma, diabetes and several vascular disorders [115]-[117]. In all these cases, one of the damage mechanisms, is the production of ROS species leading to the oxidation of lipids, DNA and protein synthesis disorders, leading to cell death [118] [119]. Studies performed in rats have shown that hydrogen in eye drops, as a gas and in saline solutions, can protect the retina against oxidative and inflammatory damage produced by retinal ischemia reperfusion injury [57] [120][123].

Ischemia in the brain leads to temporary or permanent functional deficits. It has been reported that the immediate reperfusion of the brain to stop ischemic damage paradoxically can lead to additional damage due to a change in mitochondrial inner membrane potential and an excess of production of ROS [124]. This has been proposed to constitute the primary basis of brain ischemic reperfusion injury. Examples that can lead to brain ischemia with subsequent ischemia/reperfusion injury are stroke, trauma, and inflammation [125]. Inhalation of hydrogen or using hydrogen-saline solutions has proven to be beneficial for brain damage produced by traumatic injury in rats [126] [127]. Hydrogen-rich saline solutions have been effective after rat brain ischemic damage produced by cardiac arrest or vascular causes [128] [129]. Finally, the protective effects of inhalation of hydrogen gas in mice have been also observed in damaged brains after inflammation [130].

The use of hydrogen in humans has thus far only been tested for acute brain ischemia [131]. This safety study attempted to determine the equivalent concentrations of hydrogen in humans that can reproduce the results obtained in animal studies. The authors concluded that inhalation of 3\% hydrogen for 30 minutes in humans is safe and that it might yield a similar hydrogen concentration in blood that have been shown to be useful in animals to treat or prevent this condition. However, studies of inhalation of hydrogen in humans can becomplicated, in part, because of variable hydrogen concentrations achieved in blood, and thus the results have lacked consistency. Because of this, the clinical use of hydrogen in acute brain injury needs further development [131].

\section{Hydrogen and Metabolic Diseases}

The most common metabolic disease is metabolic syndrome (MetSyn), which is a health condition characterized by a high increment for a group of risk factors that occur together (obesity, insulin resistance, dyslipidemia and hypertension). Collectively these factors increase the risk for coronary artery disease, stroke and type 2 diabetes mellitus (T2DM) [132]-[135]. In the 1980s the important role of insulin resistance in a number of diseases was determined, and this condition along with a group of risk factors was first named syndrome $\mathrm{X}$ but is now termed MetSyn [136]-[138]. Major clinical components of MetSyn are abdominal obesity, dyslipidemia with excessive flux of fatty acids, elevated blood pressure, and insulin resistance without glucose intolerance. When found together in the same patient, the long-term outcome is potentially life threatening, and in particular, there is a significant increase in risk for cardiovascular disease [135]. Also, MetSyn-linked T2DM and Alzheimer's disease 
are interconnected with overlapping oxidative stress pathways. Though these pathways are not exactly the same in these two diseases, they can have a synergic combination of detrimental effects [139]. The incidence and prevalence of MetSyn strongly increases with age, and it is often found in older populations, especially in men, in association with sex hormones changes during aging [11] [140].

Oxidative stress is a major component in the pathogenesis of MetSyn [141] [142]. The levels of ROS/RNS are significantly increased in MetSyn, along with abdominal obesity and insulin resistance [143] [144]. The increased production of ROS/RNS free-radicals, which attack and oxidize polyunsaturated fatty acids in a process known as lipid peroxidation, is particularly prevalent in MetSyn. Peroxidized lipids are eventually converted into lipid hydroperoxides, such as conjugated dienes and malondialdehyde (MDA) [145] [146]. These peroxidized lipids are elevated in patients with obesity, MetSyn, and T2DM [147]. In addition to cellular lipids, ROS/RNS free radicals can also attack and modify carbohydrates, proteins and DNA [148] [149]. These ROS/RNS modified biomolecules have been used as oxidative stress markers [12] [14]. Peroxidation and ROS/RNS damage are particularly relevant in mitochondria dysfunction, but the loss of mitochondrial function can be prevented with antioxidant and phospholpid supplements [148].

Hydrogen-enriched water has been used to treat rat models of MetSyn. For example, SHR-ND rats are genetically modified rats that develop MetSyn, and they have hyperinsulinemia, hyperglycemia, hyperlipidemia with increased oxidative stress and inflammation [149]. Treatment of SHR-ND rats for sixteen weeks with hydrogen-rich water improved renal function (creatinine clearance increment by 22\%, p < 0.05) [149]. Kidney damage as a result of glomerular sclerosis was also improved (reduced by $17 \%, \mathrm{p}<0.05$ ). Finally, the total plasma antioxidant capacity as determined by Biological Antioxidant Potential or BAP, measured by standard reactions of $\mathrm{Fe}^{3+}$ to $\mathrm{Fe}^{2+}$, was also improved by $22 \%(\mathrm{p}<0.05)$ [149]. The beneficial effect of hydrogen-enriched water has also been studied in rat myoblasts L6 cells in culture, where glucose uptake was reported to be dramatically increased [150].

Obesity is an important element and major risk factor of MetSyn, and it can constitute a pathological condition in which there is excessive accumulation of body fat along with a reduction in life expectancy and/or increased health problems [151]. Obesity is commonly related to an imbalance in the amounts and ratios of lipids in cells, tissues, and body fluids. In addition, during the development of obesity oxidative stress has been found to increase [152]. Drinking hydrogen-enriched water has been found to reduce hepatic oxidative stress in Db/db mice, which are lacking the leptin receptor [153]. It was found that $\mathrm{H}_{2}$-enriched water enhanced the hepatic expression of the hormone fibroblast growth factor 21, which is involved in pathways of fatty acid and glucose expenditure in the body, leading to the stimulation of energy metabolism. In humans consumption of $\mathrm{H}_{2-}$ enriched water (1.5 - 2 L/day produced by reaction with magnesium sticks), over a period of 8 weeks, promoted antioxidant capacity in patients with MetSyn [154]. This was quantified by measuring the increased expression of antioxidant enzymes like superoxide dismutase (increased by 39\%), and reduction of oxidative substances like MDA in urine (reduced by $43 \%$, as measured by reaction with thiobarbituric acid). Dyslipidemia was also improved, since HDL increased by $8 \%$ and the ratio of cholesterol/HDL diminished by 13\% [154]. No changes were observed in the fasting blood glucose levels for this time period [154]. Another study conducted in subjects with potential MetSyn found that the consumption of hydrogen-enriched water (1 L/day) for a period of about 10 weeks promoted a reduction in total cholesterol and in LDL-cholesterol serum levels [155]. In addition, HDL levels improved, as measured by different tests, indicating protection against LDL oxidation by an average of $31 \%$ $(p<0.05)$. The explanation for the changes in cholesterol and LDL lipoproteins were related to a reduction in apolipoprotein B10 and E. HDL was increased by several different mechanisms, such as protection against oxidation, and this resulted in inhibition of inflammatory cell adhesion and the effects of tumor necrosis factor- $\alpha$ in endothelia. It also resulted in stimulation of cholesterol efflux from macrophages [155].

Alterations in lipids or dyslipidemias, whether associated or not with obesity and MetSyn, are also improved by the use of hydrogen [156]. One of the ways hydrogen promotes such an action is by a reduction of the expression of the fatty acid translocase CD36, which diminishes excessive fatty acid uptake by human liver cells and promotes hepatic steatosis [156]. In animal models of dyslipidemias it was shown that lipid deposition in arteries is reduced upon drinking hydrogen-enriched water [157]. Also, improvements in plasma lipoprotein profiles, such as reductions in LDL-C, apoB and apoE by approximately $30 \%(\mathrm{p}<0.05)$, were observed in MetSynt apo-E knock-out mice. This was seen after four weeks of intraperitoneal injection of $\mathrm{H}_{2}$-enriched saline solutions [158]. The same effect was observed in hamsters fed with a high-fat diet. The results suggest that $\mathrm{H}_{2}$ has an important anti-atherosclerotic effect [158]. 
An important transport component in plasma membranes is the ATP-binding cassette transporter ABCA1, also known as the cholesterol efflux regulatory protein. The amounts of this membrane component have been associated with high-density lipoprotein deficiency [159]. It has been recently established in patients with hypercholesterolemia that the consumption of one $\mathrm{L} /$ day of $\mathrm{H}_{2}$-enriched water for a period of 10 weeks can activate the ATP-binding cassette transporter A1-dependent cholesterol efflux system. This improved the function of HDL lipoproteins in patients with hypercholesterolemia in a double-blind, placebo-controlled clinical trial (47\% reduction, $\mathrm{p}<0.05$ ) [160].

Another element of MetSyn is insulin resistance, a physiological condition in which cells fail to respond to the normal actions of the hormone insulin, leading to temporary or permanently increased blood glucose levels [136]. Insulin resistance is a major landmark property in the development of T2DM, which is characterized by elevated fasting glucose concentrations and dyslipidemia [136] [137] [161].

Oxidative stress also plays an essential role in insulin resistance [141]. In T2DM patients ROS damage accumulates in MetSyn and also acts at the level of trophic factors, impairs tolerance to glucose, activates pathways of apoptosis and autophagy, causes tissue remodeling, stimulates changes in the homeostasis of cellular energy, and modifies vascular biology [9]. In models for T2DM $\mathrm{H}_{2}$-water has proven to be beneficial for treating diabetic symptoms in high-fat diet-fed animals [158]. Furthermore, in subjects with insulin resistance, as well as in T2DM patients, the addition of hydrogen to drinking water has proven to be beneficial for normalizing lipid profiles and glucose levels [162]. In this study thirty T2DM patients drank an average of one L/day of hydrogen-enriched or pure water for a period of 8 weeks, and then several biomarkers of oxidative stress, insulin resistance, and glucose metabolism were compared before and after the 8-week period. T2DM patients that consumed hydrogen-rich water showed a significant decrease in the levels of modified low-density lipoprotein (LDL, 15.5\% decrease, $\mathrm{p}<0.01$ ) cholesterol, small dense LDL (5.7\% decrease, $\mathrm{p}<0.05)$, and urinary 8 isoprostanes $(6.6 \%$ decrease, $\mathrm{p}<0.05)$ [162]. $\mathrm{H}_{2}$-water intake was also associated with a reduction of insulin-resistance and oxidative stress biomarkers, such as serum concentrations of oxidized LDL $(5 \%, p<0.05)$ as well as increased adiponectin $(2 \%, \mathrm{p}<0.1)$ and increased extracellular-superoxide dismutase $(2 \%, \mathrm{p}<0.05)$. In 4 out of 6 patients who consumed $\mathrm{H}_{2}$-enriched water for 8 weeks, hydrogen normalized the glucose tolerance test ( $\mathrm{p}<$ 0.01), while it also improved the secretion of insulin (56\%, p < 0.05) [163]. Hydrogen may also be beneficial in type 1 diabetes, since it improves glycemic uptake by skeletal muscle in a type 1 diabetic animal model [163].

Since MetSyn can affect endothelial and smooth muscle cells, and these effects can be attenuated by hydrogen, $\mathrm{H}_{2}$ may also be useful for reducing blood pressure. The beneficial effects of hydrogen on hypertension are described in the next section. Also, the atherogenic susceptibility due to dyslipidemia in blood vessels can be diminished by exposure to hydrogen, and this has been tested in transgenic (apo E-/-) mice [164]. Treatment of these mice with intraperitoneal injections of $\mathrm{H}_{2}$-enriched saline for 8 weeks diminished the levels of the atherogenic apolipoprotein B (apoB) by 50\% - 75\%, in addition to other anti-inflammatory responses (suppression of proinflammatory interleukin- 6 and tumor necrosis factor- $\alpha$ by $20 \%-40 \%$, p < 0.05). Lipid deposits in the arterial walls were also reduced significantly in the aortic root upon hydrogen administration ( $20 \%$ - $40 \%$ reduction, p $<0.05)$ [164].

Neointimal hyperplasia and advanced glycation in endothelial cells leads to apoptosis. Both can be prevented by applying molecular hydrogen or $\mathrm{H}_{2}$-enriched saline in rats [165]-[167]. Thus, the use of hydrogen and $\mathrm{H}_{2}$ enriched water should be very useful in preventing or delaying the appearance of MetSyn and associated diseases.

\section{Hydrogen and Cardiovascular Diseases}

The vascular system, including endothelial cells, surrounding matrix and smooth muscle and other cells, heart and lung tissues and blood circulatory contents, constitute the cardiovascular system. As mentioned in section 7, the vascular system can be involved in pathogenic changes, including dyslipidemia, protein changes, hypertension and other determinants of cardiovascular diseases (CVD). Most CVD, including stroke, myocardial infarction, peripheral artery disease, among others, involve circulatory plaque formation or atherosclerosis caused potentially by hypertension, obesity, diet, dyslipidemia, smoking, alcohol consumption, metabolic syndrome, diabetes and other factors [168].

Animal models have been established for studying the effects of various procedures and therapeutic agents on CVD, and hypothermia models have been used to assess the effects of temperature on the physiological effects that occur after cardiac arrest. These models mimic the sequelae of effects (often called post-cardiac arrest syn- 
drome) that take place, such as neurological dysfunction, cardiac damage, systemic inflammation, among other problems [169]-[171]. For example, hypothermia has been used to protect neurons, cardiac cells, and reduce systemic inflammation in animals [169] [171] [172].

Using a hypothermia treatment model Hayashida et al. [40] compared the effects of $\mathrm{H}_{2}$ gas, with or without hypothermia or hyperthermia alone, on cardioprotection in isolated, perfused rat hearts. They found that $\mathrm{H}_{2}$ gas enhanced the recovery of left ventricular function following anoxia-reoxygenation, and reduced the infarct size without altering hemodynamic parameters. Hydrogen gas also prevented left ventricular remodeling [40]. This group later compared $\mathrm{H}_{2}$ gas with therapeutic hypothermia in rats by examining the functional outcome of cardiac arrest, followed by mechanical ventilation (MV) and treatment in four groups of rats (group 1, controls; group 2, MV with 2\% $\mathrm{H}_{2}-98 \% \mathrm{O}_{2}$ at normal temperature; group 3, MV with $2 \% \mathrm{~N}_{2}-98 \% \mathrm{O}_{2}$ at hypothermia temperature; group 4, MV with $2 \% \mathrm{H}_{2}-98 \% \mathrm{O}_{2}$ at hypothermia temperature). After return of spontaneous circulation, group 4 animals showed better improvements in survival and neurological deficit scores. They also demonstrated increases in left ventricular end-diastolic pressures measured by a transducer catheter and increases in serum interleukin-6 levels in the $\mathrm{H}_{2}$-treated animals [39]. One day later, the hearts were removed, fixed, and prepared for histological examination. Consistent with the end-diastolic pressures, water content in the lung as an indicator of edema was similar in control and $\mathrm{H}_{2}$-treated but not the other groups. Standard histology revealed less severe perivascular and interstitial fibrosis, less inflammatory cell infiltration and other changes on the endocardial side of the myocardium in the $\mathrm{H}_{2}$-treated groups. Using monoclonal antibodies against 4-hydroxy-2nonenal to assess lipid peroxidation and antibodies against 8-hydroxy-deoxyguanosine to assess nucleic acid oxidation, Hayashida et al. [39] found that there were fewer positive cells in rats administered hydrogen gas, suggesting that inhalation of $\mathrm{H}_{2}$ gas reduced oxidative myocardial injury.

The rat model of cardiac arrest has also been used to demonstrate that $\mathrm{H}_{2}$ gas inhalation improves brain function and neurological outcome [173]. After cardiac arrest and resuscitation for 2 hours and after return of spontaneous circulation, the ventilated rats were randomized into four groups: group 1, 26\% $\mathrm{O}_{2}$ at normal temperature (control group); group 2, 1.3\% $\mathrm{H}_{2}-26 \% \mathrm{O}_{2}$ at normal temperature; group 3, $26 \% \mathrm{O}_{2}$ and hypothermia; and group 4, 1.3\% $\mathrm{H}_{2}-26 \% \mathrm{O}_{2}$ and hypothermia. The survival rates were as follows: group 1, 38.4\%; group 2, 71.4\%; group 3, 71.4\%; and group 4, 85.7\% (group 1 versus group 4, p < 0.05). Neurological deficit scores based on consciousness, breathing, cranial nerve reflexes, motor function, sensory function and coordination were scored after 24, 48, 72 hours and 7 days after arrest and resuscitation [174]. Neurological scores were significantly better in the $\mathrm{H}_{2}$ group $2(\mathrm{p}<0.05)$ and even more improved in the $\mathrm{H}_{2}$ + hypothermia group $4(\mathrm{p}<0.01)$. Neurological scores were also better in $\mathrm{H}_{2}+$ hypothermia group 4 compared to hypothermia alone (group 3$)(\mathrm{p}<0.05)$. A Y-maze test was used to assess motor activity and spatial memory at 7 days. Motor activity was significantly lower in the control group $1(\mathrm{p}<0.01)$ and hypothermia group $3(\mathrm{p}<0.05)$ compared to the hydrogen groups, whereas differences in spatial working memory at 7 days were not significantly different [174].

In other models for atherogenesis, such as the apolipoprotein $\mathrm{E}$ knockout mouse (apoE [-/-]), feeding $\mathrm{H}_{2}$ saturated water ad libitum prevented development of atherosclerosis. Lesions stained by Oil-red-O in histological sections were significantly reduced $(\mathrm{p}<0.0069)$ in the $\mathrm{H}_{2}$-water group of mice at 6 months, and there was also a reduction in macrophages in the lesions in the $\mathrm{H}_{2}$ fed mice [175].

The effects of hydrogen on hypertension have also been studied using animal models. For example, using a rat model based on monocrotaline-induced hypertension He et al. studied the effects of hydrogen water on pulmonary blood pressure, right ventricle weight and hypertrophy and pulmonary inflammation [176]. They found that all of these parameters were increased in the monocrotaline-treated groups, but oral or injected $\mathrm{H}_{2}$ was found to prevent the development of hypertension and hypertrophy. They also utilized immuno-histochemistry to assess whether hydrogen prevented the monocrotaline-induced increase in 3-nitrityrosine and intercellular adhesion molecule-1-staining cells in the $\mathrm{H}_{2}$-treated animals. Hydrogen treatment reduced the chronic inflammation in monocrotaline-treated animals [176].

In clinical studies, $\mathrm{H}_{2}$-enriched water has been proposed to improve vascular health [177]. To assess vascular function and health a flow-mediated ultrasound dilation test was developed based on a pressure cuff on the brachial artery that was inflated to $50 \mathrm{~mm}$ mercury above systolic blood pressure for 5 minutes and then released [178]. After measurement of the brachial artery diameter and flow-mediated dilation at baseline, subjects drank $\mathrm{H}_{2}$-enriched water or placebo water, and measurements were taken immediately or after a 30-min interval and flow-mediated dilation determined. In the $\mathrm{H}_{2}$-enriched water group of 8 adult males and 8 adult females flowmediated dilation increased from $6.80 \% \pm 1.96 \%$ to $7.64 \% \pm 1.68 \%$, whereas in the $8+8$ placebo group 
flow-mediated dilation decreased from $8.07 \% \pm 2.41 \%$ to $6.87 \% \pm 2.94 \%$, indicating a significant improvement $(\mathrm{p}<0.05)$ [177].

The above studies indicate that $\mathrm{H}_{2}$-water could be very useful in improving vascular health. Although longterm hydrogen-water studies on human subjects and hypertension and CVD have not yet been executed, this remains a viable area for further clinical research.

\section{Hydrogen and Neurodegenerative Diseases}

Neurodegenerative diseases are caused by the progressive loss of nerves or nerve function by cell death or dysfunction [179]. Neurodegenerative diseases include: amyotrophic lateral sclerosis or ALS, Parkinson's disease, Alzheimer's disease, Huntington's disease, among others, and these diseases are associated in that there are some similarities in the roles of genetics, neurotransmitters, protein misfolding and accumulation of toxic proteins, degradation pathways, membrane damage, and mitochondrial dysfunction that lead to nerve cell dysfunction and death [180]-[182]. Important among these parameters are the dysfunction of mitochondria and excess oxidative stress that can result in programmed cell death [180] [181]. Treatment of neurodegenerative diseases has generally not been successful, but one approach points to the potential of antioxidant agents for the treatment of neurodegenerative disorders [182]-[184].

Chronic oxidative stress has been proposed to be important in Parkinson's disease (PD) [185] [186]. Models of PD have been developed that show many of the neuropathological features of the disease, such as the degeneration of the nigrostriatal dopaminergic neural circuitry controlling motor function, the presence of cytoplasmic structural abnormalities in nerve cells, and other features [186]-[188]. Alternatively, animal models of PD have been used that are based on chronic physical restraint stress that show brain oxidative stress and learning and memory impairments [46] [187]. They also show suppression of neural proliferation in the dentate gyrus of the hippocampus [189]. Nagata et al. [46] used mice fed hydrogen water to suppress the oxidative stress associated with chronic physical restraint stress and showed that hydrogen prevented cognitive impairment. The proliferation of nerves in the dentate gyrus was also restored with treatment [46].

In PD the most characteristic feature is chronic dopaminergic cell loss in the substantia nigrathat is associated with mitochondrial dysfunction and excess oxidative stress [190]. Using a rat model of PD that is based on 6-hydroxydopamine-induced nigrostriatal degeneration $\mathrm{Fu}$ et al. [191] placed $\mathrm{H}_{2}$ in the drinking water of rats before and after sterotactic surgery and found that hydrogen prevented the development and further degeneration of substantia nigra in the central nervous system. In another model for PD mice can be given acute or chronic 1-methyl-4-phenyl-1,2,3,6-tetrahydropyridine to stimulate oxidative stress and dopaminergic cell loss [192]. Feeding mice $\mathrm{H}_{2}$-water $\left(0.08-1.5 \mathrm{ppm}[\mathrm{w} / \mathrm{w}] \mathrm{H}_{2}\right.$ ) significantly reduced the loss of dopaminergic neurons in this chemically-induced mouse model of PD. Hydrogen in the drinking water also reduced the cellular accumulation of 8-oxoguanine, a marker of oxidative DNA damage, and 4-hydroxynonenal, a marker of lipid peroxidation, in the nigro-striatal dopaminergic pathway [193].

Recently, a pilot clinical trial was initiated to study the effects of hydrogen water on the progression of PD in Japanese patients [194]. The trial was a randomized, placebo-controlled, double-blind, parallel-group trial studying the effects of $\mathrm{H}_{2}$ water in levodopa-medicated PD. Participants drank one liter per day of hydrogenated water or placebo for 48 weeks. Examining the Unified Parkinson's Disease Rating Scale scores in the placebo group $\left(\mathrm{n}=8\right.$ ) showed that the PD worsened (mean score $=4.1 \pm 9.2$; median 4.5), whereas scores in the $\mathrm{H}_{2}$ water group improved (mean $-5.7 \pm 8.4$; median -1.0 ) over the course of the trial. In spite of the fact that the patient numbers were small and the short duration of the trial, the difference between the $\mathrm{H}_{2}$ water group and placebo group was significant $(\mathrm{p}<0.05)$. The results indicated that hydrogen water was a safe and well-tolerated treatment that yielded significant results in this short-term trial [194]. Follow-up will be necessary to see if the results hold-up for longer time periods, but the preliminary results in this pilot trial were encouraging.

\section{Hydrogen and Neuromuscular Diseases}

Neuromuscular diseases are represented by a heterogeneous group of disorders of the muscle, nerve or neuromuscular junction. They commonly lead to progressive muscle wasting and ultimately to premature death [195]. The most common neuromuscular diseases are Duchenne muscular dystrophy (DMD), spinal muscular atrophy, and congenital muscular disorders, comprising a large group of congenital muscular dystrophies or myopathies [196]. 
Although animal models for neuromuscular diseases exist and have been very useful for studying the genetics and other aspects of neuromuscular diseases [197]-[199], they have not been utilized to study the effects of hydrogen on these disorders. Instead, pilot clinical trials on the use of $\mathrm{H}_{2}$-enriched water in neuromuscular diseases have been attempted. First, a preliminary open-label clinical trial was conducted on 15 patients (5 with DMD, 4 with polymyositis/dermatomyositis [PM/DM] and 5 with mitochondrial myopathies [MM]) [200]. Each patient was given one liter of hydrogen-enriched water per day in 10 - 12 divided doses for 12 weeks, and clinical signs and symptoms as well as 18 serum parameters and urinary 8-isoprostane were examined every 4 weeks. Although objective clinical signs and symptoms remained the same and did not improve (most symptoms) or improved somewhat (fatigue and myalgia), other symptoms worsened (floating sensations, diarrhea) in some patients. There were also some significant changes in laboratory parameters. For example, there was a significant decrease in lactate-to-pyruvate ratio in MM and DMD patients $(\mathrm{p}<0.05)$, a decrease in fasting glucose in DMD patients ( $\mathrm{p}<0.01$ ), and a non-significant decrease in serum triglycerides in PM/DM patients [200].

A randomized, double-blind, placebo-controlled, cross-over clinical trial was then conducted with 22 patients (10 DMD, $12 \mathrm{MM}$ patients) that consumed 0.5 liter per day of $\mathrm{H}_{2}$-enriched water or placebo water daily in 2 - 5 divided doses for 8 weeks [200]. Between the 8-week arms of the trial was a 4-week washout period. During the trial, signs and symptoms as well as 18 laboratory serum measurements were determined every 4 weeks. Throughout the study there were non-significant objective improvements or some worsening of clinical signs and symptoms. One DMD patient reported subjective improvements in fatigue and reductions in diarrhea on $\mathrm{H}_{2}$-water, one $\mathrm{MM}$ patient complained of increased diarrhea but only initially on $\mathrm{H}_{2}$-water, whereas another DMD patient reported improvements in myalgia on $\mathrm{H}_{2}$-water. One MM patient had hypoglycemic episodes only on $\mathrm{H}_{2}$-water, but the episodes subsided after the insulin dose was decreased. Only serum lactose levels were significantly decreased in MM and DMD patients $(\mathrm{p}<0.05)$ in the $\mathrm{H}_{2}$-enriched water arm. There were also some non-significant decreases in MM patients in the $\mathrm{H}_{2}$-enriched water arm, such as serum lactate/pyruvate ratios, matrix metalloproteinase-3 and fasting glucose levels [200].

Although the clinical trials on the use of $\mathrm{H}_{2}$-enriched water in neuromuscular patients were mixed in terms of results, longer, more robust trials with additional patients numbers seem to be warranted.

\section{Hydrogen in Infections and Sepsis}

The lack of a proper response to infections can eventually result in widespread tissue and organ systemic infectious damage or sepsis that can result in fatal outcome. Sepsis remains one of the most common causes of death in critically ill patients in hospital settings [201]. It is a complex continuum of systemic immune failure against proven or probable infections of bacterial, viral, or fungal origin [201]-[203]. An important factor in the complex process of the development of sepsis is oxidative stress and failure of antioxidant systems, resulting in mitochondrial failure, apoptosis, and activation of inflammatory, immune, hormonal, metabolic and bioenergetic responses [204] [205]. Also important is the loss of intestinal barrier and translocation of bacteria and endotoxin into the circulatory system [205]. Treatment strategies include fluid administration, antimicrobials (antibiotics, antivirals, antifungals), neuroendocrine, coagulation and cytokine normalization, and maintaining or restoringorgan function [201]-[204]. Recently, Xie et al. [42] [205] [206] have reviewed the possibility that hydrogen can be used in the treatment of sepsis.

To address the possibility of $\mathrm{H}_{2}$ treatment for sepsis hydrogen treatment was developed in animal models of sepsis [42] [130] [205]-[207]. Using a mouse model initiated by cecal ligation and puncture initiation of $2 \% \mathrm{H}_{2}$ gas inhalation at 1 or 6 hours after puncture significantly improved the survival rate of septic mice [42]. Combining $\mathrm{H}_{2}$ therapy with hyperoxia improved the survival rate even further and reduced sepsis markers, such as proinflammatory cytokines, and decreased histological damage to organs [206]. In a more elaborate series of experiments, inhalation of hydrogen gas was found to reduce neuroinflammation, oxidative stress, and neuronal apoptosis caused by sepsis.

Histopathologic changes in brain hippocampus were reduced, along with reductions in brain water content, inflammatory cytokines, and increases in brain antioxidant activities [130].

The protective effects of hydrogen gas on sepsis in mice were proposed to be due, in part, to the activation of heme oxygenase-1 (HO-1) and its upstream regulatory nuclear factor-erythroid 2 p45-related factor 2 (Nrf2) [207]. To demonstrate this, mice were subjected to sepsis by cecal ligation and puncture and were administered $\mathrm{H}_{2}$ gas as above, and additionally, one hr prior, some mice received a zinc protoporphyrin HO-1 inhibitor. Se- 
rum and organs were homogenized and protein and mRNA levels of Nrf2, HO-1 and HMGB1 were measured at 6, 12 and 24 hours. Hydrogen gas reduced the level of inflammatory cytokine HMGB1 and increased HO-1 and Nrf2 levels in septic mice. The protoporphyrin inhibitor eliminated the protective effect of $\mathrm{H}_{2}$ on septic lung injury, indicating that hydrogen protection is partially mediated through the activation of HO-1 [207].

In a rat model sepsis was induced by cecal ligation and puncture, and hydrogen was introduced in saline intraperitoneally [208]. The researchers measured survival, cognitive function, ROS, malondialdehyde and caspase 3 levels, and superoxide dismutase activities were measured in the hippocampus to determine oxidative stress and apoptosis. Organ damage was assessed by histology. Cecal ligation and puncture resulted in poor survival rates, alterations in brain histology, and cognitive dysfunction. However, administration of the $\mathrm{H}_{2}$-enriched saline solutions reversed these changes in a dose-dependent manner [208]. Hydrogen-enriched saline also reduced lung injury as indicated by increased gas exchange, reduced water retention in the lung, reduced nitrotyrosine content, maintenance of superoxide dismutase activities, and reduced histological changes in the rat lung tissue caused by sepsis [209]. The $\mathrm{H}_{2}$-enriched saline also significantly inhibited activation of p38 and NF- $\kappa \mathrm{B}$ and suppressed production of several pro-inflammatory cytokines. The authors concluded that the effects of hydrogen were likely due to the antioxidant and anti-inflammatory properties of hydrogen [205] [210].

As of this review, clinical studies on the effects of hydrogen on sepsis have yet to be reported [205]. However, the properties of hydrogen, including its rapid penetration of tissues and cells and ability to modulate oxidative effects without interfering with metabolic and signaling systems makes hydrogen a potentially useful treatment for sepsis [205].

In terms of hydrogen use in the treatment of infections, there is a clinical report on the effects of hydrogen water on viral load, oxidative stress, and liver function in patients with chronic hepatitis B infections [210]. Sixty patients were randomized to two treatment groups with or without $\mathrm{H}_{2}$ water. The $\mathrm{H}_{2}$ water group consumed 1.2 - 1.8 liter per day for 6 consecutive weeks, and serum oxidative stress, liver function and hepatitis B virus DNA levels were determined before and after routine treatment for hepatitis. Although there were no differences in the levels of alanine aminotransferase and viral load in both groups, significant differences were found in the activities of superoxide dismutase, glutathione $S$ transferase and xanthine oxidase and levels of malondialdehyde that indicated excess oxidative stress in the control group not receiving hydrogen water $(p<0.01)$ [210]. Of note were the increases in superoxide dismutase and glutathione $\mathrm{S}$ transferase in the $\mathrm{H}_{2}$ water group above controls, indicating the antioxidant properties of hydrogen water $(\mathrm{p}<0.01)$. When the patients received treatment for their hepatitis $\mathrm{B}$ infections, liver function, monitored by the levels of alanine aminotransferase and total biliary acid, remained unchanged in the $\mathrm{H}_{2}$ water group, but increased in the $\mathrm{H}_{2}$ control group $(\mathrm{p}<0.01$ and $\mathrm{p}<0.05)$, indicating the hydrogen protected the liver from treatment damage [210]. Since the activities of superoxide dismutase and glutathione $\mathrm{S}$ transferase in the $\mathrm{H}_{2}$-water group remained higher than in the controls after treatment, the hydrogen treatment increased the antioxidant status of the hepatitis patients. Previous studies showed that hepatitis patients show increased oxidative stress and reduced antioxidant capacities [211]. Thus hydrogen-enriched water was able to improve oxidative stress status in the chronic infection patients and reduce some of the adverse effects of hepatitis treatment.

\section{Hydrogen Effects on Radiation and Cancer Treatment}

Hydrogen exhibits beneficial effects on tissues in organ transplantation and in the treatment of cancers and skin diseases, among other uses [111] [212]. For example, during cancer radiotherapy ionizing radiation causes damage to normal tissues, especially lung, heart and other organs [91] [111]. These radiotoxic effects are mainly due to production of hydroxide $(\cdot \mathrm{OH})$ and to a lesser degree other radicals [213] that damage DNA, proteins, lipids and carbohydrates [213]-[215]. Since hydrogen can neutralize free radicals, such as $\bullet \mathbf{O H}$ and other ROS/ RNS, this suggested that hydrogen might be useful as a novel protection agent for irradiated tissues [212] [216][218].

Experimentally, hydrogen has been used to protect against various types of radiation damage in a variety of animal tissues [212]. Some examples are: skin [219]-[221], intestine [216], lung [111] [212], heart [91] [216], brain [212] [222], bone marrow [216] [223] [224], testis [218] [247], and other tissues [212]. Of special clinical importance is the radioprotection of radiation-sensitive tissues, such as bone marrow, because these are the most likely to be damaged by radiation [212].

The radioprotective effects of hydrogen were also found when human cells and tissues were examined [212]. 
For example, treatment of human intestinal crypt cells, with or without hydrogen-rich phosphate-buffered saline before exposure to gamma radiation (up to $8 \mathrm{~Gy}$ ), resulted in significant reduction of radiation-induced apoptosis and an increase in viability in the $\mathrm{H}_{2}$-enriched phosphate-buffered saline-treated cells [224]. In contrast, if the cells were treated with the $\mathrm{H}_{2}$-phosphate-buffered saline after radiation exposure, then the protective effects of hydrogen were not seen [224].

Hydrogen has also been used in cancer therapy. Direct treatment of skin cancers with hydrogen was first proposed by Dole et al. [225]. They used hyperbaric hydrogen to treat hairless albino mice with cutaneous squamous cell carcinomas. The mice were exposed to a $97.5 \%$ hydrogen-2.5\% oxygen gas mixture at pressures of 8 atmospheres for periods up to two weeks to see if the gas mixture could cause regression of the skin tumors. They found that the skin tumors regressed and proposed that hydrogen might be useful for the treatment of other types of tumors by suppressing free radical production [225]. Later, Roberts et al. [226] examined the responses of five established transplantable mouse tumors and one mouse leukemia to hyperbaric hydrogen and found that $\mathrm{H}_{2}$ gas could suppress the growth of tumor cells. The actions of molecular hydrogen were established as antioxidant (and therefore anti-oxidative stress), anti-inflammatory, and anti-apoptotic in animal systems [1] [2] [40] [56] [82] [91] [111] [212]-[216].

In clinical studies on the radiation treatment of liver tumors Kang et al. [227] studied the effects of hydrogen-rich water on quality of life (QOL) parameters. Acute radiation-induced side effects often include fatigue, nausea, diarrhea, dry mouth, hair loss, skin sores, loss of appetite, changes in taste, and depression [228]. To test if $\mathrm{H}_{2}$-enriched water reduced adverse effects of radiotherapy and improved QOL scores, these investigators enrolled 49 patients (33 men and 16 women) with hepatocellular carcinomas in a clinical study. The participants were randomized into $\mathrm{H}_{2}$-water and placebo water groups, and each patient received 5040 - 6500 cGy of radiotherapy over a 7 - 8 week period. During the course of therapy each patient consumed 1.5 - 2.0 liters of $\mathrm{H}_{2}$-water or placebo control water each day. At the end of the treatment period all of the patients were evaluated for clinical response of their carcinomas to the radiotherapy and QOL determinations were made. Although the responses to radiotherapy were unchanged by the intake of $\mathrm{H}_{2}$-water, overall QOL scores were significantly improved in the $\mathrm{H}_{2}$-water group. For example, there were significant reductions in appetite loss and tasting disorders, but no differences in sleep parameters, diarrhea and vomiting [228]. During the course of the trial radiotherapy resulted in significant increases in serum hydroperoxide in the control group that were not seen in the $\mathrm{H}_{2}$-water group, indicating reductions in oxidative stress in the patients drinking $\mathrm{H}_{2}$-water. There were no differences found in liver function tests or blood tests, indicating that the $\mathrm{H}_{2}$-water was a safe and effective means of improving QOL in patients receiving radiotherapy [228].

In order to prevent or retard human skin damage after UV exposure hydrogen-enriched water has been directly applied to the dermis [229]. The $\mathrm{H}_{2}$-water application prevented UV-induced ROS/RNS and the induction of damage-associated mRNAs for MMP-1 and COX-2, as well as proinflammatory cytokine mRNAs for interleukin-6 and interleukin- $\beta$ tissue. The application of $\mathrm{H}_{2}$-wateralso increased the expression of collagen genes [231]. When elderly human subjects were examined, their constitutive levels of expression of MMP-1, interleukin-6, and interleukin- $1 \beta$ were higher but could be significantly reduced ( $\mathrm{p}<0.01$ ) with application of hydrogen-enriched water. The local application of $\mathrm{H}_{2}$-water also increased the expression of procollagen mRNA [229]. These studies indicated that $\mathrm{H}_{2}$-water has a radioprotective effect on skin, and $\mathrm{H}_{2}$-water can also reduce the increased expression of skin inflammatory cytokines.

An interesting potential use of hydrogen is its ability to protect against graft-versus-host disease (GvHD) [230]. Hematopoietic stem cell transplantation has been successfully used for the treatment of certain leukemias and other malignant and non-malignant hematologic diseases [231]. However, GvHD is a severe complication that can limit its application. Qian and Shen [230] have proposed that hydrogen therapy be used to reduce ROS/RNS important in the development of GvHD and reduce the levels of inflammatory cytokines that play a role in the development of GvHD.

\section{Hydrogen in Skin and Aging}

One of the most visible signs of aging is a change in the appearance of skin. Some of the hallmarks of aging skin include increased fragility and diminished collagen production, resulting in loss of elasticity and wrinkles. These negative characteristics are caused primarily by exposure to ROS/RNS that damage cellular proteins, membranes and DNA [224] [232]. 
The ROS concentrations in skin are among the highest of any other organ because of exposure to extrinsic environmental factors, such as ultraviolet light, ionizing radiation and pollutants. Cosmetic interventions to improve skin appearance-including pharmaceutical, surgical, and topical approaches-are considered temporary solutions, unless they deliver antioxidants to skin tissue and prevent ROS/RNS damage. Antioxidants effective in reducing ROS/RNS have been proposed to hold promise in improving skin structure and appearance [224] [233].

Antioxidants have been delivered to skin in lotions, creams and oils, and by bathing [232] [234]. For example, molecular hydrogen is considered a novel antioxidant for combating oxidative damage in skin and promoting a youthful appearance, and it has been used in water for bathing. By bathing daily for 3 months in $\mathrm{H}_{2}$-water $(0.2$ $0.4 \mathrm{ppm} \mathrm{H}_{2}$ ), Japanese subjects showed significant improvements in neck wrinkles at the end of the 90-day bathing sessions [235]. This same publication examined the ability of $\mathrm{H}_{2}$-enriched water to stimulate production of type- 1 collagen in skin fibroblasts and keratinocytes after UVA-exposure. They found that type- 1 collagen synthesis was increased over 2-fold after 3 - 5 days in the $\mathrm{H}_{2}$-enriched water samples compared to controls [235].

Another approach has been to drink $\mathrm{H}_{2}$-water. Using healthy four month-old rats fed $\mathrm{H}_{2}$-enriched or control water the effects of $\mathrm{H}_{2}$-water have been examined in aging periodontal tissues [236]. The animals fed $\mathrm{H}_{2}$-water and control water were examined after 16 months. At this time, the animals were examined for the expression of inflammation-associated genes. Although the expression of interleukin- $1 \beta$ was not different between the two groups of animals, the $\mathrm{H}_{2}$-water fed group was found to have activated Nod-like receptor protein 3 inflammasomes in periodontal tissue. In addition, oxidative damage was determined in periodontal tissue by measuring the levels of 8-hydroxydeoxyguanosine (8-OHdG) as a marker for DNA damage. Over time 8-OHdG levels increased in the control group $(\mathrm{p}<0.05)$, but in the $\mathrm{H}_{2}$-water fed group the levels of 8-OHdG were significantly lower than the control animals $(\mathrm{p}<0.05)$. Also, the serum levels of 8-OHdG were examined. In the control group the serum levels of 8-OHdG increased in an age-dependent manner, whereas in the $\mathrm{H}_{2}$-water fed group the serum levels of 8-OHdG did not change during aging [236].

When periodontal tissues were examined histologically in the $\mathrm{H}_{2}$-water and control water animals, the linear distances between the cemento-enamel junction and the alveolar bone crest were significantly lower in the $\mathrm{H}_{2}$-water fed group than in the control water group $(\mathrm{p}<0.05)$. These authors also examined the level of alveolar bone loss for the medial root region of the first molar, but significant differences were not found. In addition, the numbers of TRAP-positive osteoclasts were lower in the experimental $\mathrm{H}_{2}$-water group than in the control group $(\mathrm{p}<0.05)$, but there were no significant differences in the ratios of interleukin- $1 \beta$-positive cells to total cells between the two groups [236]. Interestingly, examination of gene expression in $\mathrm{H}_{2}$-water and control animals revealed that the expression of inflammasome NLRP3-associated caspase-1, ASC and interleukin- $1 \beta$ in periodontal tissues was higher in the $\mathrm{H}_{2}$-water group $(\mathrm{p}<0.05)$, whereas expression of NF- $\kappa \mathrm{B}$ was significantly lower in the $\mathrm{H}_{2}$-water group ( $\mathrm{p}<0.05$ ). Thus although drinking $\mathrm{H}_{2}$-water decreased oxidative damage to DNA, it did not suppress inflammatory reactions in aging periodontal tissue [236].

The protective effects of hydrogen have also been examined in animals exposed to cutaneous burns [237]. Rats were divided into sham, burn plus saline, and burn plus $\mathrm{H}_{2}$-enriched saline groups and analyzed at various times (6, 24 and 48 hours) after burning by contact with a hot metal comb for 20 seconds. Indexes of oxidative stress, apoptosis and autophagy were measured in each group, and the zone of stasis was evaluated using immuno-fluorescence staining, ELISA, and Western blot analysis. $\mathrm{H}_{2}$-enriched saline, but not control saline, attenuated the increases in apoptosis and autophagy seen in burn wounds, as measured by the expression of TUNEL staining and the expression of Bax, Bcl-2, caspase-3, Beclin-1, and Atg-5 proteins. Additionally, $\mathrm{H}_{2}$-saline treatment lowered the level of myeloperoxidase and expression of inflammation markers tumor necrosis factor- $\alpha$, interleukin- $1 \beta$, and -6 in the zone of stasis while augmenting interleukin- 10 . The elevated levels of Akt phosphorylation and NF- $\kappa$ B p65 expression post-burn were also down-regulated by $\mathrm{H}_{2}$-saline treatment [237]. The results indicated that $\mathrm{H}_{2}$-enriched saline treatment reduces the inflammation associated with cutaneous burns.

When skin is burned, there are typically changes in the epidermis and dermis tissue. Sections of the skin from $\mathrm{H}_{2}$-saline and control saline treated animals were examined. The interspaces between two burn wounds in saline control animals gradually narrowed and had a tendency to merge following the burn, whereas the interspaces remained relatively stable at various time points in the $\mathrm{H}_{2}$-saline treated skin. Certain characteristics, such as severe epidermis layer thinning, epithelium nuclei elongation, and dermis layer swelling with collagen alterations, could be observed in the normal saline-treated animals, whereas in the $\mathrm{H}_{2}$-enriched saline-treated animals these 
changes were alleviated over time [237].

Lipid peroxidation was also examined in the animals after burning their skin [237]. Skin tissue homogenates from the burn wounds reacted with thiobarbituric acid-reactive species (TBARS), a method that has been used to determine the malondialdehyde (MDA) levels. Tissue superoxide dismutase (SOD), glutathione peroxidase (GSH-Px) and catalase (CAT) activities were also evaluated to determine the oxidative stress status in the skin tissues of burn wounds. The burn-induced increases in MDA were reduced in the animals treated with $\mathrm{H}_{2}$-saline, while the activities of endogenous antioxidant enzymes were significantly increased. The results indicated that $\mathrm{H}_{2}$-enriched saline treatment attenuates burn-induced oxidative damage in the burn-wounded tissue of rats by inhibiting oxidative stress and increasing the activities of endogenous antioxidant enzymes [237].

Pressure ulcers are a routine problem in long-term hospitalization of aged patients. Li et al. [238] examined the effects of $\mathrm{H}_{2}$-water in 22 elderly Japanese patients (mean = $86.7 \pm 8.2$ years) with pressure ulcers. The purpose of this study was to clarify the clinical effectiveness of $\mathrm{H}_{2}$-water given by tube feeding. All patients received routine care treatments for pressure ulcers in combination with $\mathrm{H}_{2}$-water (600 $\mathrm{mL}$ per day) for partial moisture replenishment. Routine care included: ointment, gauze dressing, wrapping, and bed-pad use after washing by the acidic water disinfection. Pressure relief modalities and nutritional support were also employed. The 22 patients were divided into two groups: an effective care group $(E G, n=12)$ and a less effective group $(L G, n=10)$ according to the outcomes of endpoint evaluation and healing criteria. Pressure ulcer hospitalization days in EG patients were significantly shorter than in LG (113.3 days versus 155.4 days, $\mathrm{p}<0.05)$, and the reduced rate was approximately $28.1 \%$ less. In both the EG and LG groups the wound size reductions $(91.4 \%$ and $48.6 \%$, respectively) were statistically significant with the intake of $\mathrm{H}_{2}$-water $(\mathrm{p}<0.05)$. The results demonstrated that $\mathrm{H}_{2}$-water intake via tube feeding reduced wound size in hospitalized elderly patients with pressure ulcers [238].

\section{Hydrogen in Reproductive Tissues, Pregnancy, Neonatal Development and Newborns}

For successful reproduction healthy gametes (haploid cells) are necessary. The process of gamete formation takes place in the male and female gonads following meiotic cell divisions in the testis and ovaries. Oxidative stress during gamete formation is a potential risk and can lead to problems in fertility [239]-[243]. Bearing this in mind, hydrogen treatment has been used experimentally to reduce oxidative stress in both sexes.

Experiments performed in animal models have shown that $\mathrm{H}_{2}$-enriched saline can protect rats and mice testis against oxidative stress that occurs during ischemia/reperfusion injury or oxidative stress induced by nicotine [244]. Ischemia/reperfusion injury in testis can also be produced by torsion-detorsion movements, which causes irrigation to testes to be diminished. Administration of $\mathrm{H}_{2}$-enriched saline $(5 \mathrm{ml} / \mathrm{Kg})$ by intraperitoneal injection immediately after the injury reduced the testis levels of several oxidative markers, such as superoxide dismutase and MDA, compared to those animals in which no treatment was given [244].

Cigarette smoking and nicotine exposure, a common worldwide problem, also increases oxidative stress. By mechanisms that are still not clear, it has been shown that long-term nicotine exposure related to cigarette smoking increases oxidative stress in testis [245]. Mice with nicotine-induced oxidative damage in testis treated with long-term $\mathrm{H}_{2}$-enriched saline $(6 \mathrm{ml} / \mathrm{Kg}$ ) showed reduced damage in their gonads [244].

Other factors can also damage sperm. For example, sperm cells in gonads are especially susceptible to radiation. One of the mechanisms implicated in radiation damage to testes is the production of hydroxyl radicals [246]. Use of $\mathrm{H}_{2}$-saline pretreatment in mice exposed to ionizing radiation resulted in diminished radiation damage, such as reductions in lipid peroxidation, oxidation of proteins, and DNA damage, in testicular tissue. The number and quality of sperm after hydrogen treatment was also improved, and this has been related to reduced oxidative damage [247]. For example, the production of $\bullet \mathrm{OH}$ in sperm, as monitored by spin-trapping methods, was diminished up to $80 \%$ by suspending them in media containing $0.8 \mathrm{mM} \mathrm{H}_{2}$. In addition, apoptotic morphological modifications as well as chemical changes characteristic of apoptosis (measured by TUNEL terminal deoxy-nucleotidyl-transferase-mediated dUTP nick-end labeling) were reduced by $40 \%$ after $\mathrm{H}_{2}$ treatment. In addition, daily sperm production and their quality can be evaluated by staining with WR-2721 [S-2-(3-aminopropylamino)ethyl phosphorothioic acid], and high-quality sperm could be increased up to $30 \%$ after exposure to ionizing radiation and treatment with hydrogen compared to radiation alone [247].

An essential factor in male fertility is sperm motility. Sperm motility, which can be assessed by Computer 
Assisted Sperm Analysis, can be used to predict male fertility [248] [249]. Oxidative stress can diminish both sperm motility and fertility [250] [251]. However, after hydrogen exposure, the forward motility of human sperm was found to increase from $17.5 \%$ to $40 \%$ after treatment with hydrogen for 30 minutes. This increase in motility of the hydrogen-treated sperm was also preserved in treated and frozen sperm, in comparison with nitrogen-treated controls. In agreement with this finding, exposure to hydrogen also restored and improved mitochondrial potential, as evaluated by fluorescent redox dyes, indicating that hydrogen could be a promising new therapy for male infertility [252].

During embryo development and pregnancy, oxidative stress can lead to different tissue alterations and newborn diseases [253] [254]. The use of hydrogen as a possible therapeutic approach for diseases during pregnancy has been tested in vitro with trophoblast cell lines (JAR, JEG-3) [255]. This is important, as treatments with antioxidant vitamins ( $\mathrm{C}$ and $\mathrm{E}$ ) have been shown to be detrimental on placental function, as determined by decreased cell viability, decreased secretion of hormones and increased production of tumor necrosis factor- $\alpha$. In contrast to vitamins, hydrogen does not cause any detrimental effects. Moreover, molecular hydrogen promoted the secretion of human chorionic gonadotrophin (hCG) by these cells, suggesting that hydrogen might be a suitable antioxidant for the management of diseases, such as preclampsia during pregnancy [255]. The administration of hydrogen to pregnant rats has been reported to be beneficial for ischemia/reperfusion injury and hippocampal damage in fetal rats [256]. In these animals, ischemia/reperfusion injury was performed by transient occlusion of the bilateral utero-ovarian arteries. Two days before the operation to evaluate fetal damage and placental status rats drank $\mathrm{H}_{2}$-enriched water. When $\mathrm{H}_{2}$-enriched water was administered to the rats, their placenta showed less evidence of oxidative damage, and in the fetal tissues less neuronal damage was found in CA1 and CA3 hippocampal regions. Oxidative stress markers were also ameliorated when $\mathrm{H}_{2}$-enriched water was given to the rats. These studies suggest that hydrogen intake by pregnant mothers may prevent hippocampal damage produced by ischemia/reperfusion injury in the offspring [256].

Newborns have a high risk of excess oxidative stress during birth and in the first previous and post-partum months due to an increased rate of hypoxia or ischemia [257]. With that rationale in mind, several experiments in animal models have been performed in neonates. The first series of experiments performed in 2009 showed that hydrogen gas is not effective when there is moderate or severe hypoxia and ischemia in neonatal rats [258]. If there is any asphyxia during birth, neurovascular dysfunction is seen shortly after in an event known as delayed neurovascular dysfunction [259]. Hydrogen-treated newborn pigs showed less cerebrovascular reactivity of pial arterioles compared to those that received no treatment after asphyxia. Thus hydrogen had a neuro-protective effect during these accidents of birth [259].

Hemorrhage of the germinal matrix (GMH) is a neurological disease associated with low-weight premature birth leading to hydrocephalus, cerebral palsy, and mental retardation [260] [261]. The occurrence of the disease is related to oxidative stress [262]. The inhalation of hydrogen gas early after neonatal GMH reduced the incidence of cerebral palsy and mental retardation in treated rats [263]. This was evaluated at juvenile stages. Brain atrophy, splenomegaly and cardiac hypertrophy were also normalized one month after injury. These results suggest that the inhalation of hydrogen gas in low-weight premature neonates could be an important method for reducing GMH and its consequences [263].

Finally, necrotizing enterocolitis (NEC, inflammation and death of intestinal tissue) can also be observed after premature birth, leading to increased mortality [264]. In rat models of this disease it has been shown that the administration of hydrogen-rich saline to neonates is an effective way to protect premature neonates from NEC, which usually takes place two weeks after premature birth [265]. NEC can be induced in neonate rats by formula feeding plus asphyxia and cold stress. In this animal experiment the neonates were administered hydrogen intraperitoneally with $\mathrm{H}_{2}$-enriched-saline $(10 \mathrm{ml} / \mathrm{Kg})$ or normal saline before asphyxia was induced twice daily in 10 min periods. Monitoring of rat neonates continued up to 96 hours after birth and then several indicators of injury by NEC, such as body weight, histological NEC score, survival time, malondialdehyde anitoxidant capacity, inflammatory mediators, and integrity of the mucoses, were evaluated. On average, $\mathrm{H}_{2}$-enriched saline pretreatment reduced the damage scores by an average of $40 \%$. With hydrogen pretreatment the survival rate was increased by $172 \%$ (from $25 \%$ to $68 \%$ ) [265].

\section{Hydrogen in Inflammatory Diseases}

Inflammation is an innate cellular and humoral response that takes place in a multicellular organism after an in- 
jury in an attempt to restore the organism to its preinjury state by removing one or more injurious agents, repairing injured tissue, or both [266]. More than the timing of the response, it is the nature of the inflammatory cells that are immediately involved in the inflammatory response and its resolution after an injury to tissue that classifies inflammation as either acute or chronic. An early marker of an acute inflammatory response is the adhesion of neutrophils to the vascular endothelium or blood vessels, a phenomenon known as "margination." Acute inflammation is almost totally resolved by tissue response to the injuring agent. In contrast, chronic inflammation is characterized by its persistence or lack of resolution when the response is unable to overcome the effects of the injuring agent [266]. Both inflammatory processes are important mechanisms of defense against injuries, and they are associated with increased levels of ROS and RNS generated by the respiratory bursts of immune cells related to the inflammatory response. The increase of ROS/RNS species has two consequences: 1) oxidative/nitrosative modifications of biomolecules, and 2) the reversible triggering of ROS/RNS signaling cascades that strongly modulate the inflammatory response [267] [268]. Inflammation can also be classified with regard to the nature of the injuring agent. For example, it can be the result of a biological or non-biological event, such as an infectious inflammation or a sterile inflammation (trauma, chemicals, ischemia/reperfusion) [267].

Hydrogen has been used to treat both biological and non-biological inflammation. For example, studies with zymosan treatment or using sepsis as a model have utilized hydrogen treatment. Zymosan is a glucan polysaccharide usually found in fungus, and it has been used to promote generalized inflammation in animal models. The inhalation of $2 \% \mathrm{H}_{2}$ gas in mice for 1 - 6 hours post-zymosan injection improved the survival rate at day 14 after the injection from $10 \%$ to $70 \%$ [43]. The organ damage, as monitored by multiple biomarkers, such as aminotransferases, urea, and creatinine, as well as histopathological organ studies, was significantly reduced in all cases after $\mathrm{H}_{2}$ gas inhalation. Additionally, it was found that inhalation of $\mathrm{H}_{2}$ gas decreased oxidative products and proinflammatory cytokines, while it increased antioxidant levels [43]. Another form of acute inflammatory response, sepsis, has been discussed in another section of this review. It is interesting that $\mathrm{H}_{2}$-enriched saline stimulates recovery of generalized organ function in rat models of polymicrobial sepsis, resulting in decreased proinflammatory responses, oxidative stress, and apoptosis [269].

General Inflammation can be observed during allogeneic hematopoietic stem cells transplantation in hematological diseases undergoing acute-graft-versus-host disease (aGvHD). This complication is often lethal, and it decreases the efficacy of therapy and worsens prognosis in these patients. Inflammatory agents, such as cytokines, including interleukin-6 and ROS (such as hydroxyl radicals), play critical roles in GvHD. As previously discussed in this review, hydrogen lowers the expression of pro-inflammatory agents and acts as a powerful scavenger for hydroxyl radicals. Experiments done with bone marrow transplantation in mice with the complication of GvHD showed that exposure to hydrogen-rich saline solutions after transplantation results in an increase in the survival rate and improvements in all biomarker scores used for monitoring GvHD [270].

Autoimmune disorders occur when the immune system of an organism attacks and destroys healthy body tissue by mistake. More than 80 types of autoimmune disorders have been described [271]. Patients may have several autoimmune disorders at the same time. Though the ultimate causes of autoimmune disorders remain unknown, it is believed that this disorder is related to certain individuals as well as unique antigens from bacteria, viruses, and fungi that can confuse the normal responses of the immune system and result in recognition of self as foreign. The results of this can be an immune attack on self-antigens and promotion of inflammatory reactions, leading to destruction of body tissue, changes in organ function or abnormal growth of tissues [272].

Among the more common autoimmune conditions, rheumatoid arthritis (RA) is a systemic autoimmune disease characterized by joint dysfunction. The joints affected are usually symmetrical, involving hands, knees and other joints, with symptoms often being the most severe in the morning. RA causes pain, swelling, and stiffness in the joints, and in time this may cause severe joint damage, loss of function, and eventual disability. The disease can last from months to a lifetime, and symptoms may improve and then worsen over time. At variance with osteoarthritis, which is limited to the joints, RA is a systemic disease that involves other body systems. Over time, both forms of arthritis can coexist in the same patient [273]. As an example of a systemic manifestation, RA is also associated with an increased risk of atherosclerosis and cardiovascular disease [274].

Chronic inflammation and increased ROS/RNS production with a central role for the hydroxyl radical in RA have been proposed to explain the destruction of bone and cartilage, two of the most common sites of damage in most types of RA. Clinical groups in Japan have been pioneers in studying the possible therapeutic use of hydrogen in RA patients. For example, a pilot study performed in Japan with 20 RA patients showed that drinking daily $530 \mathrm{ml}$ of $\mathrm{H}_{2}$-enriched (5 ppm) water for a total of 8 weeks resulted in the reduction of biomarkers of RA 
damage, such as urinary 8-hydroxydeoxyguanine (8-OHdG) and DAS28 (C-reactive protein), of 14.3\% and $21.1 \%$, respectively, after one month $(\mathrm{p}<0.05)$. After two months of consuming hydrogen-enriched water, urinary 8-OHdG was stable and DAS28 showed a further decline of $20.41 \%(\mathrm{p}<0.05)$. Interestingly, after hydrogen treatment in 5 of the patients with early manifestations of RA, 4 of them showed complete remission of the disease, becoming symptom-free with no further evidence of elevations in biomarkers of the disease [274] [275]. Treatment with hydrogen also proved useful in preventing RA-related atherosclerosis [274].

Additional clinical trials with RA patients were also demonstrative. A double-blind, placebo-controlled trial in 24 patients receiving $500 \mathrm{ml} /$ day of $\mathrm{H}_{2}$-enriched (1 ppm) saline intravenous infusions for 5 days during a 4-week period showed the impact on biomarkers for RA, such as urinary 8-OHdG, DAS28, tumor necrosis factor- $\alpha$, interleukin-6, and matrix metalloproteinase-3. There was a 30\% reduction in DAS28 in the hydrogen treatment group compared with placebo after a 4-week period of treatment $(\mathrm{p}<0.05)$. The placebo-control patients showed no change in the levels of DAS28. Additionally, interleukin-6, matrix metalloproteinase-3 and urinary 8-OHdG were also reduced by $37.3 \%, 19.2 \%$ and $4.7 \%$, respectively, in the hydrogen treatment group ( $<<0.05)$. In contrast, the levels of interleukin- 6 and matrix metalloproteinase- 3 increased in the placebo group by $33.6 \%$ and $16.9 \%$, respectively $(\mathrm{p}<0.05)$. Tumor necrosis factor- $\alpha$ levels did not change significantly in the $\mathrm{H}_{2}$-saline or placebo groups [276].

There are also other conditions associated with RA. For example, skin lesions like psoriasis are often observed in RA patients. The administration of $\mathrm{H}_{2}$-enriched (1 ppm) saline by intravenous infusion, drinking $\mathrm{H}_{2}$ enriched water (5 ppm), or using $3 \% \mathrm{H}_{2}$ gas inhalation over a period of 4 weeks improved all of the symptoms of psoriasis (psoriasis area severity index, PASI, or biomarkers DAS28 and interleukin-6) by an average of 20\% in three patients $(\mathrm{p}<0.05)$. The psoriatic lesions almost disappeared in all of the patients treated with hydrogen [277].

Hydrogen treatment has also been tested in molecular and general models of inflammation in animals. It has been shown that hydrogen interferes with nitric oxide (NO) pathways that have been implicated in the generation of peroxynitrites. In particular, the lipopolysaccharide/interferon- $\gamma$-induced NO production in murine macrophage RAW264 cells was reduced upon hydrogen exposure. This result, in turn, was associated with a reduction of the inducible isoform of nitric oxide synthase (iNOS). Treatment with $\mathrm{H}_{2}$ inhibited lipopolysaccharide/ interferon- $\gamma$-induced phosphorylation of the apoptosis signal-regulating kinase 1 (ASK1) and its downstream signaling molecules, such as p38 MAP kinase, JNK, and $\mathrm{I} \kappa \mathrm{B} \alpha$. Drinking $\mathrm{H}_{2}$-water also ameliorated the levels of anti-type II collagen antibody-induced arthritis in mice (an animal model for human RA) [278].

Injection of carrageenan polysaccharides into mice paws can generate acute inflammation with edema, presence of lipopolysaccharide-activated macrophages, secretion of tumor necrosis factor- $\alpha$ by macrophages and infiltration of neutrophils [279]. All these parameters were mitigated by an average of $40 \%$ after 4 hours of injection of $\mathrm{H}_{2}$-enriched saline (2.5 to $\left.10 \mathrm{ml} / \mathrm{Kg}\right)(\mathrm{p}<0.05)$ [279]. Consumption of $\mathrm{H}_{2}$-water by mice also improved lipopolysaccharide-induced neuroinflammation [280]. Molecular hydrogen reduced the symptoms promoted by lipopolysaccharide injection. It was also associated with promotion of anti-inflammatory gene expression, such as down-regulation of tumor necrosis factor- $\alpha$, up-regulation of interleukin-10 and general regulation of cytokine expression towards anti-inflammatory profiles. The results showed that in addition to its role in reducing the oxidative stress during inflammation, hydrogen is also beneficial in promoting changes in the expression of the modulatory agents of inflammation [280]. In cell culture, $\mathrm{H}_{2}$ is also able to promote the expression of the gene heme-oxygenase-1 (HO-1). This result demonstrated that $\mathrm{H}_{2}$ contributes to the anti-inflammatory effect in lipopolysaccharide-stimulated macrophages (RAW 264.7) by inducing the expression of anti-inflammatory molecules [281].

During inflammation the endothelia of blood vessels suffer dramatic changes, such as leukocyte conglutination and endothelium permeability. In lipopolysaccharide-treated vein endothelial cells it was observed that $\mathrm{H}_{2}$-rich media promoted reductions in vascular cell adhesion protein (VCAM-1), intercellular adhesion molecule-1 (ICAM-1), and E-selectin levels, as well as trans-endothelial electrical resistance. This indicated that hydrogen can reduce the increased permeability of endothelial cells found during lipopolysaccharide-induced inflammation. In addition, the expression of VE-cadherin, which diminishes the permeability of the endothelium, was also increased [282]. Consistent with these results, it was shown recently that $\mathrm{H}_{2}$ is able to inhibit the adhesion of monocytes and polymorphonuclear neutrophils to endothelia, while the expression levels of the proinflammatory marker Rho-associated coiled-coil kinase (ROCK) were diminished by the hydrogen-enriched medium [283]. 
The role of hydrogen in reducing inflammation in specific organs has also been studied in detail in several animal models. At the gastrointestinal level, it has been reported that hydrogen-rich saline has a protective effect, for example, in ulcerative colitis in rats induced by acetic acid [284]. Intraperitoneal administration of hydrogen in $10-20 \mathrm{ml} / \mathrm{Kg}$ of $\mathrm{H}_{2}$-enriched saline solutions for a period of 2 weeks diminished various macroscopic and microscopic indicators of colonic mucosal damage. An interesting aspect of this work is that it also demonstrated that, in addition to its antioxidant role, hydrogen inhibited the expression of vascular endothelial growth factor [284]. In neonatal rat models, it has been shown that hydrogen-rich saline reduced the incidence of necroziting enterocolitis (NEC) from 85\% to 54.5\%, while increasing the survival rate from 25\% to 68.2\% (p < 0.05) [265]. Hydrogen-rich saline also inhibited the expression of pro-inflammatory mediators, such as iNOS, tumor necrosis factor- $\alpha$, interleukin-6 and lipid peroxidation, while enhancing the total antioxidant capacity [265]. Hydrogen-rich saline and water were also effective in reducing gastric inflammation induced by aspirin or acute peritonitis in rats [285] [286].

Inflammation of critical glands for digestion and metabolism, such as the liver and pancreas, have also been reported to be treatable with hydrogen. Regarding the liver, it is well established that reducing oxidative stress improves the prognosis in acute and chronic hepatitis [287]. Studies with hydrogen have also been performed in humans infected with hepatitis B [288]. In one study, 30 patients drank $\mathrm{H}_{2}$-enriched water (1200 - $1800 \mathrm{ml} / \mathrm{day}$, twice a day), for 6 weeks. After that period of time oxidative stress markers were measured and the values were compared with those before treatment and with patients who drank normal water. All of the oxidative stress markers were significantly reduced in all the patients who drank $\mathrm{H}_{2}$-enriched water $(\mathrm{p}<0.01)$. However, the authors reported that the results relating to liver function and hepatitis B virus DNA levels were inconsistent, especially after long-term treatments [288]. Biomarkers of acute pancreas inflammation in rats, induced by taurocholate, were significantly improved by intravenous injection of hydrogen-rich saline $(\mathrm{p}<0.05)$. Some of the markers explored were Serum tumor necrosis factor- $\alpha$, interleukin-6, and interleukin-18 [289]. In the pancreas, $\mathrm{H}_{2}$-enriched saline reduced the histopathological score as well as the levels of malondialdehyde (MDA), myeloperoxidase (MPO) contents and the expression of tumor necrosis factor- $\alpha$ and intercellular adhesion molecule- 1 mRNAs [289]. It has also been reported in mice that hydrogen-rich saline inhibits the activation of the NLRP3 inflammasome, while ameliorating acute pancreatitis [290].

At the cardiorespiratory level, hydrogen has been used to treat specific inflammation of the heart and lungs. Inflammation in the heart, as a result of ischemia/reperfusion injury, has been discussed in the corresponding section in this review. It has also been tested in rat models of regional myocardial ischemic reperfusion injury. Hydrogen-enriched saline solutions diminished the levels of biomarkers of inflammation, such as neutrophil infiltration, 3-nitrotyrosine, myeloperoxidase activity, tumor necrosis factor- $\alpha$, interleukin- $1 \beta$ and the expression of ICAM-1. Consistent with this, heart function parameters also improved in rats treated with hydrogen-enriched saline [82].

Recently, it has been reported that hydrogen-rich saline alleviates symptoms in rats with severe burns and inflammation with delayed resuscitation [291]. The mortality rate, cytokine levels, and oxidative stress biomarkers were all improved after treatment with $\mathrm{H}_{2}$-enriched saline. A likely intermediary signal in this process was the inhibition of the nuclear factor NF- $\kappa \mathrm{B}$ [291].

Oxidative stress also plays a key role in chronic obstructive pulmonary diseases (COPD). It has been hypothesized that the inhalation of hydrogen may improve lung function in COPD [292]. It has been shown in murine models of asthma that $\mathrm{H}_{2}$-enriched saline reduces airway remodeling and inflammation via inhibition of the $\mathrm{NF}-\kappa \mathrm{B}$ transcription factor pathway [293].

Regarding urinary tract inflammation, hydrogen solutions have been used in patients with interstitial cystitis and painful bladder syndrome (IC/PBS). In this study, 30 patients were mostly female, of average age 64 years, with stable clinical scores for IC/PBS lasting more than 12 weeks. They were treated with $\mathrm{H}_{2}$-enriched water or placebo for 8 weeks. Although hydrogen intake did not change significantly the IC/PBS clinical scores during the study, there were improvements in pain perception in $11 \%$ of the patients [294].

Maternal inflammation is a critical determinant in preterm births, yielding respiratory malfunction in premature infants. This has been studied in pregnant rats where maternal inflammation was induced by intraperitoneal injection of lipopolysaccharide. Hydrogen-enriched water administered 24 hours before lipopolysaccharide injection diminished the biomarkers related to inflammation, oxidative damage, and apoptosis in comparison with those rats that had liposaccharide-induced inflammation without hydrogen treatment [112].

It has also been reported that use of $\mathrm{H}_{2}$-enriched saline in mice protects immune system function and spleen 
inflammation induced by radiation. Biomarkers of oxidative stress, inflammation, apoptosis and immune response capacity were all improved after hydrogen-enriched saline administration [295].

\section{Hydrogen in Injuries}

Injuries can cause damage to the body, organs, tissues, or cells, and can be produced by physical, chemical or biological means. An important cause of injury worldwide is body trauma, leading to disability or death [296]. Hydrogen has been experimentally used as an adjuvant to treat injuries in various organs of the body, particularly in the brain, lungs, kidney, retina, and glands, such as liver and pancreas.

Traumatic brain injury (TBI) is a major cause of mortality and disability among the young, and a major problem for modern society. Brain edema, blood-brain-barrier breakdown, and neurological dysfunction can be observed in TBI. In addition, acute TBI can be transformed into a chronic injury, and this is a risk factor for neurodegenerative diseases, such as Parkinson's and Alzheimer's diseases [296]. Experimental exposure of rats with TBI to inhalation of $2 \% \mathrm{H}_{2}$ gas from 5 min to 5 hours after the injury (or surgery to treat the damage) resulted in significant reductions in oxidative stress biomarkers and brain edema, blood-brain barrier breakdown and neurological dysfunction [126] [127]. Mice with TBI induced by controlled cortical impact were also given $\mathrm{H}_{2}$-enriched water. Hydrogen-rich water reversed the brain edema by about one-half, blocked tau expression, attenuated the expression of inflammatory cytokines and restored the expression and activity of matrix metalloproteinase- 2 and matrix metalloproteinase-9. In addition, ATP levels were restored, suggesting the hydrogenenriched water could be of benefit as a preventive agent to avoid neurodegenerative changes associated with acute TBI [297].

Brain injury can also be observed after hemorrhages, such as subarachnoid hemorrhage (SAH). This condition is associated with neuronal apoptosis triggered by the nuclear transcription factor NF- $\kappa \mathrm{B}$. In such cases, early brain injury plays a key pathogenic role for the development of SAH. Intraperitoneal injections of hydrogen-rich saline in rabbits significantly reduced post-SAH apoptosis, diminishing NF- $\kappa$ B activity and other apoptosis biomarkers, such as Bcl-xL and caspase-3 [298]. Results obtained in rats treated with hydrogen-rich saline suggest that a protective role for hydrogen in SAH apoptosis could be explained using the Akt/GSK3 $\beta$ pathway [299]. A recent report emphasizes the critical role in SAH apoptosis due to the suppression of inflammatory responses through NF- $\kappa$ B and NLRP3 inflammasomes [300]. Additional benefits of hydrogen treatment have also been reported in animal models for other types of brain injury, such as those promoted by cardiac arrest and cardiopulmonary resuscitation [128], survival of retinal ganglion neurons after optic nerve crash [301] and neuroinflammation by sepsis [130].

The lungs can be injured by a variety of mechanisms. Hydrogen-rich saline has been shown to reduce lung injury promoted by intestinal ischemia/reperfusion in rats. Hydrogen-rich saline treatment diminished neutrophil infiltration, lipid membrane peroxidation, NF- $\kappa \mathrm{B}$ activation, and increases in pro-inflammatory cytokines (interleukin- $1 \beta$ and tumor necrosis factor- $\alpha$ ) in lung tissues, compared with controls without hydrogen treatment [103]. Lung injury produced by extensive burns [109], irradiation [111], or lipopolyscharide treatment [113] are also ameliorated by hydrogen treatment in animal models (rats and mice). Acute lung injury (ALI) can also be observed during sepsis. Cecal ligation and puncture is a model for producing ALI. Hydrogen-rich saline treatment in this model for ALI improved significantly lung function and gas exchange, and diminished oxidative stress and inflammation biomarkers [302]. Early fluid resuscitation and hydrogen inhalation in rats injured by sepsis have also been shown to have less lung and intestinal injury [303]. Interestingly, nitric oxide inhalation has been used to treat ALI with moderate success. However, the adverse effects of production of some toxic free radicals (ROS and RNS) remain. Since hydrogen is a scavenger for ROS/RNS species, combination therapy with NO plus $\mathrm{H}_{2}$ in mice with ALI has been used to improve on the results of inhalation of NO alone [114].

Cigarette smoking is the leading cause of chronic obstructive pulmonary disease (COPD) and a major cause of lung injury worldwide. Oxidative stress is a key factor that determines abnormal mucus production in lung diseases promoted by cigarette smoking. Hydrogen-enriched saline pretreatment of rats by intraperitoneal injection before exposure to cigarette smoke diminished oxidative stress and proinflammatory biomarkers at the level of the pulmonary epithelia and lungs [112]. Histopathological measurements also indicated that hydrogenenriched saline pretreatment inhibits the cigarette smoke damage that induces abnormal mucus production and pulmonary epithelial injury. This effect was partially explained by the antioxidant properties of hydrogen and its ability to inhibit the expression of proinflammatory agents [304]. ALI produced by cigarette smoking is also at- 
tenuated by intraperitoneal injection of hydrogen-saline in rats, inhibiting the pro-apoptotic pathways as well [305]. Finally, the gaseous emissions of laser printers and photocopiers have been associated with pulmonary health problems in chronic fatigue syndrome patients because of lung injury. A series of metals and volatile organic compounds in toners are thought to be the cause. It has been hypothesized that hydrogen treatment could be of benefit in this occupational exposure [306].

Kidney injury is a fairly common event and can be produced by a variety of mechanisms, such as chemotherapy associated with cancer, ureteral obstruction, hypertension, rhabdomyolysis, severe burns, contrast liquids for imaging techniques, pancreatitis, among other events. In chemotherapy, cisplatin is a widely used drug, but its application is limited by nephrotoxicity. Hydrogen-enriched water and hydrogen inhalation has been shown in mice to reduce kidney damage by cisplatin, without impairing the anti-tumor properties of cisplatin [47]. Carcinogens like ferric nitrilotriacetate promote the apparition of tumors in the kidney after renal injury. Consumption of hydrogen-enriched water by rats after intraperitoneal injection of ferric nitrilotriacetate alleviated kidney injury and the early promotion of tumors in the kidney. This effect was evaluated with histological and functional biomarkers for the kidney as well as biomarkers for oxidative stress and inflammation. The oxidative stress markers were all diminished by hydrogen consumption [336]. Hydrogen-rich saline (5 ml/Kg for ten days) also reduced renal injury scores promoted by unilateral ureteric obstruction in rats [307].

Hypertension is a major cause of kidney injury worldwide. Oxidative stress is an important factor in hypertension and renal disease. In spontaneously hypertensive rats, drinking $\mathrm{H}_{2}$-enriched water for 3 months alleviated renal injury by diminishing oxidative stress, as measured by the reduction of oxidative stress biomarkers. In addition, the pro-inflammatory biomarkers were also reduced by hydrogen ingestion. The results from this report suggest that the ingestion of hydrogen-enriched water is a promising strategy to reduce renal injury in hypertensive patients [308] [309]. Another major cause of acute kidney injury (AKI) is rhabdomyolysis, which occurs with increased renal oxidative stress and inflammation [310]. Rhabdomyolysis can be induced in rats by intramuscular glycerol injections, and the effects of hydrogen can be assessed by measuring creatine-kinase levels. In this rat model renal function and histology were monitored by serum creatinine, urea and histologic analysis. Biomarkers for oxidative stress and pro-inflammatory responses were also measured in the kidney. The pretreatment of rats with either high or low doses of hydrogen-rich saline improved renal health and reduced the systemic biomarkers for oxidative stress and inflammation, suggesting a protective role for hydrogen in injury produced by rhabdomyolysis [310].

AKI can also be found in severely burned patients or animals. Hydrogen-enriched saline treatment reduced the appearance of AKI in severely burned rats through the combined reduction of oxidative stress, proinflammatory cytokines, and apoptotic agents, as measured by a reduction of various biomarkers after $\mathrm{H}_{2}$-enriched saline administration [311]. AKI can be observed by the use of contrast media and image analysis. In rats injected with loversol and inhibitors of prostaglandin and nitric oxide synthesis, AKI can be induced and monitored using the above methods. In this rat model, inhalation of hydrogen reduced the biomarkers of apoptosis and oxidative stress and reduced the induction of AKI [312]. AKI is also found during pancreatitis. A rat model for acute pancreatitis was developed by taurocholate injection. Using the pancreatitis model rats were injected with hydrogen-rich saline, and this was found to diminish oxidative stress and proinflammatory biomarkers in the kidney compared to untreated animals [313].

In diabetic patients the retina can be injured causing diabetic retinopathy. Diabetic retinopathy is a major cause of blindness in developed countries [314]. Using rats a disease similar to Type I diabetes can be obtained by injection of streptozotocin. Hydrogen-rich saline $(5 \mathrm{ml} / \mathrm{Kg}, 4$ weeks) was intraperitoneally injected into streptozotocin-induced diabetic and control rats. Retinal apoptosis and vascular permeability biomarkers were assessed after hydrogen treatment and were reduced by the gas. The results suggested a potential use of hydrogen for the treatment of diabetic retinopathy [315].

Inflammation in the retina also produces tissue injury. Lipopolysaccharide-induced retinal microglia activation was explored, with and without hydrogen gas treatment in rats. Proinflammatory biomarkers were markedly reduced in the injured retina by the treatment of the rats with hydrogen gas, suggesting a role for the gas in the control of the expression of pro-inflammatory and pro-apoptotic agents [121]. Light can also promote retinal injury and degeneration through promotion of oxidative stress, and this damage can be monitored via electro-retinograms and histological scores [316]. Intraperitoneal injection of $\mathrm{H}_{2}$-enriched saline into rats improved retinal function and morphology after light-induced retinal damage [63]. Glaucomatous neurodegeneration is another major cause of retinal injury. Oxidative and nitrative processes play a key role in the pathogenesis of this dam- 
age. Using cultured adult rat retinal cells that were exposed to increased oxidative stress by introducing the nitric oxide donor S-nitroso-N-acetylpenicillamine, the response of retinal cells could be examined in the presence or absence of hydrogen. In this experiment, hydrogen diminished oxidative stress damage in the cultured retinal cells and diminished the loss of mitochondrial inner membrane potential and reduced apoptosis, presumably through a scavenging role of peroxynitrite. This in vitro experiment suggested that hydrogen might be of use in treating and preventing retinal injury induced by glaucoma [122].

Finally, hydrogen has been used to treat liver, pancreas, and heart injuries, or moderate damaged to cells from these organs in tissue culture. Liver injury is often observed after the use of common drugs like acetaminophen. Intraperitoneal $\mathrm{H}_{2}$-enriched saline $(5 \mathrm{ml} / \mathrm{Kg}$ ), administered to mice, diminished the liver lesions induced by acetaminophen; oxidative and proinflmmatory liver biomarkers were also reduced in the acetaminophen-injected animals. This suggested a liver-protecting role for hydrogen and protection against drug-induced hepatotoxicity [317]. Pancreatitis can be also induced by trauma. Hydrogen-saline has been used to lower oxidative stress biomarkers and reduce the severity of trauma-induced pancreatitis in rats [318]. In cultured heart cell lines (H9c2), hydrogen has been reported to reduce the injury induced by glucose and serum deprivation mediated through the NF-E2 related factor-2 (Nrf2)/heme oxygenase 1 signaling pathway [319].

\section{Hydrogen in Exercise and Sports Medicine}

Intense exertion during acute physical exercise results in an increased concentration of ROS/RNS in skeletal muscle. Such oxidative stress in skeletal muscles can lead to muscle weakness and fatigue, microinjury, and inflammation. Oxidative stress-induced pathogenic changes in skeletal muscle may include DNA mutations, lipid peroxidation, mitochondrial dysfunction, and apoptosis/necrosis [320] [321].

Most studies on the effects of hydrogen on physical stress and exercise involve the use of hydrogen-enriched saline or water [322]-[324]. The benefits of hydrogen-rich saline in ischemia-reperfusion of skeletal muscle have been examined in a rat model. Ischemia was induced in rats by application of a hind limb tourniquet for 3 hours, followed by 4 hours of reperfusion. Three experimental groups of male Sprague-Dawley rats were used: sham control (group 1); I/R treated with normal saline (group 2); and I/R treated with $\mathrm{H}_{2}$-enriched saline (group 3 ) [322]. Normal saline or $\mathrm{H}_{2}$-enriched saline $(1.0 \mathrm{~mL} / 100 \mathrm{~g})$ was administered intraperitoneally 10 min before reperfusion, and muscle and serum samples were analyzed for the levels of myeloperoxidase (MPO), superoxide dismutase (SOD), malondialdehyde (MDA), and hydroxyl radical $(\bullet \mathrm{OH})$ at various times in the model [322].

In the rat muscle ischemia/reperfusion model the wet/dry ratio increased significantly in the I/R group compared with that in the sham group $(\mathrm{p}<0.01)$ and decreased significantly in the hydrogen-rich saline group $(\mathrm{p}<$ 0.01). Muscle tissues and serum of the I/R group showed significantly increased levels of MPO, MDA, and $\bullet \mathrm{OH}$ content and decreased SOD activities, compared with the sham control group. The activity of SOD in the I/R group treated with $\mathrm{H}_{2}$-enriched saline was greatly elevated compared to the I/R group $(\mathrm{p}<0.01)$, whereas the levels of MPO, MDA, and $\bullet \mathrm{OH}$ content were clearly reduced in muscle tissues and serum. The integrated optical density of positive amethyst staining increased significantly in the I/R group, compared to the sham control group, and this decrease was significantly in group 3 (I/R with $\mathrm{H}_{2}$-enriched saline) compared with group 2 (I/R without $\mathrm{H}_{2}$-enriched saline). Muscle tissues of group 2 (I/R group) rats had significantly increased levels of the following: BCL2-Associated X Protein (BAX); cytochrome c, a component of the electron transport chain in mitochondria; and LC3B antibody content. There were also decreased levels of BCL2 activities compared with those in the group 1 (sham control) animals. The activity of BCL2 in the group 3 (I/R with $\mathrm{H}_{2}$-enriched saline) rats was significantly elevated, compared with $\mathrm{I} / \mathrm{R}$ without $\mathrm{H}_{2}$-enriched saline, whereas the levels of BAX, cytochrome $\mathrm{c}$, and LC3B content were reduced $(\mathrm{p}<0.01)$. The authors concluded that $\mathrm{H}_{2}$-enriched saline was an effective agent for attenuating I/R injury in rat skeletal muscle "via its antioxidant, anti-apoptosis, and anti-autophagy effects" [322].

Another animal study was designed to identify changes in oxidative stress and antioxidant levels in five treadmill-exercised Thoroughbred horses (3 to 7 years old) [323]. The BAP (Biological Antioxidant Potential) test was utilized to estimate antioxidant markers in the blood, and diacron-reactive oxygen metabolites (d-ROMs) were used to determine the total amount of free radicals in the blood and cerebrospinal fluid. Both are indicators of oxidative stress. To study the effects of $\mathrm{H}_{2}$-enriched water, animals were given nasogastric hydrogen-rich water or placebo water preceding the treadmill exercise. Each horse was subjected to a maximum exhausting level of treadmill exercise and blood samples were taken at various times. In all horses, d-ROMs tended to ele- 
vate, starting immediately after the treadmill exercise; however, there were significant differences between the horses given $\mathrm{H}_{2}$-enriched compared to placebo water. The BAP values increased in all horses post-exercise, and there were significant differences between the placebo and $\mathrm{H}_{2}$-enriched water trials.

The results revealed that significant elevations of both oxidative stress and anti-oxidative functions occurred simultaneously in all of the intensively exercised horses, but the increase was less in the horses given $\mathrm{H}_{2}$ enriched water, suggesting that $\mathrm{H}_{2}$-water has useful antioxidant-mediated effects during exercise [323].

In injured athletic subjects who were given hydrogen interventions, the efficacy of hydrogen for increasing skeletal muscle injury recovery has been examined. The first study involved a two-week pilot investigation of the effects of hydrogen on inflammation and recovery from acute soft tissue injury in male professional athletes. Thirty-six professional athletes were examined by a certified sports medicine specialist within the first 24 hours after sustaining injury, and they were then allocated to 3 randomly assigned groups in a single-blinded clinical trial [324]. The control group received a traditional treatment for soft tissue injury throughout the study, which consisted of a protocol (RICE) during the first 48 hours (rest, ice packs for 20 minutes every 2 hours, compression with elastic bandage, elevation of the injured area above the level of the heart at all possible times) and a sub-acute protocol thereafter (passive stretching 3 times per day for $90 \mathrm{sec}$, isometric strength exercise with 3 sets with 15 repetitions, and 30 min of pain-free weight-bearing exercise).

Injured subjects in the first experimental group followed the same protocol as the control group, but with the addition of oral consumption of $2 \mathrm{~g}$ of hydrogen-producing tablets per day. Subjects in the second experimental group also received the control group procedures and were given both oral $\mathrm{H}_{2}$-producing tablets ( 2 g per day) plus topical hydrogen-rich packs (6 times per day for 20 minutes each). Participants were evaluated at the time of the injury and at 7 and 14 days after baseline testing. The oral-topical hydrogen treatment group showed a decrease in plasma viscosity, when compared with the control group, and this group also showed a faster return to normal joint range of motion for both flexion and extension of the injured limb, when compared with the control group [324].

In the next clinical study ten male soccer players (aged $20.9 \pm 1.3$ years old) were examined twice for peak torque and muscle activity in a double-blind, crossover trial [325]. The subjects were given either hydrogen-rich water (HW) or placebo water (PW) for one-week intervals. Subjects were provided with three $500 \mathrm{ml}$ bottles of drinking water and instructed to place two magnesium sticks in each bottle 24 hours prior to drinking, and participants were asked to drink one bottle at 10:00 PM of the day before the test, one at 5:00 AM, and one at 6:20 AM on the day of examination. Subjects were given meals between 9:00 PM and 10:00 PM the day before experiments, and they fasted overnight. The subjects were first required to rest in a sitting position for 30 minutes before the exercise test. The exercise test consisted of the following: 1) Maximal progressive exercise to define maximal oxygen uptake $\left(\mathrm{VO}_{2} \mathrm{max}\right)$; 2) cycling an ergometer for 30 minutes at approximately $75 \% \mathrm{VO}_{2}$ max (Exercise-1); and 3) performing 100 maximal isokinetic knee extensions at $90^{\circ}$ per second (Exercise-2). Blood samples were collected just before and after Exercise-1, immediately after Exercise-2, and 30 and 60 minutes after Exercise-2. Oxidative stress markers and creatine kinase in the peripheral blood were monitored during the trial [325].

Although acute exercise resulted in increased blood lactate levels in the subjects given placebo water, oral intake of $\mathrm{H}_{2}$-enriched water prevented an elevation of blood lactate during heavy exercise. Blood lactate levels in the athletes given placebo water significantly increased immediately after exercise, compared to the levels at pre-exercise, but $\mathrm{H}_{2}$-water significantly reduced blood lactate levels post-exercise, using a bicycle ergometer (p $<0.05)$. Peak torque of the subjects treated with placebo but not $\mathrm{H}_{2}$-enriched water also significantly decreased during the initial 40 - 60 contractions by approximately $20 \%-25 \%$ of the initial values, followed by a phase with little change [325]. This study revealed that adequate hydration with hydrogen-enriched water prior to exercise decreased blood lactate levels. The intervention with $\mathrm{H}_{2}$-enriched water also improved exercise-induced decline of muscle function.

Since hydrogen therapy has been shown to be highly beneficial for the treatment of inflammation, ischemia-reperfusion injury, and oxidative stress in muscle tissue, $\mathrm{H}_{2}$-water may be of benefit in enhancing performance, as well as shortened injury times for athletes.

\section{Miscellaneous Uses of Hydrogen}

There are a variety of miscellaneous uses of hydrogen. For example, hydrogen-rich saline has been used to atte- 
nuate neuropathic pain. A useful rat model of neuropathic pain has been developed that is induced by spinal nerve ligation. Ge et al. [326] introduced $\mathrm{H}_{2}$-rich normal saline into the rat spinal cavity of rats with spinal nerve ligation and found that hydrogen relieved mechanical allodynia and thermal hyperalgesia. They also found that preemptive treatment with hydrogen-rich saline prevented development of neuropathic pain behavior, and analysis of brain slices revealed that the $\mathrm{H}_{2}$-rich saline treatment significantly attenuated the increase of 8-hydroxyguanosine-immunoreactive cells in the ipsilateral spinal dorsal horn induced by spinal nerve ligation. Isolation, fractionation, and Western blot analysis of tyrosine-nitrated spinal proteins indicated that the hydrogen treatment resulted in increased expression, but not over-expression, of tyrosine-nitrated Mn-containing superoxide dismutase (MnSOD) in the spinal cord. The infusion of $\mathrm{H}_{2}$-enriched normal saline also had an analgesic effect that was associated with decreased activation of astrocytes and microglia, along with decreased expression of interleukin- $1 \beta$ and tumor necrosis factor- $\alpha$ within the spinal cord [326].

By introducing hydrogen in their drinking water, Kawaguchi et al. [327] were able to reduce neuropathic pain in mice caused by partial sciatic nerve ligation. They showed that, while repeated intra-peritoneal or intra-thecal injections of strong antioxidants were ineffective in reducing neuropathic pain, the introduction of hydrogen into the drinking water reduced neuropathic pain, as assessed by mechanical allodynia and thermal hyperlgesia. When mice were allowed to continuously drink $\mathrm{H}_{2}$-enriched water ad libitum after spinal ligation, allodynia and hyperalgesia were alleviated. The pain symptoms were also reduced when $\mathrm{H}_{2}$-enriched water was given only during the induction phase from day 0 to 4 , but only hyperalgesia was reduced when $\mathrm{H}_{2}$-enriched water was given during the maintenance phase from day 4 to 21 [327]. Using immunochemistry staining for oxidative stress markers 4-hydroxy-2 nonenal and 8-hydroxydeoxyguanosine, Kawaguchi et al. [327] demonstrated that oxidative stress induced by spinal ligation could be reduced by drinking hydrogen-rich water.

Hyperalgesia has been induced experimentally by remifentanil administration in animals and humans [328]. Since MnSOD nitration and inactivation is caused by ROS, and activation of N-methyl-D-aspartate (NMDA) receptors are known to be involved in the induction and maintenance of central neuropathic pain, hydrogen has been used to selectively reduce ROS, remove superoxide and reduce neuropathic pain. Thus, Zhang et al. [328] used intra-peritoneal $\mathrm{H}_{2}$-enriched saline in a remifentanil-induced post-surgical hyperalgesia rat model of neuropathic pain to demonstrate that hydrogen can significantly attenuate mechanical and thermal hyperalgesia. In this rat model, remifentanil causes dose-dependent long-term hyperalgesia associated with increased expression of NR2B molecules and trafficking from the cytoplasm to the cell surface, as well as MnSOD nitration. Separately, they used spinal cord tissue slices and an in vitro clamp system to confirm the role of membrane trafficking of NR1 and NR2B subunits in controlling the amplitude and frequency of NMDA receptor-induced current [329]. Pretreatment of rats with intra-peritoneal $\mathrm{H}_{2}$-enriched saline reduced the effects of remifentanil and attenuated mechanical and thermal hyperalgesia. The authors concluded that $\mathrm{H}_{2}$-enriched saline might reverse remifentanil-induced hyperalgesia by regulating NR2B-containing NMDA receptor trafficking and by controlling MnSOD nitration and activity [329].

Hydrogen has also been proposed as a treatment for acute carbon monoxide poisoning [5]. Hydrogen is thought to exert its effects on $\mathrm{CO}$ poisoning by reducing oxidative stress, free radicals, neuronal nitric oxide synthesis, and inflammation [330]-[332]. These effects occur slowly after CO poisoning. Rats exposed to 1000 3000 ppm CO in air eventually lose consciousness, and after resuscitation, they can be injected intraperitoneally with $\mathrm{H}_{2}$-enriched saline repeatedly over 3 days to reduce the delayed effects of $\mathrm{CO}$, including tissue inflammation, cognitive dysfunction, and cell death [330]. Within one week after CO poisoning, rats show increased levels of degraded myelin basic protein, ionized calcium-binding adapter molecule one (iba1), DNA oxidation, and increases in inflammatory proteins in the cortex and hippocampal tissues, compared to normal controls. However, hydrogen-rich saline injections improved the histological appearance of brain tissue and reduced the $\mathrm{CO}$ poisoning markers listed above. Importantly, the $\mathrm{H}_{2}$-enedriched saline-injected CO-poisoned animals showed improved memory, and cognition in the Morris water maize test compared to CO-poisoned untreated controls [332]. Examining brain damage in the CO-poisoned rat model, Shen et al. [333] found that injection of $\mathrm{H}_{2^{-}}$ enriched saline reduced lipid peroxidation products and the numbers of apoptotic cells found after CO-poisoning, while increasing the levels of endogeneous cellular antioxidants in the brain cortex and hippocampus.

Another use for hydrogen-enriched saline is in reducing the effects of hemorrhagic shock, which causes low perfusion of visceral organs, ischemia and tissue hypoxemia, along with generation of ROS and multiple organ dysfunction [334]. Using a rat model for uncontrolled hemorrhagic shock caused by arterial bleeding and tail amputation, Du et al. [334] studied the effects of intra-peritoneal and intravenous injection of $\mathrm{H}_{2}$-enriched saline 
on survival and production of plasma interleukin-6, tumor necrosis factor- $\alpha$, superoxide dismutase and malondialdehyde. Although the survival rates were similar among the groups of animals, there were significant differences in the levels of oxidative and inflammatory blood markers. Intravenous injection of $\mathrm{H}_{2}$-enriched saline was superior in its anti-inflammatory and anti-oxidative effects compared to intra-peritoneal injection of $\mathrm{H}_{2}$ enriched saline $(\mathrm{p}<0.01)$, although both provided protection against release of inflammatory mediators and increased antioxidant enzymes [334]. In a follow-on study, Du et al. [335] compared the protective effects of three $\mathrm{H}_{2}$-enriched fluids $\left(\mathrm{H}_{2}\right.$-enriched Ringer's solution, $\mathrm{H}_{2}$-enriched hydroxyethyl starch and hypertonic $\mathrm{H}_{2}$-enriched hydroxyethyl starch) on hemorrhagic shock in their rat model. They found that all of the $\mathrm{H}_{2}$-enriched solutions were more effective than their non-hydrogen counterparts in reducing inflammatory mediators and increasing antioxidant enzymes $(\mathrm{p}<0.01)$, and reducing polymorphonuclear neutrophil accumulation in alveoli, capillary leakage and edema $(\mathrm{p}<0.01)$ [335].

Hydrogen has also been used to protect nerves from the effects of mechanical trauma and light-induced damage. For example, traumatic optic neuropathy is one of the more common causes of visual loss and blindness [336]. Using a rat model for optic nerve trauma, optic nerve crush, Sun et al. [301] examined the protective effects of using daily treatments of $\mathrm{H}_{2}$-enriched saline on nerve function and markers of tissue damage. Optic nerve function was measured by visual-evoked potentials and pupillary light reflexes. Tissue damage was assessed by examining tissue sections for the presence of toxins and gamma synuclein. Deoxynucleotidyl transferase-mediated dUTP nick and labeling (TUNEL) staining were used to measure nerve cell apoptosis. The animals receiving $\mathrm{H}_{2}$-enriched saline daily were shown to have significantly less optical nerve damage in terms of gamma synuclein staining and apoptosis assessed by TUNEL staining. They also had lower levels of tissue malondialdehyde ( $\mathrm{p}<0.01$ and $\mathrm{p}<0.05$, respectively). The $\mathrm{H}_{2}$-enriched saline animals showed significant improvements in optic nerve function, compared to saline controls $\left(\mathrm{p}<0.05\right.$ ). The results indicated that $\mathrm{H}_{2-}$ enriched saline had a significant protective effect on optic nerves after mechanical trauma [301].

Light-induced damage to the retina has also been ameliorated with the use of $\mathrm{H}_{2}$-enriched saline [316]. Intense light can damage photoreceptors in the retina, and this is associated with excess oxidative damage [337]. To examine the effects of $\mathrm{H}_{2}$-enriched saline on light-induced retinal damage, Tian et al. [316] used intense light to expose the right eye of a rat, while the left eye was used as a control. Animals were untreated or treated with intra-peritoneal injections of $\mathrm{H}_{2}$-enriched saline before (prevention group) or daily after light exposure for five days (treatment group), and then electroretinography (ERG) recordings were obtained and the animals' eyes prepared for sectioning and light microscopic examination. Light damage could be assessed by ERG, and both $\mathrm{H}_{2}$-enriched saline groups of animals were significantly less damaged, as assessed by less of a reduction in ERG amplitude. For example, light damage resulted in 70\% reduction in ERG amplitude, whereas the prevention group showed 50\% reduction in amplitude $(\mathrm{p}<0.001)$ and the treatment group showed only a 30\% loss (p < 0.001). Histology indicated that the light damaged animals had significant losses in retinal pigment epithelium, but the retinal epithelium in the $\mathrm{H}_{2}$-enriched saline treatment group was almost normal, and the $\mathrm{H}_{2}$ pretreatment group was intermediate between the untreated and the $\mathrm{H}_{2}$-enriched saline-treated animals. The losses in retinal pigment epithelium were almost entirely due to light damage to retinal photoreceptors [337].

The use of hydrogen in emergency medicine has been reviewed by Shen et al. [80]. They report that administration of hydrogen has a number of uses in emergency trauma and other critical situations. After discussing the different modes of hydrogen delivery, they conclude that drinking $\mathrm{H}_{2}$-enriched water may be the most practical way for consuming hydrogen in daily life.

Finally, it has been proposed that mental diseases, such as bipolar disorders and schizophrenia, be treated with hydrogen. The use of hydrogen to treat mental disorders was proposed recently by Ghanizadeh and Berk [338]. Since diseases like bipolar disorders and schizophrenia are associated with increased oxidative and inflammatory stresses, hydrogen therapy might be useful as a novel therapeutic approach [338]. Although clinical trials have not yet been conducted in this area, it is only a matter of time before this is investigated as a potential clinical use of hydrogen therapy.

\section{Future Studies and Conclusions}

This review and others [1] [2] [29] [55] [56] [73] [77] [79] [212] have documented that the clinical use of hydrogen is quite promising for the treatment of many acute and chronic illnesses and conditions, as well as its utility in support of the maintenance of good health. What started in Japan and the Far East as preliminary re- 
sults on the clinical use of hydrogen has now continued there and elsewhere, to the point where there are now a critical number of scientific and clinical studies that support the use of hydrogen as a primary or supportive component of clinical care.

With its potent and unique antioxidant properties, gene regulatory abilities, and rapid rates of diffusion across tissue and cellular barriers, as well as its excellent safety record, hydrogen has many unique characteristics that make it very valuable for utilization in medicine and health. Its systemic properties and excellent penetration abilities allow hydrogen to be effective under conditions of poor blood flow and other situations that limit many other types of systemic treatments.

The clinical justification for hydrogen use is growing because:

1) Redox imbalance and the excess production of ROS and RNS (increasing oxidative stress) have been implicated in many, if not all, pathophysiological mechanisms leading to a wide variety of medical conditions and diseases. Hydrogen is useful because of its potent free-radical scavenging properties that significantly reduce strong cellular oxidants, but it does not affect important signaling pathways that depend on mild cellular oxidants.

2) Hydrogen is effective in reducing signs and symptoms and improving quality of life in a wide variety of clinical conditions. Because most of its effects are often indirect, such as reducing excess oxidative stress, hydrogen is useful for many apparently unrelated clinical conditions that are linked to redox imbalances. Often these conditions do not have definitive treatments that eliminate the illness. In such cases, hydrogen can be used in conjunction with less than effective therapies to improve clinical outcomes.

3) Perhaps its most useful property is that hydrogen does not interfere with the underlying mechanisms of most clinical treatments. Thus, its real value may be in adjuvant therapy, along with standard treatments for many clinical conditions.

4) An important factor is the safety of hydrogen and that no adverse effects of hydrogen have been described. This is also very relevant, since many drugs are limited in their use because of toxicity, adverse reactions, and unfavorable dose-response characteristics. Hydrogen does not have these problems.

5) The ease of hydrogen administration is a useful characteristic. This is where $\mathrm{H}_{2}$-enriched water has an advantage over other methods of hydrogen delivery. Drinking $\mathrm{H}_{2}$-enriched water can be done on a long-term basis without any special requirements for administration.

Basic and clinical research on the use of hydrogen for acute and chronic illnesses will continue to improve our understanding of the mechanism of action of hydrogen therapy:

1) Hydrogen is able to promote changes in the expression and levels of particular proteins by regulating gene expression. Of particular importance is that hydrogen can inhibit or change the expression patterns of proinflammatory, pro-allergic, pro-apoptotic and pro-oxidative proteins. Many, if not most, of these proteins are over-expressed in a variety of chronic and acute illnesses. How hydrogen changes the expression of particular proteins remains an important question that is currently a topic of research in several laboratories.

2) The cellular receptors for hydrogen and the mechanisms of hydrogen action at the level of cellular membranes, enzymes, protein synthesis, and gene regulation will have to be investigated. Little is actually known about these molecular interactions involving hydrogen inside cells and tissues. This will have to also be investigated first in simple in vitro models in order to eventually understand more complex in vivo environments.

3) Hydrogen is able to quickly penetrate into tissues and cells. Further investigation is needed to monitor the actual levels of hydrogen in the microcirculation and target tissues, especially when hydrogen is administered for long periods of time. We do not yet know the levels of hydrogen administration which provide steady state and effective concentrations of hydrogen in various tissues and cells.

4) The clinical uses of hydrogen must be further investigated. Most of the published research on hydrogen has utilized animal models. Although this has been extremely useful, it is now time to shift the focus of research to patients with acute and chronic clinical conditions.

5) There are some advantages and disadvantages in the various ways hydrogen is administered, and this should be further investigated. Although inhalation of $\mathrm{H}_{2}$ gas has an advantage in that it is easy to administer; it also has some disadvantages, such as reproducibility of delivering the same dose of $\mathrm{H}_{2}$ in different patients because of variations in the amounts that effectively reach the microcirculation and tissues. It also requires highpressure containers and pressure regulators to deliver the required amounts of hydrogen gas, and the patient must use a mask or nasal insert. On the other hand, $\mathrm{H}_{2}$-enriched water can be easily and accurately delivered without any special apparatus. With any delivery method there is the problem of knowing the effective concen- 
trations of hydrogen that reach the target tissues, and this will remain an important research topic.

6) The increased use of controlled, randomized clinical trials will improve our knowledge of the benefits of hydrogen for various acute and chronic conditions. Until recently few clinical trials have used rigorous criteria for evaluation of clinical effects. Many trials have been open label in design, and this is expected for initial clinical investigations. In the future it is expected that more carefully designed (and more expensive!) placebocontrolled, blinded, randomized clinical trials will be necessary to confirm the clinical benefits of hydrogen.

Finally, the use of hydrogen for acute and chronic medical conditions is rapidly being eclipsed by the use of hydrogen for health maintenance, exercise and physical performance, as well as aging. These areas of hydrogen use will continue to grow and will ultimately dwarf the current clinical uses of hydrogen in our society.

\section{Acknowledgements}

This work has been partially funded by grants and donations to the Institute for Molecular Medicine (to G.L.N.), grants from ANII-PEDECIBA-CSIC Udelar International Cooperation Programs (to G.L.N. and G.F.), CSIC I + D 146 (to G.F.) and a grant from Naturally-Plus USA (to R.S. and G.L.N.).

\section{References}

[1] Ohta, S. (2015) Molecular Hydrogen as a Novel Antioxidant: Overview of the Advantages of Hydrogen for Medical Applications. Methods in Enzymology, 555, 289-317. http://dx.doi.org/10.1016/bs.mie.2014.11.038

[2] Ohta, S. (2014) Molecular Oxygen as a Preventive and Therapeutic Medical Gas: Initiation, Development and Potential of Hydrogen Medicine. Pharmacology and Therapeutics, 144, 1-11. http://dx.doi.org/10.1016/j.pharmthera.2014.04.006

[3] Zhai, X., Chen, X., Ohta, S. and Sun, X. (2014) Review and Prospect of the Biomedical Effects of Hydrogen. Medical Gas Research, 4, Article 19. http://dx.doi.org/10.1186/s13618-014-0019-6

[4] Pilcher, J.E. (1888) On the Diagnosis of Gastrointestinal Perforation by the Rectal Insufflation of Hydrogen Gas. Annuals of Surgery, 8, 190-204. http://dx.doi.org/10.1097/00000658-188807000-00087

[5] Ohsawa, I., Ishikawa, M., Takahashi, K., Watanabe, M., Nishimaki, K., Yamagata, K., Katsura, K., Katayama, Y., Asoh, S. and Ohta, S. (2007) Hydrogen Acts as a Therapeutic Antioxidant by Selectively Reducing Cytotoxic Oxygen Radicals. Nature Medicine, 13, 688-694. http://dx.doi.org/10.1038/nm1577

[6] Christensen, H. and Sehested, K. (1983) Reaction of Hydroxyl Radicals with Hydrogen at Elevated Temperatures. Journal of Physical Chemistry, 87, 118-120. http://dx.doi.org/10.1021/j100224a027

[7] Indo, H.P., Yen, H.C., Nakanishi, I., Matsumoto, K., Tamura, M., et al. (2015) A Mitochondrial Superoxide Theory for Oxidative Stress Diseases and Aging. Journal of Clinical Biochemistry and Nutrition, 56, 1-7.

http://dx.doi.org/10.3164/jcbn.14-42

[8] Andersen, K. (2004) Oxidative Stress in Neurodegeneration: Cause or Consequence? Nature Medicine, 10, S18-S25. http://dx.doi.org/10.1038/nrn1434

[9] Maise, K. (2015) New Insights for Oxidative Stress and Diabetes Mellitus. Oxidative Medicine and Cellular Longevity, 2015, Article ID: 875961. http://dx.doi.org/10.1155/2015/875961

[10] Vendemiale, G., Grattagliano, I. and Altomare, E. (1999) An Update on the Role of Free Radicals and Antioxidant Defense in Human Disease. International Journal of Clinical Laboratory Research, 29, 49-55. http://dx.doi.org/10.1007/s005990050063

[11] Bonomini, F., Rodella, L.F. and Rezzani, R. (2015) Metabolic Syndrome, Aging and Involvement of Oxidative Stress. Aging and Disease, 6, 109-120. http://dx.doi.org/10.14336/AD.2014.0305

[12] Harman, D. (1972) The Biologic Clock: The Mitochondria? Journal of American Geriatric Society, 20, 145-147. http://dx.doi.org/10.1111/j.1532-5415.1972.tb00787.x

[13] Miquel J., Economos, A.C., Fleming, J. and Johnson Jr., J.E. (1980) Mitochondrial Role in Cell Aging. Experimental Gerontology, 15, 575-591. http://dx.doi.org/10.1016/0531-5565(80)90010-8

[14] Turrens, J.F. (2003) Mitochondrial Formation of Reactive Oxygen Species. Journal of Physiology, 552, 335-344. http://dx.doi.org/10.1113/jphysiol.2003.049478

[15] Lipinski, B. (2011) Hydroxyl Radical and Its Scavengers in Health and Disease. Oxidative Medicine and Cell Longevity, 2011, Article ID: 809696. http://dx.doi.org/10.1155/2011/809696

[16] Harish, G., Mahadevan, A., Pruthl, N., Sreenivasamurthy, A.K., Puttamallesh, V.N., et al. (2015) Characterization of Traumatic Brain Injury in Human Brains Reveals Distinct Cellular and Molecular Changes in Contusion and Pericon- 
tusion. Journal of Neurochemistry, 134, 156-172. http://dx.doi.org/10.1111/jnc.13082

[17] Carri, M.T., Valle, C., Bozzo, F. and Coozzolino, M. (2015) Oxidative Stress and Mitochondrial Damage: Importance in Non-SOD1 ALS. Frontiers in Cellular Neuroscience, 9, Article 41. http://dx.doi.org/10.3389/fncel.2015.00041

[18] Wei, Y.H. (1992) Mitochondrial DNA Alterations as Ageing-Associated Molecular Events. Mutation Research, 275, 145-155. http://dx.doi.org/10.1016/0921-8734(92)90019-L

[19] Pak, J.W., Herbst, A., Bua, E., Gokey, N., McKenzie, D. and Aiken, J.M. (2003) Mitochondrial DNA Mutations as a Fundamental Mechanism in Physiological Declines Associated with Aging. Aging Cell, 2, 1-7. http://dx.doi.org/10.1046/j.1474-9728.2003.00034.x

[20] Reddy, P.H. (2008) Mitochondrial Medicine for Aging and Neurodegenerative Diseases. Neuromolecular Medicine, 10, 291-315. http://dx.doi.org/10.1007/s12017-008-8044-z

[21] Karowski, M. and Neutzner, A. (2011) Neurodegeneration as a Consequence of Failed Mitochondrial Maintenance. Acta Neuropatholica, 123, 157-171. http://dx.doi.org/10.1007/s00401-011-0921-0

[22] Nicolson, G.L. (2014) Mitochondrial Dysfunction and Chronic Disease: Treatment with Natural Supplements. Alternative Therapies for Health and Medicine, 20, 18-25.

[23] Maiese, K., Chong, Z.Z., Shang, Y.C. and Wang, S. (2012) Targeting Disease through Novel Pathways of Apoptosis and Autophagy. Expert Opinions in Therapeutic Targets, 16, 1203-1214. http://dx.doi.org/10.1517/14728222.2012.719499

[24] Suzen, S., Cihaner, S.S. and Coban, T. (2012) Synthesis and Comparison of Antioxidant Properties of Indole-Based Metatonin Analogue Indole Amino Acid Derivatives. Chemical and Biological Drug Design, 79, 76-83. http://dx.doi.org/10.1111/j.1747-0285.2011.01216.x

[25] Schoenfled, M.P., Ansari, R.R., Nakao, A. and Wink, D. (2012) A Hypothesis on Biological Protection from Space Radiation through the Use of New Therapeutic Gases as Medical Counter Measures. Medical Gas Research, 2, Article 8.

[26] Grassi, D., Desideri, G., Ferri, L., Aggio, A., Tiberti, S. and Ferri, C. (2010) Oxidative Stress and Endothelial Dysfunction: Say No to Cigarette Smoking! Current Pharmaceutical Design, 16, 2539-2550. http://dx.doi.org/10.2174/138161210792062867

[27] Harma, M.I., Harma, M. and Erel, O. (2006) Measuring Plasma Oxidative Stress Biomarkers in Sport Medicine. European Journal of Applied Physiology, 97, 505-508. http://dx.doi.org/10.1007/s00421-006-0202-0

[28] Aukland, K., Bower, B.F. and Berliner, R.W. (1964) Measurement of Local Blood Flow with Hydrogen Gas. Circulation Research, 14, 164-187. http://dx.doi.org/10.1161/01.RES.14.2.164

[29] Ohta, S. (2011) Recent Progress toward Understanding Hydrogen Medicine: Potential of Molecular Hydrogen for Preventive and Therapeutic Applications. Current Pharmaceutical Design, 17, 2241-2252. http://dx.doi.org/10.2174/138161211797052664

[30] Schieber, M. and Chandel, N.S. (2014) ROS Function in Redox Signaling and Oxidative Stress. Current Biology, 24, R453-R462. http://dx.doi.org/10.1016/j.cub.2014.03.034

[31] Fenkel, T. (1998) Oxygen Radicals and Signaling. Current Opinion in Cell Biology, 10, 248-253. http://dx.doi.org/10.1016/S0955-0674(98)80147-6

[32] Collins, Y., Chouchani, E.T., James, A.M., Menger, K.E., Cocheme, H.M. and Murphy, M.P. (2012) Mitochondrial Redox Signaling at a Glance. Journal of Cell Science, 125, 801-816. http://dx.doi.org/10.1242/jcs.098475

[33] Chandel, N.S., Vander Heiden, M.G., Thompson, C.B. and Schumacker, P.T. (2000) Redox Regulation of p53 during Hypoxia. Oncogene, 19, 3840-3848. http://dx.doi.org/10.1038/sj.onc.1203727

[34] Liu, H., Colavitti, R., Rovira, I.I. and Finkel, T. (2005) Redox-Dependent Transcriptional Regulation. Circulation Research, 97, 967-974. http://dx.doi.org/10.1161/01.RES.0000188210.72062.10

[35] Nakai, Y., Sato, B., Ushiama, S., Okada, S., Abe, K. and Arai, S. (2011) Hepatic Oxidoreduction-Related Genes Are Upregulated by Administration of Hydrogen-Saturated Drinking Water. Bioscience Biotechnology and Biochemistry, 75, 774-776. http://dx.doi.org/10.1271/bbb.100819

[36] Chandel, N.S., Trzyna, W.C. and McClintock, D.S. (2000) Role of Oxidants in NF-Kappa B Activation and TNFAlpha Gene Transcription Induced by Hypoxia and Endotoxin. Journal of Immunology, 165, 1013-1021. http://dx.doi.org/10.4049/jimmunol.165.2.1013

[37] Murphy, M.P. and Smith, R.A. (2000) Drug Delivery to Mitochondria: The Key to Mitochondrial Medicine. Advances in Drug Delivery Reviews, 41, 235-250. http://dx.doi.org/10.1016/S0169-409X(99)00069-1

[38] Smith, R.A. and Murphy, M.P. (2011) Mitochondria-Targeted Antioxidants as Therapies. Discovery Medicine, 11, 106-114. 
[39] Hayashida, K., Sano, M., Kamimura, N., Yokota, T., Suzuki, M., et al. (2012) H(2) Gas Improves Functional Outcome after Cardiac Arrest to an Extent Comparable to Therapeutic Hypothermia in a Rat Model. Journal of the American Heart Association, 1, e003459. http://dx.doi.org/10.1161/jaha.112.003459

[40] Hayashida, K., Sano, M., Ohsawa, I., Shinmura, K., Tamaki, K., et al. (2008) Inhalation of Hydrogen Gas Reduces Infarct Size in the Rat Model of Myocardial Ischemia-Reperfusion Injury. Biochemical and Biomedical Research Communications, 373, 30-35. http://dx.doi.org/10.1016/j.bbrc.2008.05.165

[41] Kawamura, T., Huang, C.S., Tochigi, N., Lee, S., Shigemura, N., et al. (2010) Inhaled Hydrogen Gas Therapy for Prevention of Lung Transplant-Induced Ischemia/Reperfusion Injury in Rats. Transplantation, 90, 1334-1351.

[42] Xie, K.L., Yu, Y.H., Pei, Y.P., et al. (2010) Protective Effects of Hydrogen Gas on Murine Polymicrobial Sepsis via Reducing Oxidative Stress and HMGB1 Release. Shock, 34, 90-97. http://dx.doi.org/10.1097/SHK.0b013e3181cdc4ae

[43] Xie, K., Yu, Y., Zhang, Z., Liu, W., Pei, Y., Xiong, L., Hou, L. and Wang, G. (2010) Hydrogen Gas Improves Survival Rate and Organ Damage in Zymosan-Induced Generalized Inflammation Model. Shock, 34, 495-501. http://dx.doi.org/10.1097/SHK.0b013e3181def9aa

[44] Cai, J.M., Kang, Z.M., Liu, K., et al. (2009) Neuroprotective Effects of Hydrogen Saline in Neonatal Hypoxia-Ischemia Rat Model. Brain Research, 1256, 129-137. http://dx.doi.org/10.1016/j.brainres.2008.11.048

[45] Li, J., Wang, C., Zhang, J.H., Cai, J.M., Cao, Y.P. and Sun, X.J. (2010) Hydrogen-Rich Saline Improves Memory Function in a Rat Model of Amyloid-Beta-Induced Alzheimer's Disease by Reduction of Oxidative Stress. Brain Research, 1328, 152-161. http://dx.doi.org/10.1016/j.brainres.2010.02.046

[46] Nagata, K., Nakashima-Kamimura, N., Mikami, T., Ohsawa, I. and Ohta, S. (2009) Consumption of Molecular Hydrogen Prevents the Stress-Induced Impairments in Hippocampus-Dependent Learning Tasks during Chronic Physical Restraint in Mice. Neuropsychopharmacology, 34, 501-508. http://dx.doi.org/10.1038/npp.2008.95

[47] Nakashima-Kamimura, N., Mori, T., Ohsawa, I., Asoh, S. and Ohta, S. (2009) Molecular Hydrogen Alleviates Nephrotoxicity Induced by an Anti-Cancer Drug Cisplatin without Comproising Anti-Tumor Activity in Mice. Cancer Chemotherapy and Pharmacology, 64, 753-761. http://dx.doi.org/10.1007/s00280-008-0924-2

[48] Fontanari, P., Badier, M., Guillot, C., Tomei, C., Burnet, H., Gardette, B., et al. (2000) Changes in Maximal Performance in Inspiratory and Skeletal Muscles during and after the 7.1-MPa Hydra 10 Record Human Dive. European Journal of Applied Physiology, 81, 325-328. http://dx.doi.org/10.1007/s004210050050

[49] Lillo, R.S., Parker, E.C. and Porter, W.R. (1997) Decompression Comparison of Helium and Hydrogen in Rats. Journal of Applied Physiology, 82, 892-901.

[50] Lillo, R.S. and Parker, E.C. (2000) Mixed-Gas Model for Predicting Decompression Sickness in Rats. Journal of Applied Physiology, 89, 2107-2116.

[51] Abraini, J.H., Gardette-Chauffour, M.C., Martinez, E., Rostain, J.C. and Lemaire, C. (1994) Psychophysiological Reactions in Humans during an Open Sea Dive to 500 m with a Hydrogen-Helium-Oxygen Mixture. Journal of Applied Physiology, 76, 1113-1118.

[52] Lafay, V., Barthelemy, P., Comet, B., Frances, Y. and Jammes, Y. (1995) ECG Changes during the Experimental Human Dive HYDRA 10 (71 ATM/7,200 kPa). Undersea Hyperbaric Medicine, 22, 51-60.

[53] Tomofugi, T., Kawabata, Y., Kasuyama, K., Endo, Y., Yoneda, T., Yamane, M., et al. (2014) Effects of HydrogenRich Water on Aging Periodontal Tissue in Rats. Scientific Reports, 4, Article 5534. http://dx.doi.org/10.1038/srep05534

[54] Huang, C.S., Kawamura, T., Toyoda, Y. and Nakao, A. (2010) Recent Advances in Hydrogen Research as a Therapeutic Medical Gas. Free Radical Research, 44, 971-982. http://dx.doi.org/10.3109/10715762.2010.500328

[55] Ohno, K., Ito, M., Ichihara, M. and Ito, M. (2012) Molecular Hydrogen as an Emerging Therapeutic Medical Gas for Neurodegenerative and Other Diseases. Oxidative Medicine and Cellular Longevity, 2012, Article ID: 353152. http://dx.doi.org/10.1155/2012/353152

[56] Shen, M., Zhang, H., Yu, C., Wang, F. and Sun, X. (2014) A Review of Experimental Studies of Hydrogen as a New Therapeutic Agent in Emergency and Critical Care Medicine. Medical Gas Research, 4, Article 17. http://dx.doi.org/10.1186/2045-9912-4-17

[57] Oharazawa, H., Igarashi, T., Yokota, T., Fujii, H., Suzuki, H., Machide, M., et al. (2010) Protection of the Retina by Rapid Diffusion of Hydrogen: Administration of Hydrogen-Loaded Eye Drops in Retinal Ischemia-Reperfusion Injury. Investigative Ophthalmology and Vision Science, 51, 487-492. http://dx.doi.org/10.1167/iovs.09-4089

[58] Noda, K., Shigemura, N., Tanaka, Y., Kawamura, T., Hyun Lim, S., et al. (2013) A Novel Method of Preserving Cardiac Grafts Using a Hydrogen-Rich Water Bath. Journal of Heart and Lung Transplantation, 32, 241-250. http://dx.doi.org/10.1016/j.healun.2012.11.004

[59] Gaffron, H. (1939) Reduction of Carbon Dioxide with Molecular Hydrogen in Green Algae. Nature, 143, $204-205$. 
http://dx.doi.org/10.1038/143204a0

[60] Melis, A. and Melnicki, M.R. (2006) Integrated Biological Hydrogen Production. International Journal of Hydrogen Energy, 31, 1563-1573. http://dx.doi.org/10.1016/j.ijhydene.2006.06.038

[61] Zeng, J., Zhang, M. and Sun, X. (2013) Molecular Hydrogen Is Involved in Phytohormone Signaling and Stress Responses in Plants. PLoS ONE, 8, e71038. http://dx.doi.org/10.1371/journal.pone.0071038

[62] Zeng, J., Ye, Z. and Sun, X. (2013) Progress in the Study of Biological Effects of Hydrogen on Higher Plants and Its Promising Application in Agriculture. Medical Gas Research, 4, Article 15.

[63] Vilahur, G. and Badimon, L. (2014) Ischemia/Reperfusion Activates Myocardial Innate Immune Responses: The Key Role of the Toll-Like Receptor. Frontiers in Physiology, 5, e00497. http://dx.doi.org/10.3389/fphys.2014.00496

[64] Dorweiler, B., Pruefer, D., Andrasi, T.B., Maksan, S.M., Schmiedt, W., Neufang, A. and Vahl, C.F. (2007) IschemiaReperfusion Injury. European Journal of Trauma and Emergency Surgery, 33, 600-612. http://dx.doi.org/10.1007/s00068-007-7152-z

[65] Carden, D.L. and Granger, D.N. (2000) Pathophysiology of Ischaemia-Reperfusion Injury. Journal of Pathology, 190, 255-266. http://dx.doi.org/10.1002/(SICI)1096-9896(200002)190:3<255::AID-PATH526>3.0.CO;2-6

[66] Granger, D.N. (1988) Role of Xanthine Oxidase and Granulocytes in Ischemia-Reperfusion Injury. American Journal of Physiology, 255, H1269-H1275.

[67] Di Lisa, F. and Bernardi, P. (2006) Mitochondria and Ischemia-Reperfusion Injury of the Heart: Fixing a Hole. Cardiovascular Research, 70, 191-199. http://dx.doi.org/10.1016/j.cardiores.2006.01.016

[68] Thapalia, B.A., Zhou, Z. and Lin, X. (2014) Autophagy, a Process within Reperfusion Injury: An Update. International Journal of Clinical and Experimental Pathology, 7, 8322-8341.

[69] Ostojic, S.M. (2015) Targeting Molecular Hydrogen to Mitochondria: Barriers and Gateways. Pharmacological Research, 94, 51-53. http://dx.doi.org/10.1016/j.phrs.2015.02.004

[70] Sobue, S., Yamai, K., Ito, M., Ohno, K., Ito, M., et al. (2015) Simultaneous Oral and Inhalational Intake of Molecular Hydrogen Additively Suppresses Signaling Pathways in Rodents. Molecular and Cellular Biochemistry, 403, $231-241$. http://dx.doi.org/10.1007/s11010-015-2353-y

[71] Boyle, E.M., Pohlman, T.H., Cornejo, C.J. and Verrier, E.D. (1997) Ischemia-Reperfusion Injury. The Annals of Thoracic Surgery, 64, S24-S30. http://dx.doi.org/10.1016/s0003-4975(97)00958-2

[72] Anaya-Prado, R., Toledo-Pereyra, L.H., Lentsch, A.B. and Ward, P.A. (2002) Ischemia/Reperfusion Injury. The Journal of Surgical Research, 105, 248-258. http://dx.doi.org/10.1006/jsre.2002.6385

[73] Ohta, S. (2012) Molecular Hydrogen Is a Novel Antioxidant to Efficiently Reduce Oxidative Stress with Potential for the Improvement of Mitochondrial Diseases. Biochimica et Biophysica Acta, 1820, 586-594. http://dx.doi.org/10.1016/j.bbagen.2011.05.006

[74] Casillas-Ramirez, A., Mosbah, I.B., Ramalho, F., Rosello-Catafau, J. and Peralta, C. (2006) Past and Future Approaches to Ischemia-Reperfusion Lesion Associated with Liver Transplantation. Life Sciences, 79, 1881-1894. http://dx.doi.org/10.1016/j.lfs.2006.06.024

[75] Gok, M.A., Shenton, B.K., Pelsers, M., Whitwood, A., Mantle, D., et al. (2006) Ischemia-Reperfusion Injury in Cadaveric Nonheart Beating, Cadaveric Heart Beating and Live Donor Renal Transplants. The Journal of Urology, 175, 641-647. http://dx.doi.org/10.1016/S0022-5347(05)00170-9

[76] Kosieradzki, M. and Rowinski, W. (2008) Ischemia/Reperfusion Injury in Kidney Transplantation: Mechanisms and Prevention. Transplantation Proceedings, 40, 3279-3288. http://dx.doi.org/10.1016/j.transproceed.2008.10.004

[77] Hong, Y., Chen, S. and Zhang, J.M. (2010) Hydrogen as a Selective Antioxidant: A Review of Clinical and Experimental Studies. Journal of International Medical Research, 38, 1893-1903. http://dx.doi.org/10.1177/147323001003800602

[78] Ohta, S., Nakao, A. and Ohno, K. (2011) The 2011 Medical Molecular Hydrogen Symposium: An Inaugural Symposium of the Journal Medical Gas Research. Medical Gas Research, 1, Article 10. http://dx.doi.org/10.1186/2045-9912-1-10

[79] Ostojic, S.M. (2015) Molecular Hydrogen: An Inert Gas Turns Clinically Effective. Annals of Medicine, 47, 301-314. http://dx.doi.org/10.3109/07853890.2015.1034765

[80] Shen, M., Zhang, H., Yu, C., Wang, F. and Sun, X. (2014) A Review of Experimental Studies of Hydrogen as a New Therapeutic Agent in Emergency and Critical Care Medicine. Medical Gas Research, 4, Article 17. http://dx.doi.org/10.1186/2045-9912-4-17

[81] Sun, Q., Kang, Z., Cai, J., Liu, W., Liu, Y., et al. (2009) Hydrogen-Rich Saline Protects Myocardium against Ischemia/ Reperfusion Injury in Rats. Experimental Biology and Medicine, 234, 1212-1219. 
http://dx.doi.org/10.3181/0812-RM-349

[82] Zhang, Y., Sun, Q., He, B., Xiao, J., Wang, Z. and Sun, X. (2011) Anti-Inflammatory Effect of Hydrogen-Rich Saline in a Rat Model of Regional Myocardial Ischemia and Reperfusion. International Journal of Cardiology, 148, 91-95. http://dx.doi.org/10.1016/j.ijcard.2010.08.058

[83] Wu, S., Zhu, L., Yang, J., Fan, Z., Dong, Y., et al. (2014) Hydrogen-Containing Saline Attenuates DoxorubicinInduced Heart Failure in Rats. Die Pharmazie, 69, 633-636.

[84] Shinbo, T., Kokubo, K., Sato, Y., Hagiri, S., Hataishi, R., et al. (2013) Breathing Nitric Oxide plus Hydrogen Gas Reduces Ischemia-Reperfusion Injury and Nitrotyrosine Production in Murine Heart. American Journal of Physiology, Heart and Circulatory Physiology, 305, H542-H550. http://dx.doi.org/10.1152/ajpheart.00844.2012

[85] Vander Heide, R.S. and Steenbergen, C. (2013) Cardioprotection and Myocardial Reperfusion: Pitfalls to Clinical Application. Circulation Research, 113, 464-477. http://dx.doi.org/10.1161/CIRCRESAHA.113.300765

[86] Kubler, W. and Haass, M. (1996) Cardioprotection: Definition, Classification, and Fundamental Principles. Heart, 75, 330-333. http://dx.doi.org/10.1136/hrt.75.4.330

[87] Murry, C.E., Jennings, R.B. and Reimer, K.A. (1986) Preconditioning with Ischemia: A Delay of Lethal Cell Injury in Ischemic Myocardium. Circulation, 74, 1124-1136. http://dx.doi.org/10.1161/01.CIR.74.5.1124

[88] Zhao, Z.Q., Corvera, J.S., Halkos, M.E., Kerendi, F., Wang, N.P., Guyton, R.A. and Vinten-Johansen, J. (2003) Inhibition of Myocardial Injury by Ischemic Postconditioning during Reperfusion: Comparison with Ischemic Preconditioning. American Journal of Physiology, Heart and Circulation Physiology, 285, H579-H588. http://dx.doi.org/10.1152/ajpheart.01064.2002

[89] Piot, C., Croisille, P., Staat, P., Thibault, H., Rioufol, G., et al. (2008) Effect of Cyclosporine on Reperfusion Injury in Acute Myocardial Infarction. The New England Journal of Medicine, 359, 473-481. http://dx.doi.org/10.1056/NEJMoa071142

[90] Rajesh, K.G., Sasaguri, S., Suzuki, R., Xing, Y. and Maeda, H. (2004) Ischemic Preconditioning Prevents Reperfusion Heart Injury in Cardiac Hypertrophy by Activation of Mitochondrial KATP Channels. International Journal of Cardiology, 96, 41-49. http://dx.doi.org/10.1016/j.ijcard.2003.06.010

[91] Qian, L., Cao, F., Cui, J., Wang, Y., Huang, Y., Chuai, Y., et al. (2010) The Potential Cardioprotective Effects of Hydrogen in Irradiated Mice. Journal of Radiation Research, 51, 741-747. http://dx.doi.org/10.1269/jrr.10093

[92] Sakai, K., Cho, S., Shibata, I., Yoshitomi, O., Maekawa, T. and Sumikawa, K. (2012) Inhalation of Hydrogen Gas Protects against Myocardial Stunning and Infarction in Swine. Scandinavian Cardiovascular Journal, 46, 183-189. http://dx.doi.org/10.3109/14017431.2012.659676

[93] Yoshida, A., Asanuma, H., Sasaki, H., Sanada, S., Yamazaki, S., et al. (2012) H(2) Mediates Cardioprotection via Involvements of K(ATP) Channels and Permeability Transition Pores of Mitochondria in Dogs. Cardiovascular Drugs and Therapy, 26, 217-226. http://dx.doi.org/10.1007/s10557-012-6381-5

[94] Xie, Q., Li, X., Zhang, P., Li, J.C., Cheng, Y., et al. (2014) Hydrogen Gas Protects against Serum and Glucose Deprivation Induced Myocardial Injury in H9c2 Cells through Activation of the NFE2 Related Factor 2/Heme Oxygenase 1 Signaling Pathway. Molecular Medicine Reports, 10, 1143-1149.

[95] Nakao, A., Kaczorowski, D.J., Wang, Y., Cardinal, J.S., Buchholz, B.M., et al. (2010) Amelioration of Rat Cardiac Cold Ischemia/Reperfusion Injury with Inhaled Hydrogen or Carbon Monoxide, or Both. The Journal of Heart and Lung Transplantation, 29, 544-553. http://dx.doi.org/10.1016/j.healun.2009.10.011

[96] Noda, K., Tanaka, Y., Shigemura, N., Kawamura, T., Wang, Y., et al. (2012) Hydrogen-Supplemented Drinking Water Protects Cardiac Allografts from Inflammation-Associated Deterioration. Transplant International, 25, 1213-1222. http://dx.doi.org/10.1111/j.1432-2277.2012.01542.x

[97] Tan, M., Sun, X., Guo, L., Su, C., Sun, X. and Xu, Z. (2013) Hydrogen as Additive of HTK Solution Fortifies Myocardial Preservation in Grafts with Prolonged Cold Ischemia. International Journal of Cardiology, 167, 383-390. http://dx.doi.org/10.1016/j.ijcard.2011.12.109

[98] Buchholz, B.M., Kaczorowski, D.J., Sugimoto, R., Yang, R., Wang, Y., Billiar, T.R., McCurry, K.R., Bauer, A.J. and Nakao, A. (2008) Hydrogen Inhalation Ameliorates Oxidative Stress in Transplantation Induced Intestinal Graft Injury. American Journal of Transplantation, 8, 2015-2024. http://dx.doi.org/10.1111/j.1600-6143.2008.02359.X

[99] Salehi, P., Bigam, D.L., Ewaschuk, J.B., Madsen, K.L., Sigurdson, G.T., Jewell, L.D. and Churchill, T.A. (2008) Alleviating Intestinal Ischemia-Reperfusion Injury in an in Vivo Large Animal Model: Developing an Organ-Specific Preservation Solution. Transplantation, 85, 878-884. http://dx.doi.org/10.1097/TP.0b013e318166a42f

[100] Zheng, X., Mao, Y., Cai, J., Li, Y., Liu, W., Sun, P., Zhang, J.H., Sun, X. and Yuan, H. (2009) Hydrogen-Rich Saline Protects against Intestinal Ischemia/Reperfusion Injury in Rats. Free Radical Research, 43, 478-484. http://dx.doi.org/10.1080/10715760902870603 
[101] Buchholz, B.M., Masutani, K., Kawamura, T., Peng, X., Toyoda, Y., Billiar, T.R., Bauer, A.J. and Nakao, A. (2011) Hydrogen-Enriched Preservation Protects the Isogeneic Intestinal Graft and Amends Recipient Gastric Function during Transplantation. Transplantation, 92, 985-992. http://dx.doi.org/10.1097/tp.0b013e318230159d

[102] Shigeta, T., Sakamoto, S., Li, X.K., Cai, S., Liu, C., Kurokawa, R., Nakazawa, A., Kasahara, M. and Uemoto, S. (2015) Luminal Injection of Hydrogen-Rich Solution Attenuates Intestinal Ischemia-Reperfusion Injury in Rats. Transplantation, 99, 500-507. http://dx.doi.org/10.1097/TP.0000000000000510

[103] Mao, Y.F., Zheng, X.F., Cai, J.M., You, X.M., Deng, X.M., Zhang, J.H., Jiang, L. and Sun, X.J. (2009) Hydrogen-Rich Saline Reduces Lung Injury Induced by Intestinal Ischemia/Reperfusion in Rats. Biochemical and Biophysical Research Communications, 381, 602-605. http://dx.doi.org/10.1016/j.bbrc.2009.02.105

[104] den Hengst, W.A., Gielis, J.F., Lin, J.Y., Van Schil, P.E., De Windt, L.J. and Moens, A.L. (2010) Lung IschemiaReperfusion Injury: A Molecular and Clinical View on a Complex Pathophysiological Process. American Journal of Physiology, Heart and Circulatory Physiology, 299, H1283-H1299. http://dx.doi.org/10.1152/ajpheart.00251.2010

[105] Gennai, S., Pison, C. and Briot, R. (2014) [Ischemia-Reperfusion Injury after Lung Transplantation]. Presse Medicine, 43, 921-930. http://dx.doi.org/10.1016/j.lpm.2014.01.018

[106] Dark, J. (2014) Hydrogen in Lung Reconditioning-More than Just Inflation. Transplantation, 98, 497-498. http://dx.doi.org/10.1097/TP.0000000000000311

[107] Tanaka, Y., Shigemura, N., Kawamura, T., Noda, K., Isse, K., Stolz, D.B., Billiar, T.R., Toyoda, Y., Bermudez, C.A., Lyons-Weiler, J. and Nakao, A. (2012) Profiling Molecular Changes Induced by Hydrogen Treatment of Lung Allografts Prior to Procurement. Biochemical and Biophysical Research Communications, 425, 873-879. http://dx.doi.org/10.1016/j.bbrc.2012.08.005

[108] Zhou, H., Fu, Z., Wei, Y., Liu, J., Cui, X., Yang, W., Ding, W., Pan, P. and Li, W. (2013) Hydrogen Inhalation Decreases Lung Graft Injury in Brain-Dead Donor Rats. Journal of Heart and Lung Transplantation, 32, 251-258. http://dx.doi.org/10.1016/j.healun.2012.11.007

[109] Fang, Y., Fu, X.J., Gu, C., Xu, P., Wang, Y., Yu, W.R., Sun, Q., Sun, X.J. and Yao, M. (2011) Hydrogen-Rich Saline Protects against Acute Lung Injury Induced by Extensive Burn in Rat Model. Journal of Burn Care Research, 32, e82e91. http://dx.doi.org/10.1097/bcr.0b013e318217f84f

[110] Noda, K., Shigemura, N., Tanaka, Y., Bhama, J., D’Cunha, J., Kobayashi, H., Luketich, J.D. and Bermudez, C.A. (2014) Hydrogen Preconditioning during ex Vivo Lung Perfusion Improves the Quality of Lung Grafts in Rats. Transplantation, 98, 499-506. http://dx.doi.org/10.1097/TP.0000000000000254

[111] Terasaki, Y., Ohsawa, I., Terasaki, M., Takahashi, M., Kunugi, S., Dedong, K., Urushiyama, H., Amenomori, S., Kaneko-Togashi, M., Kuwahara, N., Ishikawa, A., Kamimura, N., Ohta, S. and Fukuda, Y. (2011) Hydrogen Therapy Attenuates Irradiation-Induced Lung Damage by Reducing Oxidative Stress. American Journal of Physiology, Lung Cellular and Molecular Physiology, 301, L415-L426. http://dx.doi.org/10.1152/ajplung.00008.2011

[112] Hattori, Y., Kotani, T., Tsuda, H., Mano, Y., Tu, L., Li, H., Hirako, S., Ushida, T., Imai, K., Nakano, T., Sato, Y., Miki, R., Sumigama, S., Iwase, A., Toyokuni, S. and Kikkawa, F. (2015) Maternal Molecular Hydrogen Treatment Attenuates Lipopolysaccharide-Induced Rat Fetal Lung Injury. Free Radical Research, 49, 1026-1037. http://dx.doi.org/10.3109/10715762.2015.1038257

[113] Xie, K., Yu, Y., Huang, Y., Zheng, L., Li, J., Chen, H., Han, H., Hou, L., Gong, G. and Wang, G. (2012) Molecular Hydrogen Ameliorates Lipopolysaccharide-Induced Acute Lung Injury in Mice through Reducing Inflammation and Apoptosis. Shock, 37, 548-555. http://dx.doi.org/10.1097/shk.0b013e31824ddc81

[114] Liu, H., Liang, X., Wang, D., Zhang, H., Liu, L., Chen, H., Li, Y., Duan, Q. and Xie, K. (2015) Combination Therapy with Nitric Oxide and Molecular Hydrogen in a Murine Model of Acute Lung Injury. Shock, 43, 504-511. http://dx.doi.org/10.1097/SHK.0000000000000316

[115] Bringmann, A., Uckermann, O., Pannicke, T., Iandiev, I., Reichenbach, A. and Wiedemann, P. (2005) Neuronal versus Glial Cell Swelling in the Ischaemic Retina. Acta Ophthalmologica Scandinavia, 83, 528-538. http://dx.doi.org/10.1111/j.1600-0420.2005.00565.x

[116] Sun, M.H., Pang, J.H., Chen, S.L., Han, W.H., Ho, T.C., Chen, K.J., Kao, L.Y., Lin, K.K. and Tsao, Y.P. (2010) Retinal Protection from Acute Glaucoma-Induced Ischemia-Reperfusion Injury through Pharmacologic Induction of Heme Oxygenase-1. Investigative Ophthalmology and Vision Science, 51, 4798-4808. http://dx.doi.org/10.1167/iovs.09-4086

[117] Makita, J., Hosoya, K., Zhang, P. and Kador, P.F. (2011) Response of Rat Retinal Capillary Pericytes and Endothelial Cells to Glucose. Journal of Occular Pharmacology and Therapeutics, 27, 7-15. http://dx.doi.org/10.1089/jop.2010.0051

[118] Liu, Y., Tang, L. and Chen, B. (2012) Effects of Antioxidant Gene Therapy on Retinal Neurons and Oxidative Stress in a Model of Retinal Ischemia/Reperfusion. Free Radical Biology and Medicine, 52, 909-915. 
http://dx.doi.org/10.1016/j.freeradbiomed.2011.12.013

[119] Pazdro, R. and Burgess, J.R. (2012) Differential Effects of Alpha-Tocopherol and N-Acetyl-Cysteine on Advanced Glycation End Product-Induced Oxidative Damage and Neurite Degeneration in SH-SY5Y Cells. Biochimica et Biophysica Acta, 1822, 550-556. http://dx.doi.org/10.1016/j.bbadis.2012.01.003

[120] Varnum, M.D., Black, K.D. and Zagotta, W.N. (1995) Molecular Mechanism for Ligand Discrimination of Cyclic Nucleotide-Gated Channels. Neuron, 15, 619-625. http://dx.doi.org/10.1016/0896-6273(95)90150-7

[121] Liu, G.D., Zhang, H., Wang, L., Han, Q., Zhou, S.F. and Liu, P. (2013) Molecular Hydrogen Regulates the Expression of miR-9, miR-21 and miR-199 in LPS-Activated Retinal Microglia Cells. International Journal of Ophthalmology, 6, 280-285.

[122] Yokota, T., Kamimura, N., Igarashi, T., Takahashi, H., Ohta, S. and Oharazawa, H. (2015) Protective Effect of Molecular Hydrogen against Oxidative Stress Caused by Peroxynitrite Derived from Nitric Oxide in Rat Retina. Clinical and Experimental Ophthalmology, 43, 568-577. http://dx.doi.org/10.1111/ceo.12525

[123] Liu, H., Hua, N., Xie, K., Zhao, T. and Yu, Y. (2015) Hydrogen-Rich Saline Reduces Cell Death through Inhibition of DNA Oxidative Stress and Overactivation of Poly (ADP-Ribose) Polymerase-1 in Retinal Ischemia-Reperfusion Injury. Molecular Medicine Reports, 12, 2495-2502. http://dx.doi.org/10.3892/mmr.2015.3731

[124] Sanderson, T.H., Reynolds, C.A., Kumar, R., Przyklenk, K. and Huttemann, M. (2013) Molecular Mechanisms of Ischemia-Reperfusion Injury in Brain: Pivotal Role of the Mitochondrial Membrane Potential in Reactive Oxygen Species Generation. Molecular Neurobiology, 47, 9-23. http://dx.doi.org/10.1007/s12035-012-8344-z

[125] Pan, J., Konstas, A.A., Bateman, B., Ortolano, G.A. and Pile-Spellman, J. (2007) Reperfusion Injury Following Cerebral Ischemia: Pathophysiology, MR Imaging, and Potential Therapies. Neuroradiology, 49, 93-102. http://dx.doi.org/10.1007/s00234-006-0183-z

[126] Ji, X., Liu, W., Xie, K., Liu, W., Qu, Y., Chao, X., Chen, T., Zhou, J. and Fei, Z. (2010) Beneficial Effects of Hydrogen Gas in a Rat Model of Traumatic Brain Injury via Reducing Oxidative Stress. Brain Research, 1354, 196-205. http://dx.doi.org/10.1016/j.brainres.2010.07.038

[127] Ji, X., Tian, Y., Xie, K., Liu, W., Qu, Y. and Fei, Z. (2012) Protective Effects of Hydrogen-Rich Saline in a Rat Model of Traumatic Brain Injury via Reducing Oxidative Stress. Journal of Surgical Research, 178, e9-e16. http://dx.doi.org/10.1016/j.jss.2011.12.038

[128] Huo, T.T., Zeng, Y., Liu, X.N., Sun, L., Han, H.Z., Chen, H.G., Lu, Z.H., Huang, Y., Nie, H., Dong, H.L., Xie, K.L. and Xiong, L.Z. (2014) Hydrogen-Rich Saline Improves Survival and Neurological Outcome after Cardiac Arrest and Cardiopulmonary Resuscitation in Rats. Anesthiology and Analgiology, 119, 368-380. http://dx.doi.org/10.1213/ANE.0000000000000303

[129] Ji, Q., Hui, K., Zhang, L., Sun, X., Li, W. and Duan, M. (2011) The Effect of Hydrogen-Rich Saline on the Brain of Rats with Transient Ischemia. Journal of Surgical Research, 168, e95-e101. http://dx.doi.org/10.1016/j.jss.2011.01.057

[130] Liu, L., Xie, K., Chen, H., Dong, X., Li, Y., Yu, Y., Wang, G. and Yu, Y. (2014) Inhalation of Hydrogen Gas Attenuates Brain Injury in Mice with Cecal Ligation and Puncture via Inhibiting Neuroinflammation, Oxidative Stress and Neuronal Apoptosis. Brain Research, 1589, 78-92. http://dx.doi.org/10.1016/j.brainres.2014.09.030

[131] Ono, H., Nishijima, Y., Adachi, N., Sakamoto, M., Kudo, Y., Kaneko, K., Nakao, A. and Imaoka, T. (2012) A Basic Study on Molecular Hydrogen $\left(\mathrm{H}_{2}\right)$ Inhalation in Acute Cerebral Ischemia Patients for Safety Check with Physiological Parameters and Measurement of Blood $\mathrm{H}_{2}$ Level. Medical Gas Research, 2, Article 21. http://dx.doi.org/10.1186/2045-9912-2-21

[132] Eckel, R.H., Grundy, S.M. and Zimmet, P.Z. (2005) The Metabolic Syndrome. Lancet, 365, 1415-1428. http://dx.doi.org/10.1016/S0140-6736(05)66378-7

[133] Grundy, S.M., Cleeman, J.I., Daniels, S.R., Donato, K.A., Eckel, R.H., Franklin, B.A., Gordon, D.J., Krauss, R.M., Savage, P.J., Smith Jr., S.C., Spertus, J.A. and Costa, F. (2005) Diagnosis and Management of the Metabolic Syndrome: An American Heart Association/National Heart, Lung, and Blood Institute Scientific Statement. Circulation, 112, 2735-2752. http://dx.doi.org/10.1161/CIRCULATIONAHA.105.169404

[134] Alberti, K.G., Zimmet, P. and Shaw, J., IDF Epidemiology Task Force Consensus Group (2005) The Metabolic Syndrome-A New Worldwide Definition. Lancet, 366, 1059-1062. http://dx.doi.org/10.1016/S0140-6736(05)67402-8

[135] Eckel, R.H., Alberti, K.G., Grundy, S.M. and Zimmet, P.Z. (2010) The Metabolic Syndrome. Lancet, 375, $181-183$. http://dx.doi.org/10.1016/S0140-6736(09)61794-3

[136] Reaven, G.M. (1988) Banting Lecture 1988. Role of Insulin Resistance in Human Disease. Diabetes, 37, $1595-1607$. http://dx.doi.org/10.2337/diab.37.12.1595

[137] Reaven, G.M. (1988) Dietary Therapy for Non-Insulin-Dependent Diabetes Mellitus. New England Journal of Medi- 
cine, 319, 862-864. http://dx.doi.org/10.1056/NEJM198809293191310

[138] Kylin, E. (1923) Studien ueber das hypertonie-hyperglykamie-hyperurikamiesyndrom. Zentralblatt für innere Medizin, 44, 105-127.

[139] Rosales-Corral, S., Tan, D.X., Manchester, L. and Reiter, R.J. (2015) Diabetes and Alzheimer Disease, Two Overlapping Pathologies with the Same Background: Oxidative Stress. Oxidative Medicine and Cellular Longevity, 2015, Article ID: 985845. http://dx.doi.org/10.1155/2015/985845

[140] Muller, M., Grobbee, D.E., den Tonkelaar, I., Lamberts, S.W. and van der Schouw, Y.T. (2005) Endogenous Sex Hormones and Metabolic Syndrome in Aging Men. Journal of Clinical Endocrinology and Metabolism, 90, 26182623. http://dx.doi.org/10.1210/jc.2004-1158

[141] Tangvarasittichai, S. (2015) Oxidative Stress, Insulin Resistance, Dyslipidemia and Type 2 Diabetes Mellitus. World Journal of Diabetes, 6, 456-480. http://dx.doi.org/10.4239/wjd.v6.i3.456

[142] Yubero-Serrano, E.M., Delgado-Lista, J., Pena-Orihuela, P., Perez-Martinez, P., Fuentes, F., Marin, C., Tunez, I., Tinahones, F.J., Perez-Jimenez, F., Roche, H.M. and Lopez-Miranda, J. (2013) Oxidative Stress Is Associated with the Number of Components of Metabolic Syndrome: LIPGENE Study. Experimental Molecular Medicine, 45, e28. http://dx.doi.org/10.1038/emm.2013.53

[143] Vincent, H.K. and Taylor, A.G. (2006) Biomarkers and Potential Mechanisms of Obesity-Induced Oxidant Stress in Humans. International Journal of Obesity (London), 30, 400-418. http://dx.doi.org/10.1038/sj.ijo.0803177

[144] Kopprasch, S., Srirangan, D., Bergmann, S., Graessler, J., Schwarz, P.E. and Bornstein, S.R. (2015) Association between Systemic Oxidative Stress and Insulin Resistance/Sensitivity Indices-The PREDIAS Study. Clinical Endocrinology, 84, 48-54. http://dx.doi.org/10.1111/cen.12811

[145] Freeman, B.A. and Crapo, J.D. (1982) Biology of Disease: Free Radicals and Tissue Injury. Laboratory Investigation, 47, 412-426.

[146] Slater, T.F. (1984) Free-Radical Mechanisms in Tissue Injury. Biochemical Journal, 222, 1-15. http://dx.doi.org/10.1042/bj2220001

[147] Dobrian, A.D., Davies, M.J., Schriver, S.D., Lauterio, T.J. and Prewitt, R.L. (2001) Oxidative Stress in a Rat Model of Obesity-Induced Hypertension. Hypertension, 37, 554-560. http://dx.doi.org/10.1161/01.HYP.37.2.554

[148] Nicolson, G.L. (2007) Metabolic Syndrome and Mitochondrial Function: Molecular Replacement and Antioxidant Supplements to Prevent Membrane Peroxidation and Restore Mitochondrial Function. Journal of Cellular Biochemistry, 100, 1352-1369. http://dx.doi.org/10.1002/jcb.21247

[149] Hashimoto, M., Katakura, M., Nabika, T., Tanabe, Y., Hossain, S., Tsuchikura, S. and Shido, O. (2011) Effects of Hydrogen-Rich Water on Abnormalities in a SHR.Cg-Leprcp/NDmcr Rat-A Metabolic Syndrome Rat Model. Medical Gas Research, 1, Article 26. http://dx.doi.org/10.1186/2045-9912-1-26

[150] Shirahata, S., Hamasaki, T., Haramaki, K., Nakamura, T., Abe, M., Yan, H., Kinjo, T., Nakamichi, N., Kabayama, S. and Teruya, K. (2011) Anti-Diabetes Effect of Water Containing Hydrogen Molecule and Pt Nanoparticles. BMC Proceedings, 5, P18. http://dx.doi.org/10.1186/1753-6561-5-S8-P18

[151] Haslam, D.W. and James, W.P. (2005) Obesity. Lancet, 366, 1197-1209. http://dx.doi.org/10.1016/S0140-6736(05)67483-1

[152] Furukawa, S., Fujita, T., Shimabukuro, M., Iwaki, M., Yamada, Y., Nakajima, Y., Nakayama, O., Makishima, M., Matsuda, M. and Shimomura, I. (2004) Increased Oxidative Stress in Obesity and Its Impact on Metabolic Syndrome. Journal of Clinical Investigation, 114, 1752. http://dx.doi.org/10.1172/JCI21625

[153] Kamimura, N., Nishimaki, K., Ohsawa, I. and Ohta, S. (2011) Molecular Hydrogen Improves Obesity and Diabetes by Inducing Hepatic FGF21 and Stimulating Energy Metabolism in db/db Mice. Obesity, 19, 1396-1403. http://dx.doi.org/10.1038/oby.2011.6

[154] Nakao, A., Toyoda, Y., Sharma, P., Evans, M. and Guthrie, N. (2010) Effectiveness of Hydrogen Rich Water on Antioxidant Status of Subjects with Potential Metabolic Syndrome-An Open Label Pilot Study. Journal of Clinical Biochemistry and Nutrition, 46, 140-149. http://dx.doi.org/10.3164/jcbn.09-100

[155] Song, G., Li, M., Sang, H., Zhang, L., Li, X., Yao, S., Yu, Y., Zong, C., Xue, Y. and Qin, S. (2013) Hydrogen-Rich Water Decreases Serum LDL-Cholesterol Levels and Improves HDL Function in Patients with Potential Metabolic Syndrome. Journal of Lipid Research, 54, 1884-1893. http://dx.doi.org/10.1194/jlr.M036640

[156] Iio, A., Ito, M., Itoh, T., Terazawa, R., Fujita, Y., Nozawa, Y., Ohsawa, I., Ohno, K. and Ito, M. (2013) Molecular Hydrogen Attenuates Fatty Acid Uptake and Lipid Accumulation through Downregulating CD36 Expression in HepG2 Cells. Medical Gas Research, 3, Article 6.

[157] Ekuni, D., Tomofuji, T., Endo, Y., Kasuyama, K., Irie, K., Azuma, T., Tamaki, N., Mizutani, S., Kojima, A. and Morita, M. (2012) Hydrogen-Rich Water Prevents Lipid Deposition in the Descending Aorta in a Rat Periodontitis Model. 
Archives of Oral Biology, 57, 1615-1622. http://dx.doi.org/10.1016/j.archoralbio.2012.04.013

[158] Zong, C., Song, G., Yao, S., Li, L., Yu, Y., Feng, L., Guo, S., Luo, T. and Qin, S. (2012) Administration of HydrogenSaturated Saline Decreases Plasma Low-Density Lipoprotein Cholesterol Levels and Improves High-Density Lipoprotein Function in High-Fat Diet-Fed haMetSynters. Metabolism, 61, 794-800. http://dx.doi.org/10.1016/j.metabol.2011.10.014

[159] Brooks-Wilson, A., Marcil, M., Clee, S.M., Zhang, L.H., Roomp, K., van Dam, M., Yu, L., Brewer, C., et al. (1999) Mutations in ABC1 in Tangier Disease and Familial High-Density Lipoprotein Deficiency. Nature Genetics, 22, 336345. http://dx.doi.org/10.1038/11905

[160] Song, G., Lin, Q., Zhao, H., Liu, M., Ye, F., Sun, Y., Yu, Y., Guo, S., Jiao, P., Wu, Y., Ding, G., Xiao, Q. and Qin, S. (2015) Hydrogen Activates ATP-Binding Cassette Transporter A1-Dependent Efflux ex Vivo and Improves HighDensity Lipoprotein Function in Patients with Hypercholesterolemia: A Double-Blinded, Randomized, and PlaceboControlled Trial. Journal of Clinical Endocrinology and Metabolism, 100, 2724-2733. http://dx.doi.org/10.1210/jc.2015-1321

[161] Reaven, G.M., Hollenbeck, C., Jeng, C.Y., Wu, M.S. and Chen, Y.D. (1988) Measurement of Plasma Glucose, Free Fatty Acid, Lactate, and Insulin for 24 h in Patients with NIDDM. Diabetes, 37, 1020-1024. http://dx.doi.org/10.2337/diab.37.8.1020

[162] Shirahata, S., Nishimura, T., Kabayama, S., Aki, D., Teruya, K., Otsubo, K., Morisawa, S., Ishii, Y., et al. (2008) Supplementation of Hydrogen-Rich Water Improves Lipid and Glucose Metabolism in Patients with Type 2 Diabetes or Impaired Glucose Tolerance. Nutrition Research, 28, 137-143. http://dx.doi.org/10.1016/j.nutres.2008.01.008

[163] Amitani, H., Asakawa, A., Cheng, K., Amitani, M., Kaimoto, K., Nakano, M., Ushikai, M., Li, Y., Tsai, M., Li, J.B., Terashi, M., Chaolu, H., Kamimura, R. and Inui, A. (2013) Hydrogen Improves Glycemic Control in Type1 Diabetic Animal Model by Promoting Glucose Uptake into Skeletal Muscle. PLoS ONE, 8, e53913. http://dx.doi.org/10.1371/journal.pone.0053913

[164] Song, G., Tian, H., Qin, S., Sun, X., Yao, S., Zong, C., Luo, Y., Liu, J., Yu, Y., Sang, H. and Wang, X. (2012) Hydrogen Decreases Athero-Susceptibility in Apolipoprotein B-Containing Lipoproteins and Aorta of Apolipoprotein E Knockout Mice. Atherosclerosis, 221, 55-65. http://dx.doi.org/10.1016/j.atherosclerosis.2011.11.043

[165] Jiang, H., Yu, P., Qian, D.H., Qin, Z.X., Sun, X.J., Yu, J. and Huang, L. (2013) Hydrogen-Rich Medium Suppresses the Generation of Reactive Oxygen Species, Elevates the Bcl-2/Bax Ratio and Inhibits Advanced Glycation End Product-Induced Apoptosis. International Journal of Molecular Medicine, 31, 1381-1387.

[166] Chen, Y., Jiang, J., Miao, H., Chen, X., Sun, X. and Li, Y. (2013) Hydrogen-Rich Saline Attenuates Vascular Smooth Muscle Cell Proliferation and Neointimal Hyperplasia by Inhibiting Reactive Oxygen Species Production and Inactivating the Ras-ERK1/2-MEK1/2 and Akt Pathways. International Journal of Molecular Medicine, 31, 597-606.

[167] Song, G., Tian, H., Liu, J., Zhang, H., Sun, X. and Qin, S. (2011) $\mathrm{H}_{2}$ Inhibits TNF-Alpha-Induced Lectin-Like Oxidized LDL Receptor-1 Expression by Inhibiting Nuclear Factor KappaB Activation in Endothelial Cells. Biotechnology Letters, 33, 1715-1722. http://dx.doi.org/10.1007/s10529-011-0630-8

[168] McGill, H.C., McMahan, C.A. and Gidding, S.S. (2008) Preventing Heart Disease in the $21^{\text {st }}$ Century: Implications of the Pathobiological Determinants of Atherosclerosis in Youth (PDAY) Study. Circulation, 117, 1216-1227. http://dx.doi.org/10.1161/CIRCULATIONAHA.107.717033

[169] Colbourne, F. and Corbett, D. (1994) Delayed and Prolonged Post-Ischemic Hypothermia Is Neuroprotective in the Gerbil. Brain Research, 654, 265-272. http://dx.doi.org/10.1016/0006-8993(94)90488-X

[170] Gisvold, S.E., Sterz, F., Abramson, N.S., Bar-Joseph, G., Ebmeyer, U., et al. (1996) Cerebral Resuscitation from Cardiac Arrest: Treatment Potentials. Critical Care Medicine, 24, S69-S80.

[171] Hickey, R.W., Ferimer, H., Alexander, H.L., Garman, R.H., Callaway, C.W., et al. (2000) Delayed, Spontaneous Hypothermia Reduces Neuronal Damage after Asphyxia Cardiac Arrest in Rats. Critical Care Medicine, 28, 3511-3516. http://dx.doi.org/10.1097/00003246-200010000-00027

[172] Ye, S., Weng, Y., Sun, S., Chen, W., Wu, X., et al. (2012) Comparison of the Durations of Mild Therapeutic Hypothermia on Outcome after Cardiopulmonary Resuscitation in the Rat. Circulation, 125, 123-129. http://dx.doi.org/10.1161/CIRCULATIONAHA.111.062257

[173] Hayashida, K., Sano, M., Kamimura, N., Yokota, T., Suzuki, M., et al. (2014) Hydrogen Inhalation during Normoxic Resuscitation Improves Neurological Outcome in a Rat Model of Cardiac Arrest Independently of Targeted Temperature Management. Circulation, 130, 2173-2180. http://dx.doi.org/10.1161/CIRCULATIONAHA.114.011848

[174] Neumar, R.W., Bircher, N.G., Sim, K.M., Xiao, F., Zadach, K.S., et al. (1995) Epinephrine and Sodium Bicarbonate during CPR Following Asphyxia Cardiac Arrest in Rats. Resuscitation, 29, 249-263. http://dx.doi.org/10.1016/0300-9572(94)00827-3 
[175] Ohsawa, I., Nishimaki, K., Yamagata, K., Ishikawa, M. and Ohta, S. (2008) Consumption of Hydrogen Water Prevents Atherosclerosis in Apolipoprotein E Knockout Mice. Biochemical and Biophysical Research Communications, 377, 1195-1198. http://dx.doi.org/10.1016/j.bbrc.2008.10.156

[176] He, B., Zhang, Y., Kang, B., Xiao, J., Xie, B. and Wang, Z. (2013) Protection of Oral Hydrogen Water as an Antioxidant on Pulmonary Hypertension. Molecular Biology Reports, 40, 5513-5521. http://dx.doi.org/10.1007/s11033-013-2653-9

[177] Sakai, T., Sato, B., Hara, K., Hara, Y., Naritomi, Y., et al. (2014) Consumption of Water Containing over 3.5 mg of Dissolved Hydrogen Could Improve Vascular Endothelial Function. Vascular Health and Risk Management, 10, 591597.

[178] Harris, R.A., Nishiyama, S.K., Wray, D.W. and Richardson, R.S. (2010) Ultrasound Assessment of Flow-Mediated Dilation. Hypertension, 55, 1075-1085. http://dx.doi.org/10.1161/HYPERTENSIONAHA.110.150821

[179] Thompson, L.M. (2008) Neurodegeneration: A Question of Balance. Nature, 452, 707-708. http://dx.doi.org/10.1038/452707a

[180] Lin, M.T. and Beal, M.F. (2006) Mitochondrial Dysfunction and Oxidative Stress in Neurodegenerative Diseases. Nature, 443, 787-795. http://dx.doi.org/10.1038/nature05292

[181] Vila, M. and Przedbroski, S. (2003) Targeting Programmed Cell Death in Neurodegenerative Diseases. Nature Reviews, 4, 1-11. http://dx.doi.org/10.1038/nrn1100

[182] Pagano, G., Talamanca, A.A., Castello, G., Cordero, M.D., d’Ischia, M., et al. (2014) Oxidative Stress and Mitochondrial Dysfunction across Broad-Ranging Pathologies: Toward Mitochondria-Targeted Clinical Strategies. Oxidative Medicine and Cellular Longevity, 2014, Article ID: 541230. http://dx.doi.org/10.1155/2014/541230

[183] Moosmann, B. and Behl, C. (2002) Antioxidants as Treatment for Neurodegenerative Disorders. Expert Opinions on Investigative Drugs, 11, 1407-1435. http://dx.doi.org/10.1517/13543784.11.10.1407

[184] Dania, C.C. and Piplani, P. (2014) The Discovery and Development of New Potential Antioxidant Agents for the Treatment of Neurodegenerative Diseases. Expert Opinions in Drug Discovery, 9, 1205-1222. http://dx.doi.org/10.1517/17460441.2014.942218

[185] Camilleri, A. and Vassallo, N. (2014) The Centrality of Mitochondria in the Pathogenesis and Treatment of Parkinson's Disease. CNS Neuroscience and Therapy, 20, 591-602. http://dx.doi.org/10.1111/cns.12264

[186] Moon, H.E. and Paek, S.H. (2015) Mitochondrial Dysfunction in Parkinson’s Disease. Experimental Neurobiology, 24, 103-116. http://dx.doi.org/10.5607/en.2015.24.2.103

[187] Abrous, D.N., Koehl, M. and Le Moal, M. (2003) Adult Neurogenesis: From Precursors to Network and Physiology. Physiology Reviews, 85, 523-569. http://dx.doi.org/10.1152/physrev.00055.2003

[188] Trancikova, A., Tsika, E. and Moore, D.J. (2012) Mitochondrial Dysfunction in Genetic Animal Models of Parkinson’s Disease. Antioxidants and Redox Signaling, 16, 896-919. http://dx.doi.org/10.1089/ars.2011.4200

[189] Montaron, M.F., Koehl, M., Lemaire, V., Drapeau, E., Abrous, D.N. and Le Moal, M. (2004) Environmentally Induced Long-Term Structural Changes: Cues for Functional Orientation and Vulnerabilities. Neurotoxin Research, 6, 571-580. http://dx.doi.org/10.1007/BF03033453

[190] Schapira, A.H. (2008) Mitochondria in the Aetiology and Pathogenesis of Parkinson's Disease. Lancet Neurology, 7, 97-109. http://dx.doi.org/10.1016/S1474-4422(07)70327-7

[191] Fu, Y., Ito, M., Fujita, Y., Ichihara, M., Masuda, A., Suzuki, A., et al. (2009) Molecular Hydrogen Is Protective against 6-Hydroxydopamine-Induced Nigrostriatal Degeneration in a Rat Model of Parkinson's Disease. Neuroscience Letters, 453, 81-85. http://dx.doi.org/10.1016/j.neulet.2009.02.016

[192] Daur, W. and Przedborski, S. (2003) Parkinson’s Disease: Mechanisms and Models. Neuron, 39, 889-909. http://dx.doi.org/10.1016/S0896-6273(03)00568-3

[193] Fujita, K., Seike, K., Yutsudo, N., Ohno, M., Yamada, H., Yamaguchi, H., et al. (2009) Hydrogen in the Drinking Water Reduces Dopaminergic Neuronal Loss in the 1-Methyl-4-Phenyl-1,2,3,6-Tetrahydropyridine Mouse Model of Parkinson's Disease. PLoS ONE, 4, e7247. http://dx.doi.org/10.1371/journal.pone.0007247

[194] Yoritaka, A., Takanashi, M., Hirayama, M., Nakahara, T., Ohta, S. and Hattori, N. (2013) Pilot Study of $\mathrm{H}_{2}$ Therapy in Parkinson's Disease: A Randomized Double-Blind Placebo-Controlled Trial. Movement Disorders, 28, 836-839. http://dx.doi.org/10.1002/mds.25375

[195] Gintjee, J.J., Magh, A.S.H. and Bertoni, C. (2014) High Throughput Screening in Duchenne Muscular Dystrophy: From Drug Discovery to Functional Genomics. Biology, 3, 752-780. http://dx.doi.org/10.3390/biology3040752

[196] Rauroux, B. and Khirani, S. (2014) Neuromuscular Disease and Respiratory Physiology in Children: Putting Lung Function into Perspective. Respriology, 19, 782-791. http://dx.doi.org/10.1111/resp.12330 
[197] Rahimov, F. and Kunkel, L.M. (2013) The Cell Biology of Disease: Cellular and Molecular Mechanisms Underlying Muscular Dystrophy. Journal of Cell Biology, 201, 499-510. http://dx.doi.org/10.1083/jcb.201212142

[198] Vaquer, G., Riviere, F., Mavris, M., Bignami, F., Linares-Garcia, J., Westemark, K. and Sepodes, B. (2013) Animal Models for Metabolic, Neuromuscular and Ophthalmological Rare Diseases. Nature Reviews on Drug Discovery, 12, 287-305. http://dx.doi.org/10.1038/nrd3831

[199] Whitmore, C. and Morgan, J. (2014) What Do Mouse Models of Muscular Dystrophy Tell Us about the DAPC and Its Components? International Journal of Experimental Pathology, 95, 365-377. http://dx.doi.org/10.1111/iep.12095

[200] Ito, M., Ibi, T., Sahashi, K., Ichihara, M., Ito, M. and Ohno, K. (2011) Open-Label Trial and Randomized, DoubleBlind, Placebo-Controlled Crossover Trial of Hydrogen-Enriched Water for Mitochondrial and Inflammatory Myopathies. Medical Gas Research, 1, Article 24. http://dx.doi.org/10.1186/2045-9912-1-24

[201] Kojic, D., Siegler, B.H., Uhle, F., Lichtenstern, C., Nawroth, P.P., Weigand, M.A., Hofer, S. and Brenner, T. (2015) Are There New Approaches for Diagnosis, Therapy Guidance and Outcome Prediction of Sepsis? World Journal of Experimental Medicine, 5, 50-63. http://dx.doi.org/10.5493/wjem.v5.i2.50

[202] Levy, M.M., Fink, M.P., Marshall, J.C., Abraham, E., Angus, D., et al. (2001) SCCM/ESICM/ACCP/ATS/SIS International Sepsis Definitions Conference. Intensive Care Medicine, 29, 530-538. http://dx.doi.org/10.1007/s00134-003-1662-X

[203] Rittirsch, D., Flierl, M.A. and Ward, P.A. (2008) Harmful Molecular Mechanisms in Sepsis. Nature Reviews in Immunology, 8, 776-787. http://dx.doi.org/10.1038/nri2402

[204] Duran-Bedolla, J., Montes de Oca-Sandoval, M.A., Saldaña-Navor, V., Villalobos-Silva, J.A., Rodriguez, M.C. and Rivas-Arancibia, S. (2014) Sepsis, Mitochondrial Failure and Multiple Organ Dysfunction. Clinical Investigative Medicine, 37, E58-E69.

[205] Xie, K., Liu, L., Yu, Y. and Wang, G. (2014) Hydrogen Gas Presents a Promising Therapeutic Strategy for Sepsis. Biomed Research International, 2014, Article ID: 807635. http://dx.doi.org/10.1155/2014/807635

[206] Xie, K., Fu, W., Xing, W., Li, A., Chen, H., Han, H., Yu, Y. and Wang, G. (2012) Combination Therapy with Molecular Hydrogen and Hyperoxia in a Murine Model of Polymicrobial Sepsis. Shock, 38, 656-663.

[207] Li, Y., Xie, K., Chen, H., Wang, G. and Yu, Y. (2015) Hydrogen Has Inhibits High-Mobility Group Box 1 Release in Septic Mice by Upregulation of Heme Oxygenase 1. Journal of Surgical Research, 196, 136-148. http://dx.doi.org/10.1016/j.jss.2015.02.042

[208] Zhou, J., Chen, Y., Huang, G.Q., Li, J., Wu, G.M., Liu, L., Bai, Y.P. and Wang, J. (2012) Hydrogen-Rich Saline Reverses Oxidative Stress, Cognitive Impairment and Mortality in Rats Submitted to Sepsis by Cecal Ligation and Puncture. Journal of Surgical Research, 178, 390-400. http://dx.doi.org/10.1016/j.jss.2012.01.041

[209] Zhai, Y., Zhou, X., Dai, Q., Fan, Y. and Huang, X. (2015) Hydrogen-Rich Saline Ameliorates Lung Injury Associated with Cecal Ligation and Puncture-Induced Sepsis in Rats. Experimental and Molecular Pathology, 98, 268-276. http://dx.doi.org/10.1016/j.yexmp.2015.03.005

[210] Xia, C., Liu, W., Zeng, D., Zhu, L., Sun, X. and Sun, X. (2013) Effect of Hydrogen-Rich Water on Oxidative Stress, Liver Function and Viral Load in Patients with Chronic Hepatitis B. Clinical and Translational Science, 6, 372-375. http://dx.doi.org/10.1111/cts.12076

[211] Seronello, S., Sheikh, M.Y. and Choi, J. (2007) Redox Regulation of Hepatitis C in Nonalcoholic and Alcoholic Liver. Free Radical Biology and Medicine, 43, 869-882. http://dx.doi.org/10.1016/j.freeradbiomed.2007.05.036

[212] Qian, L., Shen, J., Chuai, Y. and Cai, J. (2013) Hydrogen as a New Class of Radioprotective Agent. International Journal of Biological Science, 9, 887-894. http://dx.doi.org/10.7150/ijbs.7220

[213] Ward, J.F. (1988) DNA Damage Produced by Ionizing Radiation in Mammalian Cells: Identities, Mechanisms of Formation, and Reparability. Progress in Nucleic Acid Research and Molecular Biology, 35, 95-125. http://dx.doi.org/10.1016/S0079-6603(08)60611-X

[214] Fan, X. (2003) Ionizing Radiation Induces Formation of Malondialdehyde, Formaldehyde and Acetaldehyde from Carbohydrates and Organic Acid. Journal of Agriculture and Food Chemistry, 51, 5946-5949. http://dx.doi.org/10.1021/jf0344340

[215] Marnett, L.J. (2000) Oxyradicals and DNA Damage. Carcinogenesis, 21, 361-370. http://dx.doi.org/10.1093/carcin/21.3.361

[216] Qian, L., Cao, F., Cul, J., Huang, Y., Zhou, X., Liu, S. and Cai, J. (2010) Radioprotective Effect of Hydrogen in Cultured Cells and Mice. Free Radical Research, 44, 275-282. http://dx.doi.org/10.3109/10715760903468758

[217] Liu, C., Cui, J., Sun, Q. and Cai, J. (2010) Hydrogen Therapy May Be an Effective and Specific Novel Treatment for Acute Radiation Syndrome. Medical Hypotheses, 74, 145-146. http://dx.doi.org/10.1016/j.mehy.2009.07.017

[218] Chuai, Y., Gao, F., Li, B., Zhao, L., Qian, L., Cao, F., et al. (2012) Hydrogen-Rich Saline Attenuates Radiation- 
Induced Male Germ Cell Loss in Mice through Reducing Hydroxyl Radicals. Biochemical Journal, 442, 49-56. http://dx.doi.org/10.1042/BJ20111786

[219] Guo, Z., Zhou, B., Li, W., Sun, X. and Luo, D. (2012) Hydrogen-Rich Saline Protects against Ultraviolet B Radiation Injury in Rats. Journal of Biomedical Research, 26, 365-371. http://dx.doi.org/10.7555/JBR.26.20110037

[220] Mei, K., Zhao, S., Qian, L., Li, B., Ni, J. and Cai, J. (2013) Hydrogen Protects Rats from Dermatitis Caused by Local Irradiation. Journal of Dermatology Treatment, 25, 182-188. http://dx.doi.org/10.3109/09546634.2012.762639

[221] Ignacio, R.M., Yoon, Y.-S., Sajo, M.E.J., Kim, C.-S., Kim, D.-H., Kim, S.-K., et al. (2013) The Balneotherapy Effect of Hydrogen Reduced Water on UVB-Mediated Skin Injury in Hairless Mice. Molecular and Cellular Toxicology, 9, 15-21. http://dx.doi.org/10.1007/s13273-013-0003-6

[222] Huo, H.-M., Yang, S., Chen, L.-S., Lu, H.-J., Wang, A.-D. and Zhang, L.-Y. (2012) Hydrogen-Rich Saline Alleviation of the Oxidative Stress and Early-Phase Radiation-Induced Brain Injury in Rats. Chinese Journal of Radiological Medicine and Protection, 32, 485-487.

[223] Yuan, L., Chen, X., Shen, J. and Cai, J. (2015) Administration of Hydrogen-Rich Saline in Mice with Allegeneic Hematopoietic Stem-Cell Transplantation. Medical Science Monitor, 21, 749-754. http://dx.doi.org/10.12659/MSM.891338

[224] Qian, L., Li, B., Cao, F., Huang, Y., Liu, S., Cai, J., et al. (2010) Hydrogen-Rich PBS Protects Cultured Human Cells from Ionizing Radiation-Induced Cellular Damage. Nuclear Technology and Radiation Protection, 25, $23-29$. http://dx.doi.org/10.2298/NTRP1001023Q

[225] Dole, M., Wilson, F.R. and Fife, W.P. (1975) Hyperbaric Hydrogen Therapy: A Possible Treatment for Cancer. Science, 190, 152-154. http://dx.doi.org/10.1126/science.1166304

[226] Roberts, B.J., Fife, W.P., Corbett, T.H. and Schabel Jr., F M. (1978) Response of Five Established Solid Transplantable Mouse Tumors and One Mouse Leukemia to Hyperbaric Hydrogen. Cancer Treatment Reports, 62, 1077-1099.

[227] Kang, K.-M., Kang, Y.-N., Choi, I.-B., Gu, Y., Kawamura, T., Toyoda, Y. and Nakao, A. (2011) Effects of Drinking Hydrogen-Rich Water on the Quality of Life of Patients Treated with Radiotherapy for Liver Tumors. Medical Gas Research, 1, Article 11. http://dx.doi.org/10.1186/2045-9912-1-11

[228] Citrin, D., Cotrim, A.P., Hyodo, F., Baum, B.J., Krishna, M.C. and Mitchell, J.B. (2010) Radioprotectors and Mitigators of Radiation-Induced Normal Tissue Injury. Oncologist, 15, 360-371. http://dx.doi.org/10.1634/theoncologist.2009-S104

[229] Shin, M.H., Park, R., Nojima, H., Kim, H.-C., Kim, Y.K., et al. (2013) Atomic Hydrogen Surrounded by Water Molecules, $\left.\mathrm{H}_{(} \mathrm{H}_{2} \mathrm{O}\right)_{\mathrm{m}}$, Modulates Basal and UV-Induced Gene Expression in Human Skin in Vivo. PloS ONE, 8, e61696. http://dx.doi.org/10.1371/journal.pone.0061696

[230] Qian, L. and Shen, J. (2013) Hydrogen Therapy May Be an Effective and Specific Novel Treatment for Acute Graftversus-Host Disease (GvHD). Journal of Cellular and Molecular Medicine, 17, 1059-1063. http://dx.doi.org/10.1111/jcmm.12081

[231] Barrett, A.J. and Ito, S. (2015) The Role of Stem Cell Transplantation for Chronic Myelogenous Leukemia in the $21^{\text {st }}$ Century. Blood, 125, 3230-3235. http://dx.doi.org/10.1182/blood-2014-10-567784

[232] Scarci, F. and Mailland, F. (2014) In Vitro Evaluations for a New Topical Anti-Aging Formulation. Journal of Cosmetics, Dermatological Sciences and Applications, 4, 316-322. http://dx.doi.org/10.4236/jcdsa.2014.45041

[233] Rinnerhaler, M., Bischof, J., Streubel, M.K., Trost, A. and Richter, K. (2015) Oxidative Stress in Aging Human Skin. Biomolecules, 5, 545-589. http://dx.doi.org/10.3390/biom5020545

[234] Vedamurthy, M. (2006) Antiaging Therapies. Indian Journal of Dermatology, Venereology and Leprology, 72, 183186. http://dx.doi.org/10.4103/0378-6323.25776

[235] Kato, S., Saitoh, Y., Iwai, K. and Miwa, N. (2012) Hydrogen-Rich Electrolyzed Warm Water Represses Wrinkle Formation against UVA Ray Together with Type-1 Collagen Production and Oxidative Stress Dimishment in Fibroblasts and Cell-Injury Prevention in Keratinocytes. Journal of Photochemistry and Photobiology B, 106, 24-33. http://dx.doi.org/10.1016/j.jphotobiol.2011.09.006

[236] Tomofuji, T., Kawabata, Y., Kasuyama, K., Endo, Y., et al. (2014) Effects of Hydrogen-Rich Water on Aging Periodontal Tissues in Rats. Scientific Reports, 4, 5534. http://dx.doi.org/10.1038/srep05534

[237] Guo, S.X., Jin, Y.Y., Fang, Q., You, C.G., et al. (2015) Beneficial Effects of Hydrogen-Rich Saline on Early BurnWound Progression in Rats. PLoS ONE, 10, e0124897. http://dx.doi.org/10.1371/journal.pone.0124897

[238] Li, Q., Kato, S., Matsuoka, D., Tanaka, H. and Miwa, H. (2013) Hydrogen Water Intake via Tube-Feeding for Patients with Pressure Ulcers and Its Reconstructive Effects on Normal Human Skin Cells in Vitro. Medical Gas Research, 3, Article 2.

[239] Miesel, R., Drzejczak, P.J. and Kurpisz, M. (1993) Oxidative Stress during the Interaction of Gametes. Biology of Re- 
production, 49, 918-923. http://dx.doi.org/10.1095/biolreprod49.5.918

[240] Lane, M., McPherson, N.O., Fullston, T., Spillane, M., Sandeman, L., Kang, W.X. and Zander-Fox, D.L. (2014) Oxidative Stress in Mouse Sperm Impairs Embryo Development, Fetal Growth and Alters Adiposity and Glucose Regulation in Female Offspring. PLoS ONE, 9, e100832. http://dx.doi.org/10.1371/journal.pone.0100832

[241] Tamura, H., Takasaki, A., Miwa, I., Taniguchi, K., Maekawa, R., Asada, H., Taketani, T., Matsuoka, A., Yamagata, Y., Shimamura, K., Morioka, H., Ishikawa, H., Reiter, R.J. and Sugino, N. (2008) Oxidative Stress Impairs Oocyte Quality and Melatonin Protects Oocytes from Free Radical Damage and Improves Fertilization Rate. Journal of Pineal Research, 44, 280-287. http://dx.doi.org/10.1111/j.1600-079X.2007.00524.x

[242] Armstrong, J.S., Rajasekaran, M., Chamulitrat, W., et al. (1999) Characterization of Reactive Oxygen Species Induced Effects on Human Spermatozoa Movement and Energy Metabolism. Free Radical Bilogy and Medicine, 26, 869-880. http://dx.doi.org/10.1016/S0891-5849(98)00275-5

[243] Gavriliouk, D. and Aitken, R.J. (2015) Damage to Sperm DNA Mediated by Reactive Oxygen Species: Its Impact on Human Reproduction and the Health Trajectory of Offspring. Advances in Experimental Medicine and Biology, 868, 23-47. http://dx.doi.org/10.1007/978-3-319-18881-2__2

[244] Jiang, D., Wu, D., Zhang, Y., Xu, B., Sun, X. and Li, Z. (2012) Protective Effects of Hydrogen Rich Saline Solution on Experimental Testicular Ischemia-Reperfusion Injury in Rats. Journal of Urology, 187, 2249-2253. http://dx.doi.org/10.1016/j.juro.2012.01.029

[245] Oyeyipo, I.P., Raji, Y., Emikpe, B.O. and Bolarinwa, A.F. (2011) Effects of Nicotine on Sperm Characteristics and Fertility Profile in Adult Male Rats: A Possible Role of Cessation. Journal of Reproduction and Infertility, 12, 201207.

[246] Vijayalaxmi, Reiter, R.J., Tan, D.X., Herman, T.S. and Thomas Jr., C.R. (2004) Melatonin as a Radioprotective Agent: A Review. International Journal of Radiation, Oncology and Biological Physics, 59, 639-653. http://dx.doi.org/10.1016/j.ijrobp.2004.02.006

[247] Chuai, Y., Gao, F., Li, B., Zhao, L., Qian, L., Cao, F., Wang, L., Sun, X., Cui, J. and Cai, J. (2012) Hydrogen-Rich Saline Attenuates Radiation-Induced Male Germ Cell Loss in Mice through Reducing Hydroxyl Radicals. Biochemical Journal, 442, 49-56. http://dx.doi.org/10.1042/BJ20111786

[248] Matzuk, M.M. and Lamb, D.J. (2008) The Biology of Infertility: Research Advances and Clinical Challenges. Nature Medicine, 14, 1197-1213. http://dx.doi.org/10.1038/nm.f.1895

[249] Ruiz-Pesini, E., Lapena, A.C., Diez-Sanchez, C., Perez-Martos, A., Montoya, J., Alvarez, E., Diaz, M., Urries, A., Montoro, L., Lopez-Perez, M.J. and Enriquez, J.A. (2000) Human mtDNA Haplogroups Associated with High or Reduced Spermatozoa Motility. American Journal of Human Genetics, 67, 682-696. http://dx.doi.org/10.1086/303040

[250] Gharagozloo, P. and Aitken, R.J. (2011) The Role of Sperm Oxidative Stress in Male Infertility and the Significance of Oral Antioxidant Therapy. Human Reproduction, 26, 1628-1640. http://dx.doi.org/10.1093/humrep/der132

[251] El-Taieb, M.A., Herwig, R., Nada, E.A., Greilberger, J. and Marberger, M. (2009) Oxidative Stress and Epididymal Sperm Transport, Motility and Morphological Defects. European Journal of Obstetrics, Gynecology and Reproductive Biology, 144, S199-S203. http://dx.doi.org/10.1016/j.ejogrb.2009.02.018

[252] Nakata, K., Yamashita, N., Noda, Y. and Ohsawa, I. (2015) Stimulation of Human Damaged Sperm Motility with Hydrogen Molecule. Medical Gas Research, 5, Article 2.

[253] Guerin, P., El Mouatassim, S. and Menezo, Y. (2001) Oxidative Stress and Protection against Reactive Oxygen Species in the Pre-Implantation Embryo and Its Surroundings. Human Reproduction Update, 7, 175-189. http://dx.doi.org/10.1093/humupd/7.2.175

[254] Menezo, Y. and Guerin, P. (2005) Gamete and Embryo Protection against Oxidative Stress during Medically Assisted Reproduction. Bulletin of Academy of National Medicine, 189, 715-726.

[255] Guan, Z., Li, H.F., Guo, L.L. and Yang, X. (2015) Effects of Vitamin C, Vitamin E, and Molecular Hydrogen on the Placental Function in Trophoblast Cells. Archives of Gynecology and Obstetrics, 292, 337-342. http://dx.doi.org/10.1007/s00404-015-3647-8

[256] Mano, Y., Kotani, T., Ito, M., Nagai, T., Ichinohashi, Y., Yamada, K., Ohno, K., Kikkawa, F. and Toyokuni, S. (2014) Maternal Molecular Hydrogen Administration Ameliorates Rat Fetal Hippocampal Damage Caused by in Utero Ischemia-Reperfusion. Free Radical Biology and Medicine, 69, 324-330. http://dx.doi.org/10.1016/j.freeradbiomed.2014.01.037

[257] Saugstad, O.D. (2005) Oxidative Stress in the Newborn-A 30-Year Perspective. Neonatology, 88, 228-236. http://dx.doi.org/10.1159/000087586

[258] Matchett, G.A., Fathali, N., Hasegawa, Y., Jadhav, V., Ostrowski, R.P., Martin, R.D., Dorotta, I.R., Sun, X. and Zhang, J.H. (2009) Hydrogen Gas Is Ineffective in Moderate and Severe Neonatal Hypoxia-Ischemia Rat Models. Brain Research, 1259, 90-97. http://dx.doi.org/10.1016/j.brainres.2008.12.066 
[259] Olah, O., Toth-Szuki, V., Temesvari, P., Bari, F. and Domoki, F. (2013) Delayed Neurovascular Dysfunction Is Alleviated by Hydrogen in Asphyxiated Newborn Pigs. Neonatology, 104, 79-86. http://dx.doi.org/10.1159/000348445

[260] Papile, L.-A., Burstein, J., Burstein, R. and Koffler, H. (1978) Incidence and Evolution of Subependymal and Intraventricular Hemorrhage: A Study of Infants with Birth Weights Less than 1,500 gm. Journal of Pediatrics, 92, 529-534. http://dx.doi.org/10.1016/S0022-3476(78)80282-0

[261] Salafia, C.M., Minior, V.K., Rosenkrantz, T.S., Pezzullo, J.C., Popek, E.J., Cusick, W. and Vintzileos, A.M. (1995) Maternal, Placental, and Neonatal Associations with Early Germinal Matrix/Intraventricular Hemorrhage in Infants Born before 32 Weeks’ Gestation. American Journal of Perinatology, 12, 429-436. http://dx.doi.org/10.1055/s-2007-994514

[262] Zia, M.T., Csiszar, A., Labinskyy, N., Hu, F., Vinukonda, G., LaGamma, E.F., Ungvari, Z. and Ballabh, P. (2009) Oxidative-Nitrosative Stress in a Rabbit Pup Model of Germinal Matrix Hemorrhage Role of NAD (P) H Oxidase. Stroke, 40, 2191-2198. http://dx.doi.org/10.1161/STROKEAHA.108.544759

[263] Lekic, T., Manaenko, A., Rolland, W., Fathali, N., Peterson, M., Tang, J. and Zhang, J.H. (2011) Protective Effect of Hydrogen Gas Therapy after Germinal Matrix Hemorrhage in Neonatal Rats. Acta Neurochirurgica, 111, $237-241$. http://dx.doi.org/10.1007/978-3-7091-0693-8_40

[264] Holman, R.C., Stoll, B.J., Clarke, M.J. and Glass, R.I. (1997) The Epidemiology of Necrotizing Enterocolitis Infant Mortality in the United States. American Journal of Public Health, 87, 2026-2031. http://dx.doi.org/10.2105/AJPH.87.12.2026

[265] Sheng, Q., Lv, Z., Cai, W., Song, H., Qian, L. and Wang, X. (2013) Protective Effects of Hydrogen-Rich Saline on Necrotizing Enterocolitis in Neonatal Rats. Journal of Pediatric Surgery, 48, 1697-1706. http://dx.doi.org/10.1016/j.jpedsurg.2012.11.038

[266] Serhan, C.N., Ward, P.A. and Gilroy, D.W. (2010) Fundamentals of Inflammation. Cambridge University Press, Cambridge. http://dx.doi.org/10.1017/CBO9781139195737

[267] Lei, Y., Wang, K., Deng, L., Chen, Y., Nice, E.C. and Huang, C. (2015) Redox Regulation of Inflammation: Old Elements, a New Story. Medical Research Reviews, 35, 306-340. http://dx.doi.org/10.1002/med.21330

[268] Maccarrone, M. and Brune, B. (2009) Redox Regulation in Acute and Chronic Inflammation. Cell Death and Differentation, 16, 1184-1186. http://dx.doi.org/10.1038/cdd.2009.65

[269] Li, G.M., Ji, M.H., Sun, X.J., Zeng, Q.T., Tian, M., Fan, Y.X., Li, W.Y., Li, N. and Yang, J.J. (2013) Effects of Hydrogen-Rich Saline Treatment on Polymicrobial Sepsis. Journal of Surgical Research, 181, 279-286. http://dx.doi.org/10.1016/j.jss.2012.06.058

[270] Qian, L., Mei, K., Shen, J. and Cai, J. (2013) Administration of Hydrogen-Rich Saline Protects Mice from Lethal Acute Graft-Versus-Host Disease (aGvHD). Transplantation, 95, 658-662. http://dx.doi.org/10.1097/TP.0b013e31827e6b23

[271] Rose, N.R. and Mackay, I.R. (2006) The Autoimmune Diseases. Elsevier Academic Press.

[272] Mackay, I.R. and Rose, N.R. (2013) The Autoimmune Diseases. Elsevier Science.

[273] Clair, E.W.S., Pisetsky, D.S. and Haynes, B.F. (2004) Rheumatoid Arthritis. Lippincott Williams \& Wilkins.

[274] Ishibashi, T. (2013) Molecular Hydrogen: New Antioxidant and Anti-Inflammatory Therapy for Rheumatoid Arthritis and Related Diseases. Current Pharmiceutical Design, 19, 6375-6381. http://dx.doi.org/10.2174/13816128113199990507

[275] Ishibashi, T., Sato, B., Rikitake, M., Seo, T., Kurokawa, R., Hara, Y., Naritomi, Y., Hara, H. and Nagao, T. (2012) Consumption of Water Containing a High Concentration of Molecular Hydrogen Reduces Oxidative Stress and Disease Activity in Patients with Rheumatoid Arthritis: An Open-Label Pilot Study. Medical Gas Research, 2, Article 27. http://dx.doi.org/10.1186/2045-9912-2-27

[276] Ishibashi, T., Sato, B., Shibata, S., Sakai, T., Hara, Y., Naritomi, Y., Koyanagi, S., Hara, H. and Nagao, T. (2014) Therapeutic Efficacy of Infused Molecular Hydrogen in Saline on Rheumatoid Arthritis: A Randomized, Double-Blind, Placebo-Controlled Pilot Study. International Immunopharmacology, 21, 468-473. http://dx.doi.org/10.1016/j.intimp.2014.06.001

[277] Ishibashi, T., Ichikawa, M., Sato, B., Shibata, S., Hara, Y., Naritomi, Y., Okazaki, K., Nakashima, Y., Iwamoto, Y., Koyanagi, S., Hara, H. and Nagao, T. (2015) Improvement of Psoriasis-Associated Arthritis and Skin Lesions by Treatment with Molecular Hydrogen: A Report of Three Cases. Molecular Medicine Reports, 12, 2757-2764. http://dx.doi.org/10.3892/mmr.2015.3707

[278] Itoh, T., Hamada, N., Terazawa, R., Ito, M., Ohno, K., Ichihara, M., Nozawa, Y. and Ito, M. (2011) Molecular Hydrogen Inhibits Lipopolysaccharide/Interferon Gamma-Induced Nitric Oxide Production through Modulation of Signal Transduction in Macrophages. Biochemical Biophysical Research Communications, 411, 143-149. 
http://dx.doi.org/10.1016/j.bbrc.2011.06.116

[279] Xu, Z., Zhou, J., Cai, J., Zhu, Z., Sun, X. and Jiang, C. (2012) Anti-Inflammation Effects of Hydrogen Saline in LPS Activated Macrophages and Carrageenan Induced Paw Oedema. Journal of Inflammation (London), 9, 2. http://dx.doi.org/10.1186/1476-9255-9-2

[280] Spulber, S., Edoff, K., Hong, L., Morisawa, S., Shirahata, S. and Ceccatelli, S. (2012) Molecular Hydrogen Reduces LPS-Induced Neuroinflammation and Promotes Recovery from Sickness Behaviour in Mice. PLoS ONE, 7, e42078. http://dx.doi.org/10.1371/journal.pone.0042078

[281] Chen, H.G., Xie, K.L., Han, H.Z., Wang, W.N., Liu, D.Q., Wang, G.L. and Yu, Y.H. (2013) Heme Oxygenase-1 Mediates the Anti-Inflammatory Effect of Molecular Hydrogen in LPS-Stimulated RAW 264.7 Macrophages. International Journal of Surgery, 11, 1060-1066. http://dx.doi.org/10.1016/j.ijsu.2013.10.007

[282] Yu, Y., Wang, W.N., Han, H.Z., Xie, K.L., Wang, G.L. and Yu, Y.H. (2015) Protective Effects of Hydrogen-Rich Medium on Lipopolysaccharide-Induced Monocytic Adhesion and Vascular Endothelial Permeability through Regulation of Vascular Endothelial Cadherin. Genetic and Molecular Research, 14, 6202-6212. http://dx.doi.org/10.4238/2015.June.9.6

[283] Xie, K., Wang, W., Chen, H., Han, H., Liu, D., Wang, G. and Yu, Y. (2015) Hydrogen-Rich Medium Attenuated Lipopolysaccharide-Induced Monocyte-Endothelial Cell Adhesion and Vascular Endothelial Permeability via RhoAssociated Coiled-Coil Protein Kinase. Shock, 44, 58-64. http://dx.doi.org/10.1097/SHK.0000000000000365

[284] He, J., Xiong, S., Zhang, J., Wang, J., Sun, A., Mei, X., Sun, X., Zhang, C. and Wang, Q. (2013) Protective Effects of Hydrogen-Rich Saline on Ulcerative Colitis Rat Model. Journal of Surgical Research, 185, 174-181. http://dx.doi.org/10.1016/j.jss.2013.05.047

[285] Zhang, J.Y., Wu, Q.F., Wan, Y., Song, S.D., Xu, J., Xu, X.S., Chang, H.L., Tai, M.H., Dong, Y.F. and Liu, C. (2014) Protective Role of Hydrogen-Rich Water on Aspirin-Induced Gastric Mucosal Damage in Rats. World Journal of Gastroenterology, 20, 1614-1622. http://dx.doi.org/10.3748/wjg.v20.i6.1614

[286] Zhang, J., Wu, Q., Song, S., Wan, Y., Zhang, R., Tai, M. and Liu, C. (2014) Effect of Hydrogen-Rich Water on Acute Peritonitis of Rat Models. International Immunopharmacology, 21, 94-101. http://dx.doi.org/10.1016/j.intimp.2014.04.011

[287] Esrefoglu, M. (2012) Oxidative Stress and Benefits of Antioxidant Agents in Acute and Chronic Hepatitis. Hepatitis Monthly, 12, 160-167. http://dx.doi.org/10.5812/hepatmon.5090

[288] Xia, C., Liu, W., Zeng, D., Zhu, L., Sun, X. and Sun, X. (2013) Effect of Hydrogen-Rich Water on Oxidative Stress, Liver Function, and Viral Load in Patients with Chronic Hepatitis B. Clinical and Translational Science, 6, 372-375. http://dx.doi.org/10.1111/cts.12076

[289] Zhang, D.Q., Feng, H. and Chen, W.C. (2013) Effects of Hydrogen-Rich Saline on Taurocholate-Induced Acute Pancreatitis in Rat. Evidence-Based Complementary and Alternative Medicine, 2013, Article ID: 731932.

[290] Ren, J.D., Ma, J., Hou, J., Xiao, W.J., Jin, W.H., Wu, J. and Fan, K.H. (2014) Hydrogen-Rich Saline Inhibits NLRP3 Inflammasome Activation and Attenuates Experimental Acute Pancreatitis in Mice. Mediators of Inflammation, 2014, Article ID: 930894. http://dx.doi.org/10.1155/2014/930894

[291] Wang, X., Yu, P., Yang, Y., Liu, X., Jiang, J., Liu, D. and Xue, G. (2015) Hydrogen-Rich Saline Resuscitation Alleviates Inflammation Induced by Severe Burn with Delayed Resuscitation. Burns, 41, 379-385. http://dx.doi.org/10.1016/j.burns.2014.07.012

[292] Liu, S.L., Liu, K., Sun, Q., Liu, W.W., Tao, H.Y. and Sun, X.J. (2011) Hydrogen Therapy May Be a Novel and Effective Treatment for COPD. Frontiers in Pharmacology, 2, 19. http://dx.doi.org/10.3389/fphar.2011.00019

[293] Xiao, M., Zhu, T., Wang, T. and Wen, F.Q. (2013) Hydrogen-Rich Saline Reduces Airway Remodeling via Inactivation of NF-KappaB in a Murine Model of Asthma. European Review for Medical and Pharmacological Science, 17, 1033-1043.

[294] Matsumoto, S., Ueda, T. and Kakizaki, H. (2013) Effect of Supplementation with Hydrogen-Rich Water in Patients with Interstitial Cystitis/Painful Bladder Syndrome. Urology, 81, 226-230. http://dx.doi.org/10.1016/j.urology.2012.10.026

[295] Zhao, S., Yang, Y., Liu, W., Xuan, Z., Wu, S., Yu, S., Mei, K., Huang, Y., Zhang, P., Cai, J., Ni, J. and Zhao, Y. (2014) Protective Effect of Hydrogen-Rich Saline against Radiation-Induced Immune Dysfunction. Journal of Cell and Molecular Medicine, 18, 938-946. http://dx.doi.org/10.1111/jcmm.12245

[296] Page, D.W. (2006) Body Trauma: A Writer’s Guide to Wounds and Injuries. Vol. 978, No. 1-933042, Behler Publications.

[297] Dohi, K., Kraemer, B.C., Erickson, M.A., McMillan, P.J., Kovac, A., Flachbartova, Z., Hansen, K.M., Shah, G.N., Sheibani, N., Salameh, T. and Banks, W.A. (2014) Molecular Hydrogen in Drinking Water Protects against Neurodegenerative Changes Induced by Traumatic Brain Injury. PLOS ONE, 9, e108034. 
http://dx.doi.org/10.1371/journal.pone.0108034

[298] Zhuang, Z., Sun, X.J., Zhang, X., Liu, H.D., You, W.C., Ma, C.Y., Zhu, L., Zhou, M.L. and Shi, J.X. (2013) Nuclear Factor-KappaB/Bcl-XL Pathway Is Involved in the Protective Effect of Hydrogen-Rich Saline on the Brain Following Experimental Subarachnoid Hemorrhage in Rabbits. Journal of Neuroscience Research, 91, 1599-1608. http://dx.doi.org/10.1002/jnr.23281

[299] Hong, Y., Shao, A., Wang, J., Chen, S., Wu, H., McBride, D.W., Wu, Q., Sun, X. and Zhang, J. (2014) Neuroprotective Effect of Hydrogen-Rich Saline against Neurologic Damage and Apoptosis in Early Brain Injury Following Subarachnoid Hemorrhage: Possible Role of the Akt/GSK3beta Signaling Pathway. PLoS ONE, 9, e96212. http://dx.doi.org/10.1371/journal.pone.0096212

[300] Shao, A., Wu, H., Hong, Y., Tu, S., Sun, X., Wu, Q., Zhao, Q., Zhang, J. and Sheng, J. (2015) Hydrogen-Rich Saline Attenuated Subarachnoid Hemorrhage-Induced Early Brain Injury in Rats by Suppressing Inflammatory Response: Possible Involvement of NF-KappaB Pathway and NLRP 3 Inflammasome. Molecular Neurobiology, 1-15. http://dx.doi.org/10.1007/s12035-015-9242-y

[301] Sun, J.C., Xu, T., Zuo, Q., Wang, R.B., Qi, A.Q., Cao, W.L., Sun, A.J., Sun, X.J. and Xu, J. (2014) Hydrogen-Rich Saline Promotes Survival of Retinal Ganglion Cells in a Rat Model of Optic Nerve Crush. PLoS ONE, 9, e99299. http://dx.doi.org/10.1371/journal.pone.0099299

[302] Zhai, Y., Zhou, X., Dai, Q., Fan, Y. and Huang, X. (2015) Hydrogen-Rich Saline Ameliorates Lung Injury Associated with Cecal Ligation and Puncture-Induced Sepsis in Rats. Experimental and Molecular Pathology, 98, 268-276. http://dx.doi.org/10.1016/j.yexmp.2015.03.005

[303] Liu, W., Shan, L.P., Dong, X.S., Liu, X.W., Ma, T. and Liu, Z. (2013) Combined Early Fluid Resuscitation and Hydrogen Inhalation Attenuates Lung and Intestine Injury. World Journal of Gastroenterology, 19, 492-502. http://dx.doi.org/10.3748/wjg.v19.i4.492

[304] Ning, Y., Shang, Y., Huang, H., Zhang, J., Dong, Y., Xu, W. and Li, Q. (2013) Attenuation of Cigarette SmokeInduced Airway Mucus Production by Hydrogen-Rich Saline in Rats. PLOS ONE, 8, e83429. http://dx.doi.org/10.1371/journal.pone.0083429

[305] Chen, X., Liu, Q., Wang, D., Feng, S., Zhao, Y., Shi, Y. and Liu, Q. (2015) Protective Effects of Hydrogen-Rich Saline on Rats with Smoke Inhalation Injury. Oxidative Medicine and Cell Longevity, 2015, Article ID: 106836. http://dx.doi.org/10.1155/2015/106836

[306] Lucas, K. and Maes, M. (2013) Molecular Mechanisms Underpinning Laser Printer and Photocopier Induced Symptoms, including Chronic Fatigue Syndrome and Respiratory Tract Hyperresponsiveness: Pharmacological Treatment with Cinnamon and Hydrogen. Neuroendocrinology Letters, 34, 723-737.

[307] Li, F.Y., Zhu, S.X., Wang, Z.P., Wang, H., Zhao, Y. and Chen, G.P. (2013) Consumption of Hydrogen-Rich Water Protects against Ferric Nitrilotriacetate-Induced Nephrotoxicity and Early Tumor Promotional Events in Rats. Food and Chemical Toxicology, 61, 248-254. http://dx.doi.org/10.1016/j.fct.2013.10.004

[308] Xu, B., Zhang, Y.B., Li, Z.Z., Yang, M.W., Wang, S. and Jiang, D.P. (2013) Hydrogen-Rich Saline Ameliorates Renal Injury Induced by Unilateral Ureteral Obstruction in Rats. International Immunopharmacology, 17, 447-452. http://dx.doi.org/10.1016/j.intimp.2013.06.033

[309] Xin, H.G., Zhang, B.B., Wu, Z.Q., Hang, X.F., Xu, W.S., Ni, W., Zhang, R.Q. and Miao, X.H. (2014) Consumption of Hydrogen-Rich Water Alleviates Renal Injury in Spontaneous Hypertensive Rats. Molecular and Cellular Biochemistry, 392, 117-124. http://dx.doi.org/10.1007/s11010-014-2024-4

[310] Gu, H., Yang, M., Zhao, X., Zhao, B., Sun, X. and Gao, X. (2014) Pretreatment with Hydrogen-Rich Saline Reduces the Damage Caused by Glycerol-Induced Rhabdomyolysis and Acute Kidney Injury in Rats. Journal of Surgical Research, 188, 243-249. http://dx.doi.org/10.1016/j.jss.2013.12.007

[311] Guo, S.X., Fang, Q., You, C.G., Jin, Y.Y., Wang, X.G., Hu, X.L. and Han, C.M. (2015) Effects of Hydrogen-Rich Saline on Early Acute Kidney Injury in Severely Burned Rats by Suppressing Oxidative Stress Induced Apoptosis and Inflammation. Journal of Translational Medicine, 13, 183. http://dx.doi.org/10.1186/s12967-015-0548-3

[312] Homma, K., Yoshida, T., Yamashita, M., Hayashida, K., Hayashi, M. and Hori, S. (2014) Inhalation of Hydrogen Gas Is Beneficial for Preventing Contrast-Induced Acute Kidney Injury in Rats. Nephron Expimental Nephrology, 128, 116-122. http://dx.doi.org/10.1159/000369068

[313] Shi, Q., Liao, K.S., Zhao, K.L., Wang, W.X., Zuo, T., Deng, W.H., Chen, C., Yu, J., Guo, W.Y., He, X.B., Abliz, A., Wang, P. and Zhao, L. (2015) Hydrogen-Rich Saline Attenuates Acute Renal Injury in Sodium Taurocholate-Induced Severe Acute Pancreatitis by Inhibiting ROS and NF-KappaB Pathway. Mediators of Inflammation, 2015, Article ID: 685043. http://dx.doi.org/10.1155/2015/685043

[314] Eye Diseases Prevalence Research Group (2004) The Prevalence of Diabetic Retinopathy among Adults in the United States. Archives of Ophthalmology, 122, 552. http://dx.doi.org/10.1001/archopht.122.4.552 
[315] Xiao, X., Cai, J., Xu, J., Wang, R., Cai, J., Liu, Y., Xu, W., Sun, X. and Li, R. (2012) Protective Effects of Hydrogen Saline on Diabetic Retinopathy in a Streptozotocin-Induced Diabetic Rat Model. Journal of Ocular Pharmacology and Therapeutics, 28, 76-82. http://dx.doi.org/10.1089/jop.2010.0129

[316] Tian, L., Zhang, L., Xia, F., An, J., Sugita, Y. and Zhang, Z. (2013) Hydrogen-Rich Saline Ameliorates the Retina against Light-Induced Damage in Rats. Medical Gas Research, 3, Article 19. http://dx.doi.org/10.1186/2045-9912-3-19

[317] Zhang, J.Y., Song, S.D., Pang, Q., Zhang, R.Y., Wan, Y., Yuan, D.W., Wu, Q.F. and Liu, C. (2015) Hydrogen-Rich Water Protects against Acetaminophen-Induced Hepatotoxicity in Mice. World Journal of Gastroenterology, 21, 41954209. http://dx.doi.org/10.3748/wjg.v21.i14.4195

[318] Ren, J., Luo, Z., Tian, F., Wang, Q., Li, K. and Wang, C. (2012) Hydrogen-Rich Saline Reduces the Oxidative Stress and Relieves the Severity of Trauma-Induced Acute Pancreatitis in Rats. Journal of Trauma and Acute Care Surgery, 72, 1555-1561. http://dx.doi.org/10.1097/TA.0b013e31824a7913

[319] Xie, Q., Li, X.X., Zhang, P., Li, J.C., Cheng, Y., Feng, Y.L., Huang, B.S., Zhuo, Y.F. and Xu, G.H. (2014) Hydrogen Gas Protects against Serum and Glucose Deprivation Induced Myocardial Injury in H9c2 Cells through Activation of the NFE2 Related Factor 2/Heme Oxygenase 1 Signaling Pathway. Molecular Medicine Reports, 10, 1143-1149.

[320] Steinbacher, P. and Eckl, P. (2015) Impact of Oxidative Stress on Exercising Skeletal Muscle. Biomolecules, 5, 356377. http://dx.doi.org/10.3390/biom5020356

[321] Niess, A.M. and Simon, P. (2007) Response and Adaptation of Skeletal Muscle to Exercise-The Role of Reactive Oxygen Species. Frontiers in Bioscience, 12, 4826-4838. http://dx.doi.org/10.2741/2431

[322] Huang, T., Wang, W., Tu, C., Yang, Z., Bramwell, D. and Sun, X. (2015) Hydrogen-Rich Saline Attenuates IschemiaReperfusion Injury in Skeletal Muscle. Journal of Surgical Research, 194, 471-480. http://dx.doi.org/10.1016/j.jss.2014.12.016

[323] Tsubone, H., Hanafusa, M., Endo, M., Manabe, N., et al. (2013) Effect of Treadmill Exercise and Hydrogen-Rich Water Intake on Serum Oxidative and Anti-Oxidative Metabolites in Serum of Thoroughbred Horses. Journal of Equine Science, 24, 1-8. http://dx.doi.org/10.1294/jes.24.1

[324] Ostojic, S.M., Vukomanovic, B., Calleja-Gonzalez, J. and Hoffman, J.R. (2014) Effectiveness of Oral and Topical Hydrogen for Sports-Related Soft Tissue Injuries. Postgraduate Medicine, 126, 187-195. http://dx.doi.org/10.3810/pgm.2014.09.2813

[325] Aoki, K., Nakao, A., Adachi, T., et al. (2012) Pilot Study: Effects of Drinking Hydrogen-Rich Water on Muscle Fatigue Caused by Acute Exercise in Elite Athletes. Medical Gas Research, 2, Article 12. http://dx.doi.org/10.1186/2045-9912-2-12

[326] Ge, Y., Wu, F., Sun, X., Xiang, Z., Yang, L., Huang, S., Lu, Z., Sun, Y. and Yu, W.-F. (2014) Intrathecal Infusion of Hydrogen-Rich Normal Saline Attenuates Neuropathic Pain via Inhibition of Activation of Spinal Astrocytes and Microglia in Rats. PLoS ONE, 9, e97436. http://dx.doi.org/10.1371/journal.pone.0097436

[327] Kawaguchi, M., Satoh, Y., Otsubo, Y. and Kazama, T. (2014) Molecular Hydrogen Attenuates Neuropathic Pain in Mice. PLoS ONE, 9, e100352. http://dx.doi.org/10.1371/journal.pone.0100352

[328] Zhang, L., Shu, R., Wang, H., Yu, Y., Wang, C., Yang, M. and Wang, G. (2014) Hydrogen-Rich Saline Prevents Remifentanil-Induced Hyperalgesia and Inhibits MnSOD Nitration via Regulation of NR2B-Containing NMDA Receptor in Rats. Neuroscience, 280, 171-180. http://dx.doi.org/10.1016/j.neuroscience.2014.09.024

[329] Wang, C., Li, Y., Wang, H., Xie, K., Shu, R., Zhang, L., Hu, N., Yu, Y. and Wang, G. (2015) Inhibition of DOR Prevents Remifentanil-Induced Postoperative Hyperalgesia through Regulating the Trafficking and Function of Spinal NMDA Receptors in Vivo and in Vitro. Brain Research Bulletin, 110, 30-39. http://dx.doi.org/10.1016/j.brainresbull.2014.12.001

[330] Shen, M., He, J., Cai, J., Sun, Q. and Huo, Z. (2010) Hydrogen as a Novel and Effective Treatment of Acute Carbon Monoxide Poisoning. Medical Hypotheses, 75, 235-237. http://dx.doi.org/10.1016/j.mehy.2010.02.029

[331] Yu, Y.P., Li, Z.G., Wang, D.Z., Zhan, X. and Shao, J.H. (2011) Hydrogen Sulfide as an Effective and Specific Novel Therapy for Acute Carbon Monoxide Poisoning. Biochemical and Biophysical Research Communications, 404, 6-9. http://dx.doi.org/10.1016/j.bbrc.2010.11.113

[332] Sun, Q., Cai, J., Zhou, J., Zhang, J.H., Zhang, W. and Sun, X.J. (2011) Hydrogen-Rich Saline Reduces Delayed Neurological Sequelae in Experimental Carbon Monoxide Toxicity. Critical Care Medicine, 39, 765-769. http://dx.doi.org/10.1097/CCM.0b013e318206bf44

[333] Shen, M.-H., Cai, J.-M., Sun, Q., Zhang, D.-W., Zheng, L.H., He, J. and Sun, X.J. (2013) Neuroprotective Effect of Hydrogen-Rich Saline in Acute Carbon Monoxide Poisoning. CNS Neuroscience and Therapeutics, 19, 361-363. http://dx.doi.org/10.1111/cns.12094

[334] Du, Z., Jia, H., Liu, J., Zhao, X., Wang, Y. and Sun, X. (2014) Protective Effects of Hydrogen-Rich Saline in Uncontrolled Hemorrhagic Shock. Experimental and Therapeutic Medicine, 7, 1253-1258. 
[335] Du, Z., Jia, H., Liu, J., Zhao, X. and Xu, W. (2015) Effects of Three Hydrogen-Rich Liquids on Hemorrhagic Shock in Rats. Journal of Surgical Research, 193, 377-382. http://dx.doi.org/10.1016/j.jss.2014.06.051

[336] Bien, A., Seidenbecher, C.I., Bockers, T.M., Sabel, B.A. and Kreutz, M.R. (1999) Apptotic versus Necrotic Characteristics of Retinal Ganglion Cell Death after Partial Optic Nerve Injury. Journal of Neurotrauma, 16, 153-163. http://dx.doi.org/10.1089/neu.1999.16.153

[337] Organisciak, D.T. and Vaughan, D.K. (2010) Retinal Light Damage: Mechanisms and Protection. Progress in Retinal and Eye Research, 29, 113-134. http://dx.doi.org/10.1016/j.preteyeres.2009.11.004

[338] Ghanizadeh, A. and Berk, M. (2013) Molecular Hydrogen: An Overview of Its Neurobiological Effects and Therapeutic Potential for Bipolar Disorder and Schizophrenia. Medical Gas Research, 3, Article 11. http://dx.doi.org/10.1186/2045-9912-3-11 


\section{Abbreviations}

8-OHdG-8-hydroxydeoxyguanosine;

AKI-Acute kidney injury;

ALI-Acute lung injury;

BAP_Biological antioxidant potential;

CO_Carbon monoxide;

DMD_Duchenne muscular dystrophy;

ERG_Electroretinography;

GMH_-Germinal matrix;

GvHD_Graft-versus host disease;

$\mathrm{H}$-Hydrogen;

HDL-High-density lipoprotein;

HO-1-Heme oxygenase-1;

IC/PBS - Interstitial cystitis/painful bladder syndrome;

I/R-Ischemia-reprofusion;

LDL_Low-density lipoprotein;

MDA-Malondialdehyde;

MetSyn-Metabolic syndrome;

mKATP_ATP-potassium channel;

MM-Mitochondrial myopathies;

NEC-Necrotizing enterocolitis;

Nrf2-Nuclear factor-erythroid 2 p45-related factor;

MPTP_Mitochondrial permeability pore;

mKATP_ATP-potassium channel;

MMP_-Matrix metalloproteinase;

MPTP_-The opening of mitochondrial pore;

MPO-Myeloperoxidase;

NMDA-N-methyl-D-aspartate;

$\mathrm{NO}$ - Nitric oxide;

PD_Parkinson's disease;

PM/DM-Polymyositis/dermatomyositis;

QOL-Quality of life;

RA-Rheumatoid arthritis;

RNS-Reactive nitrogen species;

ROS-Reactive oxygen species;

SOD-Superoxide dismutase;

T2DM-Type 2 diabetes mellitus;

TBI-Traumatic brain injury;

TUNEL-Deoxynucleotidyl transferase-mediated dUTP nick and labeling. 